\title{
Niche partitioning of 5 sympatric Bornean ungulates in response to spatiotemporal variation in fruit availability and resulting implications for predator-prey interactions
}

\author{
BY \\ RACHEL SELWYN \\ A thesis submitted to Victoria \\ University of Wellington in \\ fulfilment of the requirements for \\ the degree of Master of Science in \\ Ecology \& Biodiversity
}

School of Biological Sciences

Faculty of Science

Victoria University of Wellington

July 2020 


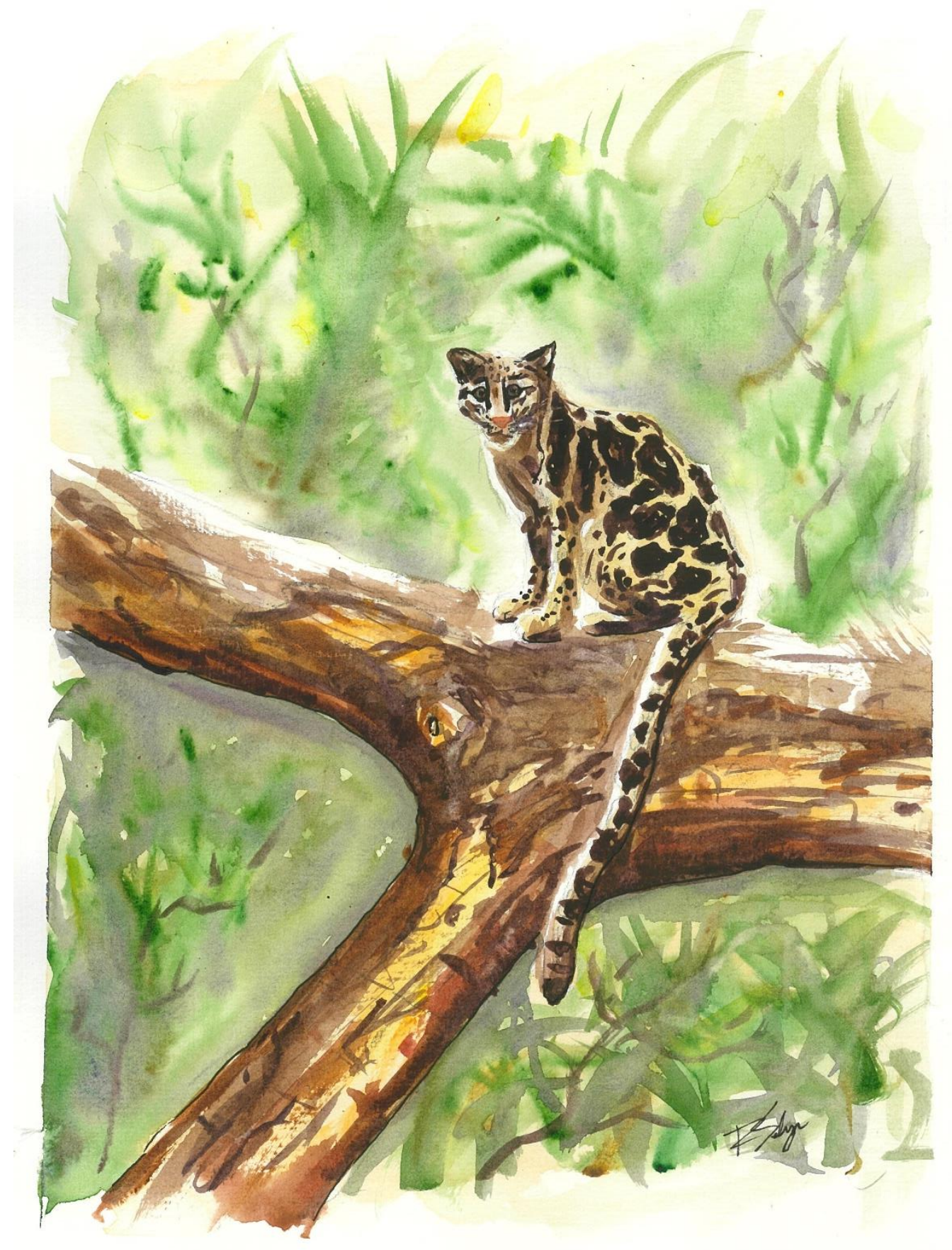

Author's watercolour depiction of a Sunda clouded leopard. 
Borneo's rainforests are experiencing some of the fastest deforestation rates worldwide and are home to increasingly vulnerable species, most of which remain poorly understood. Bornean rainforests exhibit dramatic fluctuations in fruit and seed availability during mast-fruiting events which can exert considerable influence on frugivore ecology. Comprehensive spatiotemporal assessments of habitat use, resource partitioning, and responses to fruit availability in mast-fruiting rainforests are lacking for most species, including ungulates. The distribution and habitat use of an apex predator, the Sunda clouded leopard (Neofelis diardi), may be largely shaped by the availability of these ungulates. Yet, factors driving the spatial ecology of this elusive felid remain uncertain. I aimed to quantify spatiotemporal habitat use dynamics of these species and consequently inform effective conservation planning. Specifically, I quantified the effects of human activity, forest type, elevation, and mast-induced fluctuations in resources on the habitat use of lesser mousedeer (Tragulus kanchil), greater mousedeer (T. napu), Bornean yellow muntjacs (Muntiacus atherodes), red muntjacs (M. muntjak), and bearded pigs (Sus barbatus) in Gunung Palung National Park, West Kalimantan, Indonesian Borneo. I applied data from an extensive camera trapping study ( $n=42,610$ trap nights) to a modified single-season occupancy model to evaluate habitat use over space and time. I then applied estimates of occurrence $(\Psi)$ of the five ungulate species to quantify if habitat use of the Sunda clouded leopard was influenced by prey occurrence and thus if this apex predator responded to bottom-up effects of resource variability. The results from the ungulate modelling revealed that forest type was an important predictor of habitat use of all ungulate species, each preferring different forest habitats. Habitat use estimates were highest in peat swamp forests for lesser mousedeer $(\widehat{\Psi}=0.92 \pm 0.05)$, alluvial bench forests for greater mousedeer $(\widehat{\Psi}=0.52 \pm 0.08)$, lowland granite forests for yellow $(\widehat{\Psi}=0.95 \pm 0.07)$ and red muntjacs $(\widehat{\Psi}=0.98 \pm$ $0.09)$, and freshwater swamp forests for bearded pigs $(\widehat{\Psi}=0.84 \pm 0.07)$. Bearded pigs exhibited a link between variation in fruit availability and habitat use, indicating an ability to respond to resource variability. Occupancy modelling for Sunda clouded leopards revealed forest type, fruit availability, and bearded pig occurrence as the best predictors of habitat use. The highest estimates were associated with lowland granite forests $(\widehat{\Psi}=0.87 \pm 0.09)$. My results reveal a novel pattern of niche partitioning through both food and habitat resources among five sympatric ungulate species and demonstrate that Sunda clouded leopards may use fruiting events as a cue for abundant prey. My research sheds light on important factors influencing habitat use of understudied ungulates and an apex predator and can be 
used to refine estimates of habitat suitability across a greater landscape to inform conservation practice amidst continually shrinking remnant forests in Indonesian Borneo. 
I am extremely grateful to Dr. Heiko U. Wittmer, my supervisor, for his guidance, insight, and patience. Thank you for putting up with my frequent impromptu meetings and for giving me this opportunity that ignited my interest in research. Thank you, Dr. Andrew Marshall, for all your help; for making yourself available to talk through any challenges that arose and always offering suggestions.

I would like to express my gratitude for the financial support from the Eastbourne-Bays Community Trust through the Eastbourne Freemasons scholarship, and Victoria University of Wellington through the Hunter postgraduate scholarship that gave me the privilege to focus on this research without distraction.

A huge thank you to the many field assistants involved in collecting the data for this project, who conducted field work in the hot humid forests and regularly trekked up the mountainside to service the cameras. I would like to extend my appreciation to Agus Trianto for the endless hours spent identifying species recorded on videos, maintaining the database, and helping work through the kinks of acquiring the data.

Johannes, thank you for not only inspiring me with your beautiful graphs and analytical modelling skills, but for putting up with my endless questions. Grace-thank you for always looking out for me, the endless emotional support, and continually reminding me that it would soon be over. I cannot possibly acknowledge everyone who has helped me over the past couple years, so thank you to the many un-named supportive wonderful people around me-you are much appreciated.

Mum and dad, thank you for all your support, seeing me through the frustrations, always lending an ear for advice, and the wonderful home-cooked meals that gave me sustenance. Thank you for the endless supply of walnuts that no doubt contributed some brain power.

Lastly, my biggest thanks go to Henry: you stood by me through it all, I cannot put my gratitude into words. You have gotten very good at pep talks, especially through a global pandemic and the oftenunpleasant process of writing up a thesis. Truly my anchor in the storm. 


\section{Contents}

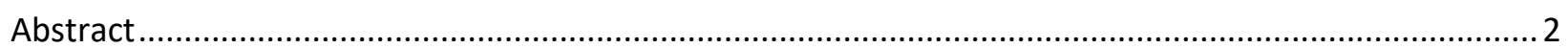

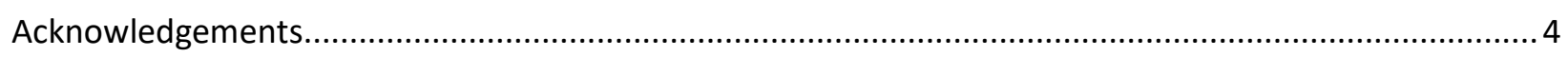

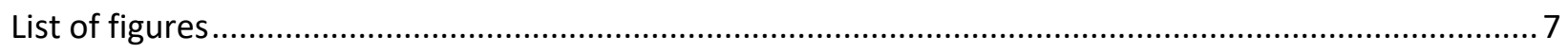

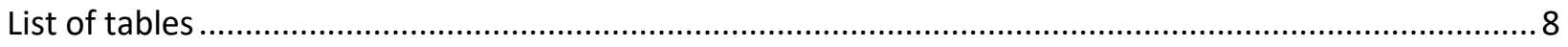

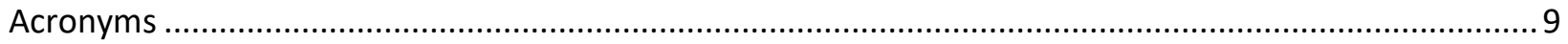

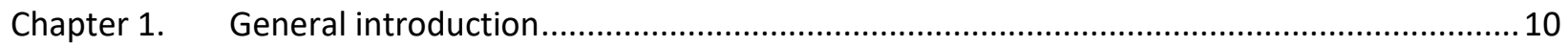

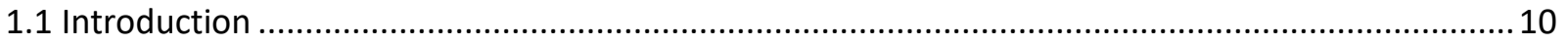

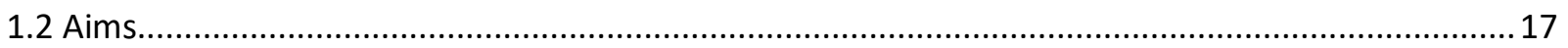

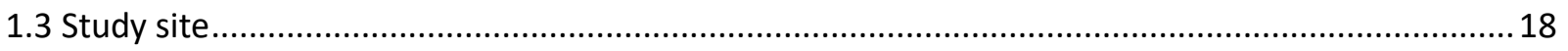

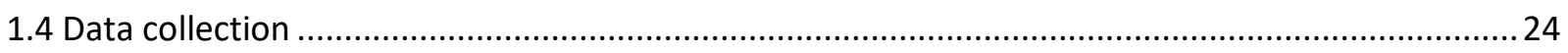

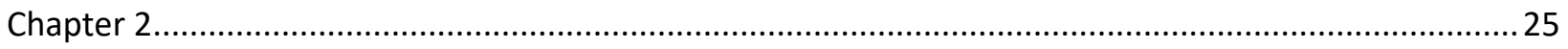

Habitat use and niche partitioning of ungulates in response to spatiotemporal variation in fruit

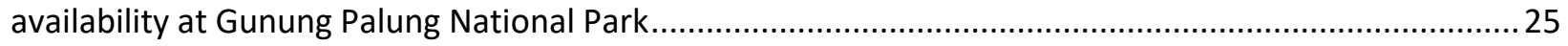

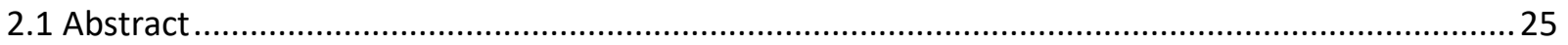

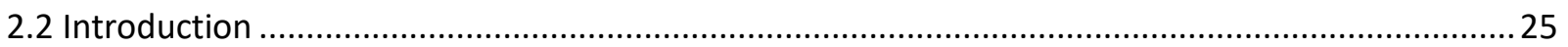

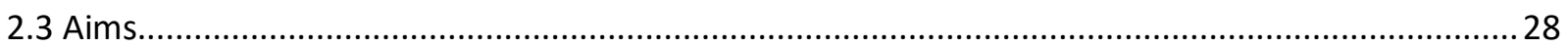

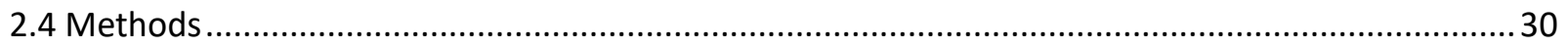

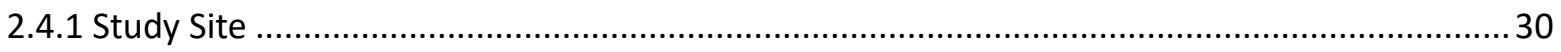

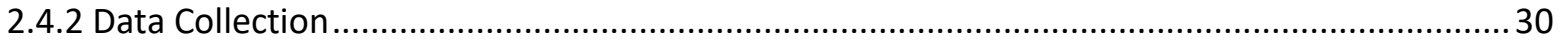

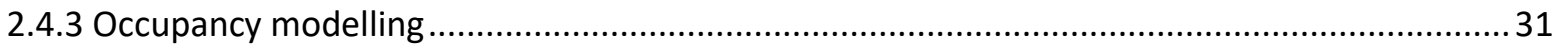

2.4.4 Hypothesized predictors of habitat use and detection ......................................................... 34

2.4.5 Modelling the effects of covariates on occupancy and detection probabilities.......................36

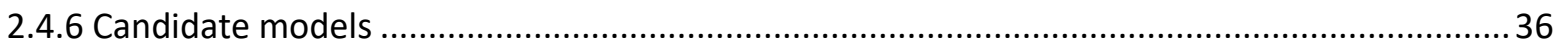

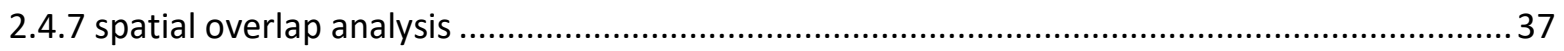

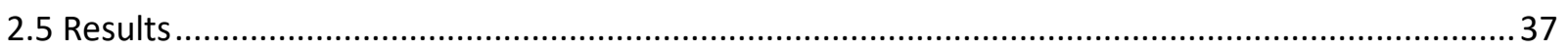

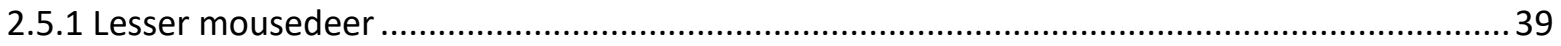

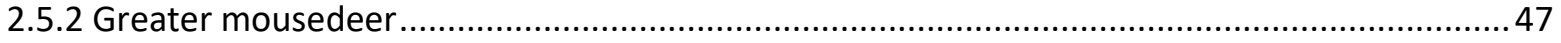

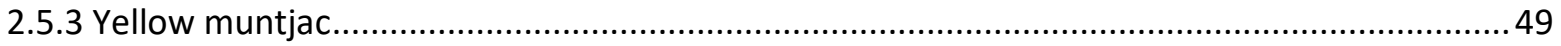

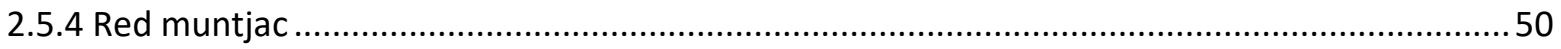

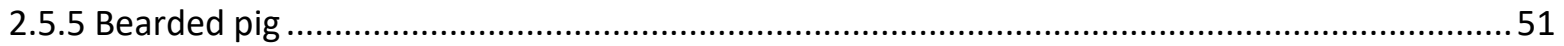

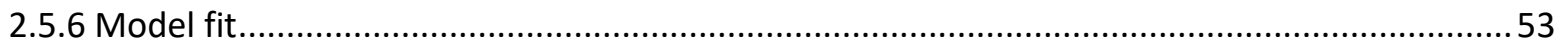

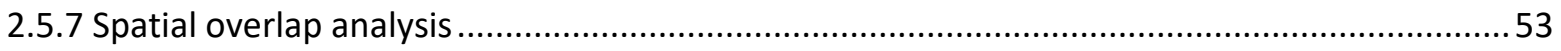


2.6 Discussion.

Spatiotemporal habitat use patterns of Sunda clouded leopard (Neofelis diardi) in a mast-fruiting rainforest: influence of forest type, prey occurrence, humans, and fluctuations in fruit resources. ........61

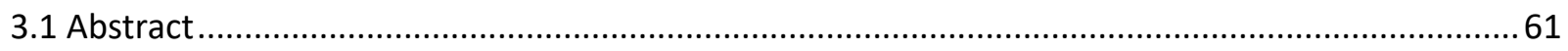

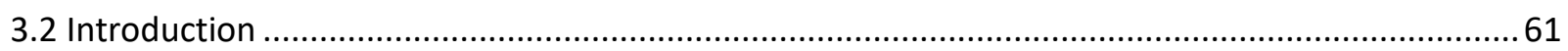

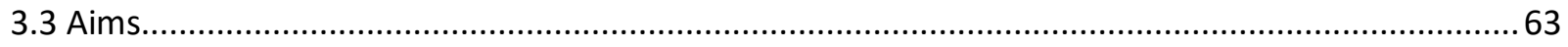

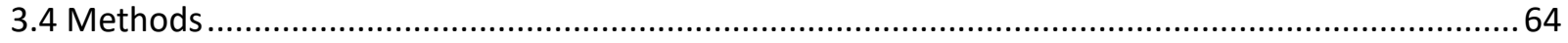

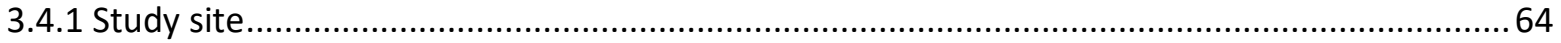

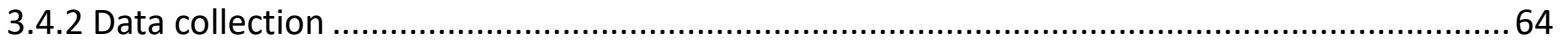

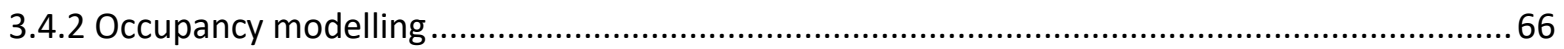

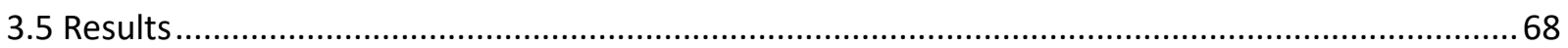

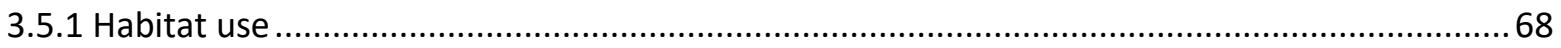

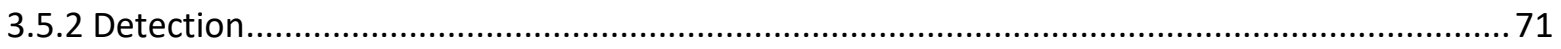

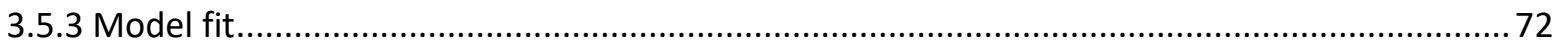

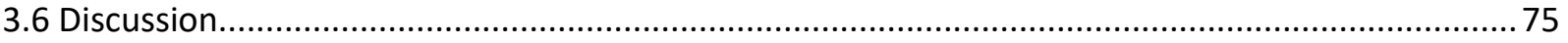

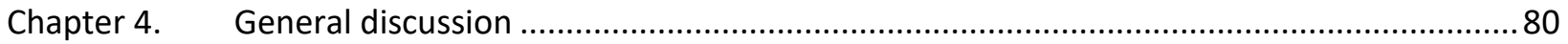

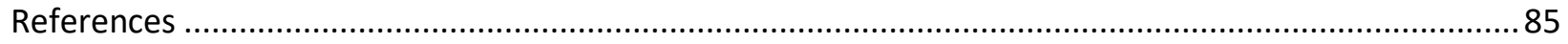

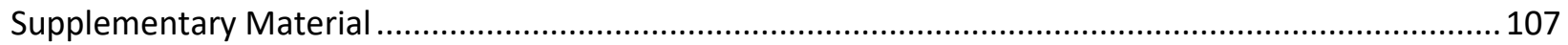




\section{LIST OF FIGURES}

Figure 1.1: Map illustrating the location of Cabang Panti Research Station and Gunung Palung National

Park. 19

Figure 1.2: Total monthly rainfall and maximum and minimum temperatures at Cabang Panti Research Station between July 2015 and October 2019

Figure 2.1: Trends in fruit availability at Cabang Panti Research Station

Figure 2.2: The independent detections of 5 ungulate species across forest types in CPRS recorded by motion triggered cameras between July 2015 and October 2019.

Figure 2.3: The proportion of detections at on and off trail camera locations at CPRS between July 2015 and October 2019.

Figure 2.4: Model-averaged estimates of ungulate habitat use $(\Psi)$ across forest types at CPRS.

Figure 2.5: The probability of dection for ungulates at on or off trail camera stations.........................46

Figure 2.6: The relationship between human activity and habitat use of lesser mousedeer. .47

Figure 2.7: The trend of greater mousedeer habitat use over time. .48

Figure 2.8: The trend of yellow muntjac habitat use over time. 49

Figure 2.9: The trend of red muntjac habitat use over time. 51

Figure 2.10: The relationship of fruit availability and habitat use of bearded pigs. .52

Figure 2.11: Correlation between the model-averaged occupancy estimates across the study area.......54

Figure 3.1: Model-averaged habitat use estimates for clouded leopards by forest type. 70

Figure 3.2: The relationship between bearded pig occurrence and clouded leopard habitat use across forest types.. 71

Figure 3.3: The probability of detecting clouded leopards at on or off trail camera stations 72

Figure S.1: Index of detections of poachers at camera sites in CPRS along an elevational gradient.......109 
Table 1.1: Characteristics of 7 distinct forest types present in Cabang Panti Research Station.

Table 2.1: The comparative body mass, taxonomy, and conservation status of the artiodactyl species observed at the Cabang Panti Research Station.....

Table 2.2: A description of the covariates used for habtiat use and detection modelling

Table 2.3: AIC comparisons of top performing habitat use models $(\triangle \mathrm{AIC}<7$ ) for ungulates at Cabang Panti Research Station.

Table 2.4: AIC comparison of top performing detection models for ungulates at Cabang Panti Research Station $(\triangle \mathrm{AIC}<7)$.

Table 2.5: Estimates from null models of habitat use and detection probabilities assuming constant estimates among sites.

Table 2.6: The dispersion parameter ( $\hat{c})$ for the best performing general habitat use and detection models for each species.

Table 3.1: Independent detections of clouded leopards across Cabang Panti Research Station by forest type between July 2015-October 2019. 68

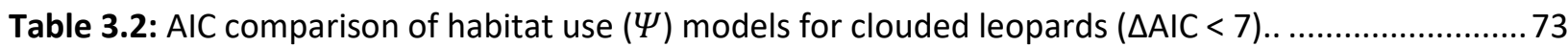

Table 3.3: AIC comparison of models of clouded leopard detection $(p)(\triangle \mathrm{AIC}<7)$. .75

Table S.1: Set of candidate models for modelling habitat use of lesser mousedeer, greater mousedeer, yellow muntjacs, red muntjacs, and bearded pigs. 107

Table S.2: Set of candidate models for detection probabilities of lesser mousedeer, greater mousedeer, yellow muntjacs, red muntjacs, and bearded pigs.. .108

Table S.3: The independent detections of ungulate species across forest types at the Cabang Panti Research Station. .108

Table S.4: The detections of ungulates at on and off trail locations at the Cabang Panti Research Station.

Table S.5: The average fruit availability and variability for each forest type between July 2015-October 2019 at the Cabang Panti Research Station. 


\section{ACRONYMS}

\begin{tabular}{ll} 
AB & Alluvial bench \\
AIC & Akaike Information Criterion \\
BP & Bearded pig (Sus barbatus) \\
CL & Sunda clouded leopard (Neofelis diardi) \\
CPRS & Cabang Panti Research Station \\
Dbh & Diameter at breast height \\
GMD & Greater mousedeer (Tragulus napu) \\
GPNP & Gunung Palung National Park \\
FS & Freshwater swamp \\
LG & Lowland granite \\
LMD & Lesser mousedeer (Tragulus kanchil) \\
LS & Lowland sandstone \\
RS & Peat swamp \\
RGM & Red muntjac (Muntiacus muntjak) \\
\hline
\end{tabular}

YM Bornean yellow muntjac (Muntiacus atherodes) 


\section{Chapter 1. GENERAL INTRODUCTION}

"We must not let a forest full of trees fool us into believing all is well."

- Kent H. Redford

\subsection{Introduction}

The extraordinary biodiversity and ecological complexity of the tropics has been of interest to ecologists for over the two centuries. The latitudinal biodiversity gradient - the dramatic rise in species richness around the equator-was described as early as the $19^{\text {th }}$ century by Alexander von Humboldt (Hawkins 2001). The majority of the world's species, including $91 \%$ of the world's terrestrial bird species and $77 \%$ of mammals (Barlow et al. 2018), are found in the tropics, many clinging to strongholds and refugia not yet destroyed by anthropogenic forces. The high degree of species richness is sustained by intricate patterns of resource partitioning and adaptations. However, these beautiful and diverse ecosystems are inseparable from human influence, with the tropics home to more than $40 \%$ of the global population (Edelman et al. 2014).

Although these ecosystems have indisputable global importance, tropical forests are disappearing at rates faster than forests anywhere else in the world (Austin et al. 2017). Increasing rates of habitat loss and disturbance are resulting in disproportionate defaunation in the tropics (Dirzo et al. 2014) and increasing extinction risks threaten to degrade biodiversity (Kerr \& Burkey 2002, Vamosi \& Vamosi 2008).

The dangers these tropical ecosystems face are exacerbated by the fact they remain severely understudied (Rodriguez 2003). The majority of ecological research is conducted by wealthy countries in temperate regions, leaving a paucity of research conducted in developing countries, most of which are situated around the equator (Tydecks et al. 2018). Research deficits in tropical ecosystems leave species further vulnerable to anthropogenic disturbances, exacerbating the current biodiversity crisis.

\section{Borneo}

Straddling the equator at the centre of the Malay Archipelago, the island of Borneo is an evolutionary hotspot of flora and fauna. The island is governed by three separate countries: Malaysia and Brunei in the north and Indonesia in the south. The majority of the island falls under Indonesian jurisdiction; however, the split governance creates challenges in conducting cohesive conservation efforts. 
The $3^{\text {rd }}$ largest island globally, Borneo supports a wealth of endemic species and rich biodiversity with the highest levels of species richness in South-East Asia (de Bruyn et al. 2014). Representing less than $0.2 \%$ of the global landmass, it is home to $5 \%$ of the world's vertebrate species (MacKinnon et al. 1996).

Although the diversity of this rainforest ecosystem has attracted researchers and naturalists since the $19^{\text {th }}$ century (Beccari 1904, Shelford 1917), most notably A.R. Wallace (Wallace 1856), there remain many facets of its ecology that are not only not well understood but difficult to study. Researchers have been working in Bornean rainforests for decades, contributing towards a functional understanding of this valuable ecosystem. Although much progress has been made, there remain many knowledge gaps. This is due, in part, to the elusive nature of many key species that occur at low densities, making them challenging to study (Mathai et al. 2013). Additionally, the terrain in Borneo can make research efforts almost impossible as forests rise steeply up into central highlands that are difficult to access. Until recently, this inaccessibility had succeeded in protecting central highland forests which remained relatively untouched until the early 1990s (Bodmer et al. 1991). Today, these previously untouched areas of Borneo are now under threat from a number of anthropogenic forces.

\section{Anthropogenic threats}

Prior to the 1970s, three quarters of Borneo was covered in tropical forests and had largely escaped the exploitation of natural resources occurring around the globe (McAlpine et al. 2018). Unfortunately, although industrial-scale resource extraction arrived late to Borneo, it arrived with force. Indonesia, which governs the largest portion of Borneo, experienced a political coup in 1998, resulting in the decentralization of the government, giving regional autonomy to districts (Hill \& Shiraishi 2007). Given fresh authority over local resources, the Kalimantan province of Borneo (governed by Indonesia) experienced a boom in logging, land-use changes, and resource extraction as underdeveloped areas were put under financial strain (Resosudarmo 2005). The coincidence of this political change (Resosudarmo 2005), along with the Asian Financial Crisis (Hill \& Shiraishi 2007), and growing demand for plantation products (Gaveau et al. 2016) led to large-scale deforestation, reducing remaining forests to less than $50 \%$ of the coverage that existed in 1973 (Ocampo-Penuela et al. 2020). Now exhibiting among the fastest rates of decline worldwide (Hansen et al. 2013), Borneo's forests are at risk of disappearing altogether, along with the unique ecosystems they hold.

Industrial logging of Borneo's rainforests, ongoing since the 1970s, is reducing remaining forest stands at an alarming rate (Gaveau et al. 2014). Between 1970 and the 1990s, more than half of the 
tropical hardwood exports globally were from Borneo (Brookfield \& Byron 1990). In addition to industrial operations, illegal logging is a prevalent and complex issue often targeting protected areas that contain some of the only remaining stands of valuable hardwoods (Curran et al. 2004, Hiller et al. 2004). Over two thirds of deforestation recorded in the Kalimantan province of Indonesian Borneo occurred within protected or proposed protected areas between1997 and 2002 (Fuller et al. 2004). Limited resources and widespread involvement make it difficult to police/regulate illegal logging: with operations frequently involving entire communities and villages (Hiller et al. 2004). A 2008 survey of villages surrounding Gunung Palung National Park (West Kalimantan, Indonesian Borneo) found $47 \%$ of households were dependant on illegal logging as their primary source of income (Hiller et al. 2004). Although logging is a considerable threat to forests in Borneo, the primary driver of deforestation is plantation industries (Gaveau et al. 2016). Converting forests into plantations has shown to have a significantly worse influence on biodiversity long-term than forest loss due to logging (Wilcove \& Koh 2010). Burivalova et al. (2020) have shown that after the initial deforestation from logging, logged areas recover biodiversity levels relatively quickly, with secondary forests showing higher floral species richness and rates of carbon storage than primary forests (Berry et al. 2010). As the global demand for products like palm oil and pulpwood has increased, Indonesia has sought to meet demand, resulting in an estimated 7.9 million ha of industrial palm-oil plantations in Borneo in 2015 (Gaveau et al. 2016). The demand for palm oil is predicted to continue to rise encouraging further land conversion (Corley 2009, Malins 2017).

As ongoing deforestation draws more attention towards conservation in Borneo, the extent of intact forest is frequently estimated to evaluate the threat facing forest-dwelling species (Proctor et al. 2011, Hearn et al. 2016, Miettinen et al. 2016, Cushman et al. 2017, Ocampo-Penuela et al. 2020). Focusing on the presence of trees does not guarantee a healthy forest and overlooks the extent of defaunation occurring within tropical forests (Redford 1992). Therefore, evaluating threats permeating forests is necessary to prevent the defaunation of these ecosystems.

One such threat in Borneo comes from poaching, which imposes considerable danger to target species. Increased access into forests from logging and new roads has been linked to increased poaching activity (Laurance et al. 2006, Mohd-Azlan \& Lading 2006, Alamgir et al. 2019). Many species, such as orangutans (Pongo pygmaeus), bearded pigs (Sus barbatus), various ungulates, and small carnivores are hunted for bushmeat (Bernard et al. 2013, Marshall et al. 2006, Cheyne et al. 2010). Additionally, other species such as pangolins (Manis javanica), sun bears (Helarctos malayanus), freshwater turtles and Sunda clouded leopards (Neofelis diardi) are live-trapped and sold for the wildlife trade (Pantel \& Chin 
2009, D’Cruze \& Macdonald 2015, Jensen \& Das 2008) or medicinal purposes (Wong \& Servheen 2010). Species targeted by poachers in Borneo are frequently driven to very low population numbers or even local extinction as poaching pressure remains consistent in chronically over-hunted areas (Brodie et al. 2014). Brodie et al. (2014) studied mammal occurrences across Malaysian Borneo and found that poaching pressure poses a more serious threat to species richness than logging, with poaching linked to a $31 \%$ decline in species richness compared to an $11 \%$ decline in freshly logged sites. Poaching also leads to indirect effects on many species by depleting the prey-bases of carnivore species (Burton et al. 2012, Hearn et al. 2017) and contributing to a 'landscape of fear' altering species behaviours (Oriol-Cotterill et al. 2015).

To effectively study the effect of anthropogenic threats on rainforest ecosystems, a basic understanding of individual species' ecology is needed along with an understanding of how species interact within functional rainforest communities.

\section{Importance of spatiotemporal studies}

Understanding the impact of anthropogenic disturbances within forest ecosystems becomes an impossible task when there is a paucity of data about the species of interest (Morais et al. 2013, Pimm et al. 2014, Brodie 2009). Determining where a species is present is necessary to understand their basic habitat needs. Assessing the environmental and physical factors influencing species occurrence in an intact ecosystem can be used to develop Species Distribution Models (SDMs). This form of modelling can extrapolate known local distributions across large landscapes that could not be feasibly surveyed, determine potentially suitable habitats, and can be used to model changes to distributions in response to influential factors (e.g. climate change, human disturbance, habitat loss) (Rodriguez et al. 2007, Sinclair et al. 2010). While other research is necessary to gain a full understanding of a species' needs, the study of distribution is at the heart of ecology and creates a foundation of knowledge that can be further built upon (Krebs 1972).

Comparing patterns of distributions amongst multiple species can provide further ecological insight by identifying possible species interactions and patterns of niche partitioning. Possible interspecific interactions can be inferred by analysing patterns of either overlapping or avoidant habitat use between species (Toft et al. 1982, Heithaus 2001, Razgour et al. 2011, Steinmetz et al. 2013). Identifying competitive interactions between species can then be applied to help describe patterns of niche partitioning-considered to be an attempt to reduce interspecific competition for a shared resource (i.e. habitat or food) (Hutchinson 1957, Holt 1987). 
Studying patterns of habitat use, or distribution, solely on a spatial perspective can fail to identify temporal patterns of niche partitioning, and changes in response to natural or anthropogenic factors. Species competing for a shared resource may reduce competition by differentiating along several dimensions: either differentiating by habitat, specializing to a different food resource, or shifting activity patterns to use the same resource at a different time (Hutchinson 1959). Similarly, species may attempt to avoid predation by altering the habitats they use or time of day they use them (Sih 1980, Werner et al. 1983). A growing number of studies have focused on temporal patterns of habitat use, identifying species interactions and niche partitioning (Albrecht \& Gotelli 2001, Gosselink et al. 2003, Hampton 2004, Valeix et al. 2007). Additionally, changes in habitat use occurring in response to variables may only be identified if observed over long periods. Fluctuations in resources, predator populations, disease, climate, and anthropogenic threats can alter patterns of habitat use leading to an incomplete depiction of overall patterns if observed as an instantaneous snapshot.

Examining patterns of habitat use, over both space and time, in communities is vital to inform individual species' ecology, identify interspecific interactions, and ultimately obtain a well-developed picture of an intact ecosystem to determine how it may respond to anthropogenic influences.

\section{Camera traps}

In recent years, the use of camera traps has become increasingly popular to collect data on understudied tropical ecosystems (Ahumada et al. 2011, 2013, Rovero et al. 2014). Although camera traps have been used in ecological studies in various forms over the past several decades, technological advances and lower prices have resulted in growing deployment. The development of infrared motion sensors and compact digital cameras with long battery lives have made camera traps a more costeffective means to conduct ecological surveys. This technology has begun to replace traditional labourintensive sampling methods like distance sampling (Burton et al. 2015).

In recent years, many studies using motion-triggered cameras have shifted focus from identifying individuals of a species to community biodiversity studies (Steenweg et al. 2017). This reflects the flexibility of this sampling method: which once set up can consistently collect data that can be used for a variety of analyses, including animal behaviour, species richness, abundance, and occupancy on multiple species simultaneously (Steenweg et al. 2017).

The use of camera traps was quickly adopted by ecologists studying large elusive carnivores that typically occur in low densities and have low detectability with traditional transect sampling approaches (Fragoso et al. 2016). There is a breadth of research using camera traps to study elusive cat species in 
Borneo alone (Cheyne \& Macdonald 2011, Brodie \& Giordano 2013, Wilting et al. 2012, Wearn et al. 2013, Hearn et al. 2018b). However, without the use of consistent and standardized camera trap protocols or long study periods, differing detection probabilities or low number of detections can make it difficult to draw robust conclusions about density, distribution or activity patterns from findings (Cheyne et al. 2010, Wearn et al. 2013). A growing number of researchers have been calling for the use of standardized protocol and data sharing, allowing for global conservation collaborations (Ahumada et al. 2011, Meek et al. 2014, Schmeller et al. 2015). Camera trapping provides an opportunity for consistent, efficient, and cost-effective sampling that can be used to unite local projects into massive global initiatives like TEAM (Tropical Ecology Assessment and Monitoring) to effectively assess and monitor ecological communities (Rovero \& Ahumada 2017, Galvez et al. 2016).

\section{Occupancy modelling}

A further advantage of using a camera trap framework for ecological research is its ability to provide large amounts of presence-absence data required for a robust form of analysis called occupancy modelling. Occupancy $(\Psi)$ refers to the proportion of sites or patches occupied by a species (Mackenzie et al. 2002) and can be used as a surrogate for abundance, to infer distribution, evaluate species cooccurrence, and many other applications (Mackenzie \& Nichols 2004).

Occupancy modelling was developed to account for imperfect detection, a prevalent weakness in abundance and distribution analysis (Mackenzie et al. 2002, Pollock et al. 2002, Royle et al. 2005). In a review of ecological papers in $2014,77 \%$ neglected to account for imperfect detection despite available methods (Kellner \& Swihart 2014). Occupancy modelling addresses this issue by explicitly modelling detection probabilities as a function of various environmental and sampling parameters and then adjusting estimates of occupancy accordingly. Accounting for imperfect detection directly in the modelling allows final occupancy estimates to reflect situations when an individual may have been present but failed to be detected.

Occupancy modelling works well in combination with camera trapping as this form of analysis requires a large amount of simple data (Rich et al. 2016). Instead of count data required for abundance estimates, occupancy modelling requires basic presence-absence data for a range of sampling sites within the study area. For robust estimates repeated sampling at each site is necessary, however, this is a labour-intensive and often unfeasible request for more traditional sampling techniques (Mackenzie et al. 2002). With camera trap studies, following the initial setup the continuous data acquired can be split into consecutive surveys to easily address this need. 
The combination of camera trap data and occupancy modelling analysis is increasingly the method of choice for studies of species with little knowledge about their ecology (Galvez et al. 2016, Rich et al. 2016, Rovero et al. 2014, Tobler et al. 2015). Covariate analysis in an occupancy modelling framework enables researchers to use the simple presence-absence data in combination with various covariates to create estimates of habitat use and evaluate the factors affecting the occupancy of a species (Mackenzie et al. 2006). Conducting occupancy modelling in combination with a model selection approach, such as Information Theoretic Approaches and Akaike Information Criterion (AIC)(Burnham \& Anderson 2002), allows a set of a priori candidate models to be designed and tested alongside each other (Mackenzie et al. 2006). Occupancy modelling has been valuable to researchers studying species where a wealth of abundance data is difficult to obtain and therefore relying on traditional approaches would provide weak inferences with a large margin of error (Rovero et al. 2014, Mackenzie et al. 2006, Galvez et al. 2016).

\section{Knowledge gaps in Bornean rainforest ecosystems}

Elusive species, occurring at low densities throughout large expanses of inaccessible terrain have provided significant hurdles to researchers in Borneo leading to numerous species remaining understudied (Struebig et al. 2008, Mathai et al. 2016, Mathai et al. 2010). As a result, the majority of ecological research conducted in Borneo has focused on a select few species and mostly comprises of descriptive studies overlooking assessments of population changes, cause-effect analysis, threats, and species interactions (Meijaard \& Sheil 2007). Despite 16 Bornean mammal species listed as either critically endangered or endangered on the IUCN Red List of Threatened Species, of these only orangutans and other primates are well represented in the research literature (Meijaard \& Sheil 2007, IUCN 2020). Many other species responsible for key ecological roles are often overlooked and remain poorly understood.

Ungulates play key roles in ecosystems as seed dispersers (Blate et al. 1998), assist forest regeneration (Webb and Peart 2008), and typically comprise a large portion of biomass in ecological communities; making up a prey base for many endangered carnivore species (Albert et al. 2015, Fritz et al. 2002). Despite decades of research on ungulates around the world, a paucity of research focuses on Artiodactyla within the tropical ecosystems. Historically, studying ungulates in Bornean rainforests has been challenging partially due to difficulties accurately identifying species during transect sampling and behaviours that reduce their detectability (Fragoso et al. 2016). 
Borneo also supports a diverse guild of endemic carnivores, a large proportion of which are classified as threatened. However, there is a disproportionate lack of ecological knowledge of many of these species. A growing number of studies have focused on felid species in Borneo (Hearn et al. 2018b), although small sample sizes and study limitations combined with the elusive nature of carnivores have limited the extent of our knowledge base. Carnivores can exert crucial top-down regulation on ecological communities, maintaining food web stability and diversity, and their conservation must be prioritized accordingly (Allen et al. 2017).

In addition to several taxa remaining understudied in Bornean rainforests, the ecological response to dramatic spatiotemporal fluctuations in fruit resources remains understudied for many species. Tropical rainforest systems in South East Asia are frequently characterized by mast-fruiting, resulting in considerable fluctuations in fruit and seed resources (Ashton et al. 1988). The wide-spread synchronous fruiting of predominantly dipterocarp species during these events is followed by several years of little or no fruit production. The supra-annual basis of mast events is thought to be linked to the El Nino-Southern Oscillation (ENSO) cycles, however, the cause and reason for this phenomenon is still debated (Wich \& Schaik 2000, Williamson \& Ickes 2002). Fluctuations in fruit availability have been theorized to exert a bottom-up influence on frugivore species, however, this influence remains understudied in tropical systems with most research focusing on primate species (Marshall \& Leighton 2006). Understanding the effect of dramatic variation in resource availability on consumer species, and potentially other trophic levels, should be a priority for research hoping to aid in the preservation of tropical rainforests.

To effectively conserve Borneo's rainforest ecosystems, it is necessary to fill the gaps in our ecological knowledge with further research, particularly with a focus on understudied species and dynamics that play key ecological roles. The application of a standardized camera trap methodology in Bornean forest ecosystems can help collect valuable information on ungulate and carnivore populations. Long-term studies of habitat use and distribution following an analytical framework that accounts for imperfect detection could result in robust estimates of habitat use that are critical for informed conservation and management actions.

\subsection{Aims}

Using data from a long-term camera trapping study, the objectives of my research are to 1) use occupancy modelling to develop an understanding of the spatial ecology of members of two taxonomic groups that remain poorly understood in an intact tropical rainforest, 2) evaluate the influence of 
spatiotemporal fluctuations in fruiting resources on the habitat use of a top carnivore and 5 sympatric ungulate species, 3 ) investigate species co-occurrence patterns to inform an understanding of species interactions and niche partitioning within the rainforest community, and 4) generate baseline data for the distribution of some key species across an intact rainforest system site to inform future research, monitoring and conservation.

\subsection{Study site}

The data for this study were collected at the Cabang Panti Research Station (CPRS) in Gunung Palung National Park, in West Kalimantan, Borneo. The national park is 100,000 ha, covering a mosaic of diverse rainforest habitats (Paoli et al. 2001). Located on the southwest coast of Borneo, Gunung Palung is 130 km south of the provincial capital, Pontianak. Gunung Palung is one of the largest remaining primary lowland forests on Borneo, which despite having been protected since 1937 still experiences some illegal logging (Fawzi et al. 2018, Hiller et al. 2008).

The CPRS (Figure 1.1) is a $34 \mathrm{~km}^{2}$ long-term research site within the National Park. Despite increasing population pressure in areas surrounding the park the limited access into the research area by foot or river has kept human disturbance at CPRS relatively low compared to other unprotected areas in Borneo. Gunung Palung National Park still experiences some poaching (A.J. Marshall, personal communication 2020), and illegal logging (Hiller et al. 2008, Felton et al. 2003) which remain a source of sustenance and primary income for local villagers (Hiller et al. 2008). The climate is considered tropical and aseasonal with little variation in temperature and rainfall across the year (Figure 1.2). CPRS encompasses mangrove forests and low-lying swamps around sea-level rising into a lowland forest that change abruptly into the next forest type as they follow the river upstream. The Air Putih river valley then rises on either side into two ridges leading to the upland montane habitat on the western slope of Mt. Palung (1080 m) and Mt. Panti (1100 m) (Curran and Leighton 2000). 

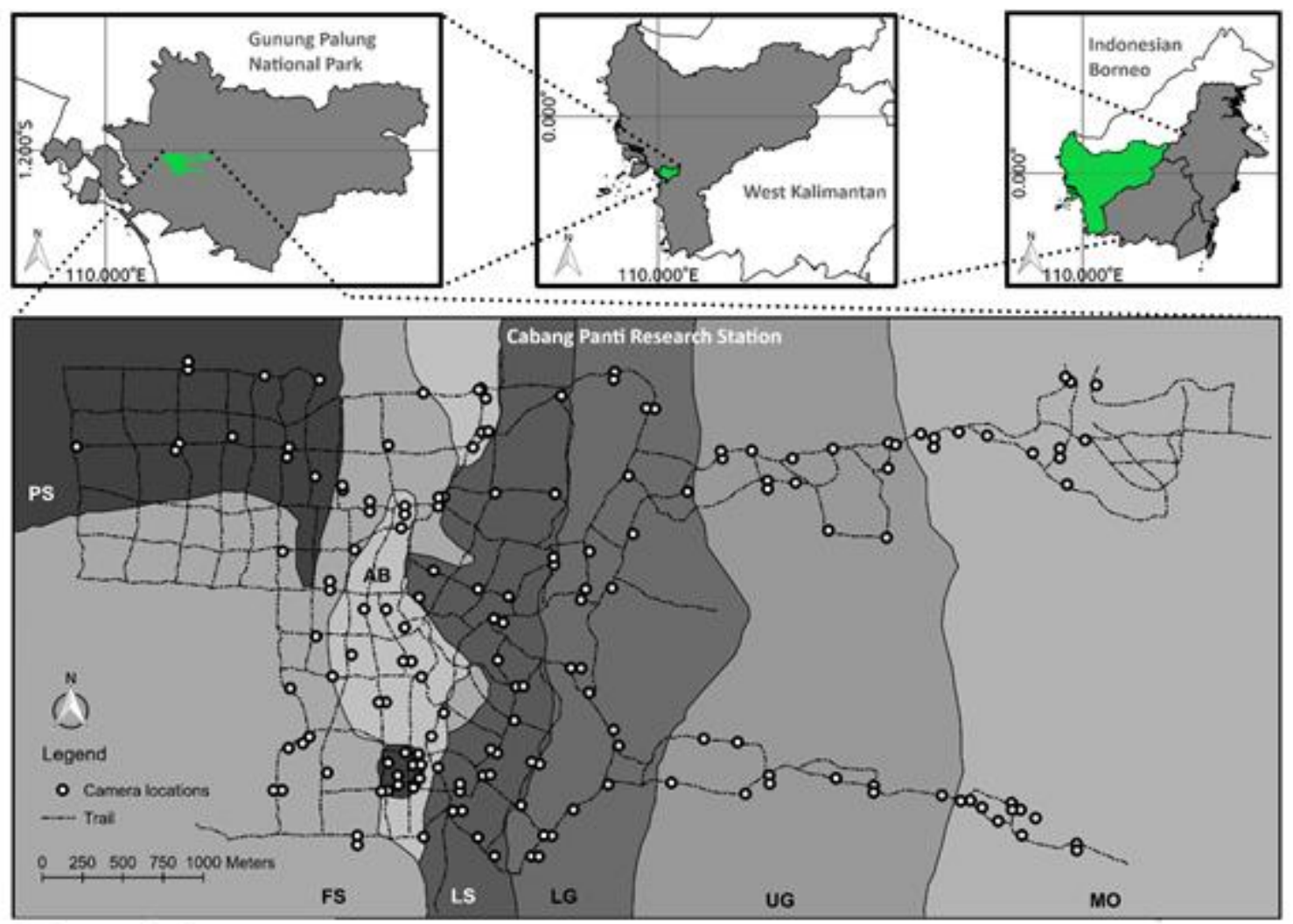

PS Peat swamp [FS] Freswater swamp

AB. Alluvid bench [LS Lowland sandstone L

Lowand granile UG Upland granile MO Montane

Figure 1.1: Map illustrating the location of Gunung Palung National Park within the west Kalimantan province of Indonesian Borneo. The primary image shows the habitat types, camera locations, and trail system throughout the study site at Cabang Panti Research Station. Forest types are indicated by twoletter abbreviations described in the legend beneath the image.

\section{Forest types}

The presence of 7 distinct forest habitat types across an elevational gradient makes CPRS an ideal site to study the variation in species distribution over space and time. The forest types differ in structure, levels of productivity, and species composition due to differences in soil composition and climate variation among the habitat types (Marshall 2009, Marshall et al. 2014).

The mosaic of forest types within the compact study area provides an opportunity to investigate relationships between species distributions and forest productivity, mast synchronicity, forest structure, and community composition. Much of the research that has been conducted at CPRS has accordingly focused on frugivore species (Knott 1999, Johnson et al. 2005, Marshall et al. 2014, Marshall 2009, Curran and Leighton 2000, Clink et al. 2017, Dillis et al. 2015) seed dispersal (Webb and Peart 2008, Blate et al 1998), masting and forest productivity (Curran and Leighton 2000, Marshall et al. 2014), and forest reproduction (Cannon et al. 2007a, Cannon and Leighton 2004). 
A. Rainfall by forest type

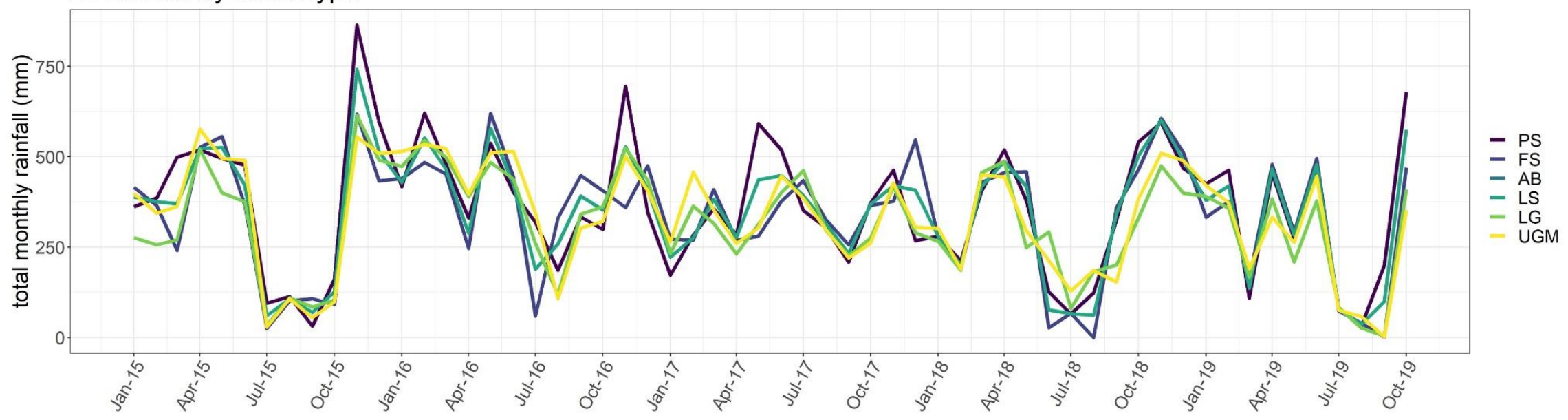

B. Monthly Maximum and minimum temperature

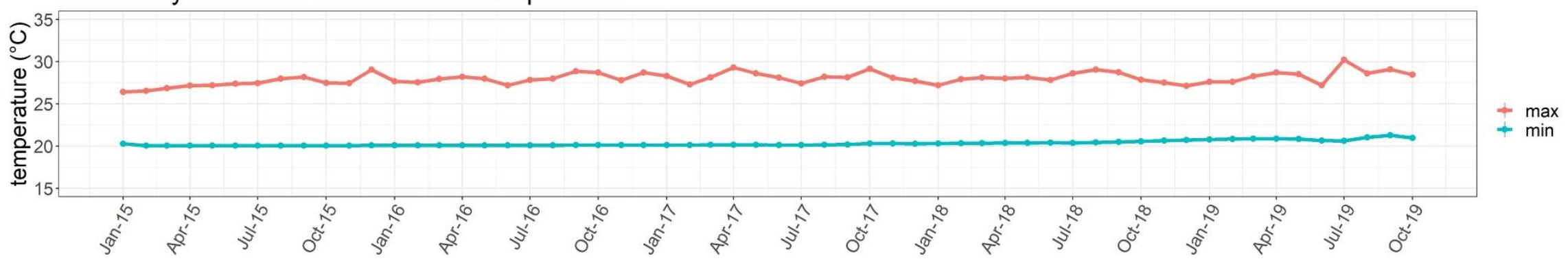

Figure 1.2: Climate at the Cabang Panti Research Station between July 2015 and October 2019. A) Total monthly rainfall by forest type (PS-peat swamp, FS-freshwater swamp, AB-alluvial bench, LS-lowland sandstone, LG-lowland granite, and UGM-upland granite/ montane), and B) maximum and minimum temperatures with error bars depicting the standard deviation $\left({ }^{\circ} \mathrm{C}\right)$. 


\section{Mammal community}

The study area at CPRS supports an intact rainforest community considered to remain largely unaffected by human disturbance (Laman et al. 1996, Blundell 1996, Marshall et al. 2009a). Under the protection of the park, the mammal community has remained diverse and is thought to remain at densities characteristic of undisturbed Bornean rainforest ecosystems (Marshall et al. 2009a). The mixture of forest types in the region and abundance of synchronous masting plants provide a rich food source sustaining a diverse guild of vertebrate frugivore species (Curran and Leighton 2000, Marshall et al. 2014). Five sympatric ungulates are frequently observed across the study site, feeding on a mixture of fruit and browse (Phillips 2016). Consisting of two chevrotain species (Tragulus kanchil, T. napu), a pair of muntjacs (Muntiacus atherodes, M. muntjak), and the bearded pig (Sus barbatus), little is known about how these species differentiate in resource or habitat use. The set of ungulates are thought to comprise a large portion of the prey base for Borneo's endangered carnivores (Hearn et al. 2018b, Ross et al. 2013). The Sunda clouded leopard (Neofelis diardi) is the top predator in Borneo, and the largest of the five sympatric felids. Alongside the Sunda clouded leopard is the leopard cat (Prionailurus bengalensis), Bornean bay cat (Catopuma badia), flat-headed cat (Prionailurus planiceps), and the marbled cat (Pardofelis marmorata). The co-occurrence of all five felid species is rarely recorded across Borneo as the Bornean bay cat and flat-headed cat are categorized as endangered by the IUCN (2020) (Cheyne et al. 2016, Hearn et al. 2018b, Mohamed et al. 2009). Over the past 20 years, all 5 species have been recorded at GPNP (Nowak 2012, Allen et al. 2016), indicating that it may remain an ecological stronghold, however, the contemporary occurrence within the study site is unclear. 
Table 1.1: Characteristics of 7 distinct forest types present in Cabang Panti Research Station, Gunung Palung National Park, Indonesian Borneo (Whitmore 1984, Curran \& Leighton 2000, Paoli et al. 2001, Cannon \& Leighton 2004, Marshall et al. 2014).

\begin{tabular}{|c|c|c|c|c|}
\hline Forest type & Elevation & Soil type & Dominant vegetation & Forest structure \\
\hline $\begin{array}{l}\text { Freshwater } \\
\text { swamp } \\
\text { (FS) }\end{array}$ & $5-10 \mathrm{~m}$ asl & $\begin{array}{l}\text { - Nutrient-rich soil } \\
\text { Poorly draining gleyic soil that } \\
\text { is flooded seasonally }\end{array}$ & $\begin{array}{c}\text { Dominant species: Pternandra coerulescens } 11 \% \\
\text { Dominant family: Melastomataceae } 12 \%, \\
\text { Euphorbiaceae } 12 \%, \text { Annonaceae } 10 \% \\
\text { moderate proportion of figs } \\
\text {. low species diversity }\end{array}$ & $\begin{array}{l}\text { Mostly small trees and } \\
\text { woody climbers } \\
\text { - Low density of trees }\end{array}$ \\
\hline $\begin{array}{l}\text { Alluvial bench } \\
\qquad(A B)\end{array}$ & $5-50 \mathrm{~m}$ asl & $\begin{array}{l}\text { - Nutrient-rich soil } \\
\text { Soils derived from alluvial } \\
\text { deposits of upstream } \\
\text { sandstone and granite parent } \\
\text { material }\end{array}$ & $\begin{array}{c}\text { Dominant species: Dipterocarpus sublamellatus } 9 \% \\
\text { Dominant family: Dipterocarpaceae } 20 \%, \\
\text { Myristicaceae } 9 \% \text {, Euphorbiaceae } 8 \% \\
\text {. Large proportion of figs }\end{array}$ & $\begin{array}{l}\text { Slightly lower tree } \\
\text { densities (small and } \\
\text { large) }\end{array}$ \\
\hline $\begin{array}{l}\text { Lowland } \\
\text { sandstone } \\
\text { (LS) }\end{array}$ & $\begin{array}{l}20-200 \mathrm{~m} \\
\text { asl }\end{array}$ & $\begin{array}{l}\text { - Nutrient-rich soil } \\
\text { Sandy well-drained soil } \\
\text { derived from sandstone and } \\
\text { quartzite sedimentary rock } \\
\text {. High clay content }\end{array}$ & $\begin{array}{c}\text { Dominant species: Strombosia ceylanica } 5 \% \text {, } \\
\text { Dipterocarpus sublamellatus } 5 \% \\
\text { Dominant family: Euphorbiaceae } 10 \%, \text { Annonaceae } \\
7 \% \\
\text {. Moderate proportion of figs } \\
\cdot \text { High fruit productivity } \\
\text {. High species diversity }\end{array}$ & $\begin{array}{c}\text { High density of large } \\
\text { trees }\end{array}$ \\
\hline
\end{tabular}




\begin{tabular}{|c|c|c|c|c|}
\hline Forest type & Elevation & Soil type & Dominant vegetation & Forest structure \\
\hline $\begin{array}{l}\text { Lowland } \\
\text { granite } \\
\text { (LG) }\end{array}$ & $\begin{array}{l}200-400 \\
m \text { asl }\end{array}$ & $\begin{array}{l}\text { Well-drained granite-derived } \\
\text { podzolic soil }\end{array}$ & $\begin{array}{c}\text { Dominant species: Shorea crassa } 5 \% \\
\text { Dominant family: Dipterocarpaceae } 20 \%, \\
\text { Sapotaceae } 11 \% \\
\text {. High species diversity }\end{array}$ & $\begin{array}{l}\text { High density of small } \\
\text { and large trees }\end{array}$ \\
\hline $\begin{array}{l}\text { Montane } \\
\text { (MO) }\end{array}$ & $\begin{array}{l}750-1100 \\
\mathrm{~m} \text { asl }\end{array}$ & Granite-derived soil & $\begin{array}{l}\text {. Low species diversity } \\
\text { Low level of fruit production }\end{array}$ & $\begin{array}{l}\text { High density of small } \\
\text { trees } \\
\text { - No large trees } \\
\text { · Transitioning to } \\
\text { predominantly small } \\
\text { trees with stunted } \\
\text { growth at higher } \\
\text { elevations with } \\
\text { Massenerhebung effect }\end{array}$ \\
\hline
\end{tabular}




\subsection{Data collection}

Motion-triggered camera traps (Bushnell TrophyCam, Overland Park, KS) were set up at 192 locations throughout Cabang Panti Research Station between June 2015 and October 2019 ( $n=42,610$ trap nights) to monitor terrestrial wildlife. Camera locations were randomly selected along trails $(n=134)$ and paired with off-trail cameras $(n=58)$ to evaluate differences in detection probability due to camera placement. Cameras were set up in each of the 7 habitat types with a minimum of 4 cameras active per habitat at any time (PS $n=28, F S n=30, A B n=38, L S n=28, L G n=22, U G M n=48$ ). Of the 7 distinct forest types identified (Table 1.1), I pooled the upland granite and montane forests (UGM) as phenological data was unavailable for the montane forest within the study period. The adjacent upland forests are considered to have substantial interdigitation and similar floral composition.

Sites were sampled on a rolling basis with an average of 31.8 sites actively surveyed during a 30 day survey period and each site was effectively resampled an average of 4.87 times. Camera traps were regularly serviced every 3-4 weeks to ensure the batteries remained active and the cameras had not been damaged or stolen. Cameras were programmed to record $20 \mathrm{~s}$ videos when triggered, with a refractory period of $10 \mathrm{~s}$ before becoming active again. All footage was reviewed by local wildlife experts and animals were identified to a species level. In some cases, closely related species that could not be clearly identified were recorded at the genus level and were omitted from analysis. To reduce autocorrelation, I treated multiple recordings of the same species at a site during a $24 \mathrm{~h}$ period (starting at 00:00) as one sighting.

Monthly data on fruit availability was compiled from phenology data collected by Dillis et al. (2015) using 10 randomly selected phenology plots, summing to 1.5 ha sampled in each forest type. Within plots, fruit availability was assessed for all trees with stems larger than $14.5 \mathrm{~cm}$ dbh, lianas larger than $3.5 \mathrm{~cm}$ dbh, and all hemi-epiphytic figs with roots touching the ground. Fruit availability was measured as the density of stems bearing ripe fruit and plot-specific values were averaged to obtain one monthly value for each forest type. 
Chapter 2.

\section{Habitat use and niche partitioning of ungulates in response to spatiotemporal variation in fruit availability at Gunung Palung National Park}

\subsection{Abstract}

A paucity of data on the diets, distribution, and basic ecology of tropical ungulates contributes towards the vulnerability of tropical rainforest ecosystems to anthropogenic threats. Ungulates likely play key ecosystem roles through seed dispersal, forest regeneration, and in that they comprise a large portion of the prey biomass supporting carnivore populations. A detailed understanding of the spatial ecology and niche partitioning is lacking for ungulates in Borneo. I used remote camera traps and a modified single-season occupancy modelling approach, using time as a covariate, to study spatiotemporal habitat use patterns of 5 ungulate species in Gunung Palung National Park, West Kalimantan, Borneo, over a 4 1/2 year period ( $n=42,610$ trap nights). Specifically, I estimated habitat use of lesser mousedeer (Tragulus kanchil), greater mousedeer (T. napu), Bornean yellow muntjac (Muntiacus atherodes), red muntjac (M. muntjak) and bearded pig (Sus barbatus) across 6 distinct forest types along an elevational gradient and a temporal gradient of fruit availability. Forest type was an important variable explaining habitat use and distribution of each species. Habitat use estimates peaked in peat swamp forests for lesser mousedeer ( $\widehat{\Psi}=0.92 \pm 0.05$ ), alluvial bench forests for greater mousedeer $(\widehat{\Psi}=0.52 \pm 0.08$ ), lowland granite forests for yellow ( $\widehat{\Psi}=0.95 \pm 0.07$ ) and red muntjacs ( $(\widehat{\Psi}=0.98 \pm 0.09$ ) and freshwater swamp forests for bearded pigs $(\widehat{\Psi}=0.84 \pm 0.07)$. Bearded pigs were strongly linked to temporal variation in fruit availability, providing evidence of their ability to track changes in fruit availability. My results demonstrate a novel pattern of niche partitioning through distinct habitat and food resources among 5 sympatric ungulate species in a mast-fruiting tropical rainforest system. Given the increasingly negative impact of anthropogenic disturbances on these ecosystems, my results will aid in developing effective conservation strategies of threatened tropical ungulate communities.

\subsection{Introduction}

The interplay between resource availability, competition, and their effects on niche partitioning has been well studied and can be used to provide key information on species' distributions and the integral roles they play within their ecosystem. Niche partitioning can be described as occurring 
when species who compete over a shared resource differentiate along an additional dimension (i.e. habitat, food resources, or time) to reduce interspecific competition (Hutchinson 1957, Holt 1987). Examining habitat and resource use among competing species is a simple way to identify patterns of niche partitioning (Schoener 1974).

A variety of factors, including species interactions, human activity, and physical/environmental factors can be at play, shaping the realized niche of species. The fundamental niche is shaped by environmental and physical characteristics influencing habitat suitability (i.e. climate, resource availability, elevation, etc.). Interactions between species-either as competition, mutualism, commensalism, or predation-differentiates a realized niche from the fundamental niche (Hutchinson 1957). The influence of humans either through direct negative interactions analogous to predation (i.e. poaching), or through passive human activity (i.e. researchers) can form a landscape of fear based on perceived predation risk and has the potential to similarly influence the distribution of a species (Lima et al. 1990, Laundre et al. 2001). Accordingly, to effectively describe the realized niche of a species, the influence of numerous factors must be evaluated collectively.

Mast-induced variation in fruit availability may be a key factor shaping niche partitioning within tropical rainforest ecosystems. In contrast to temperate forests that have predictable seasonal fruiting (Smith-Ramirez \& Armesto 1994, Lechowicz 1995), a high degree of variation in resource availability, over both space and time, is characteristic of many tropical rainforest ecosystems (Wich \& Van Schaik 2000). Mast events show extreme peaks in flowering and fruit production, occurring on a variable supra-annual basis and are thought to be linked to ENSO and triggered by specific climate conditions (Williamson \& Ickes 2002, Ashton et al. 1988). Resource pulses can have pronounced responses rippling through ecological communities influencing individual fitness, habitat use, and species interactions (Yang et al. 2008, Bogdziewicz et al. 2016). The synchronized brief surge of fruit availability has been theorized to assist seedling recruitment through satiating seed predators (Janzen 1971) and more recently has been hypothesized to help escape seed predation through delays in nomadic seed predators arriving at regional masts (Curran \& Leighton 2000). In Borneo, populations of bearded pig (Sus barbatus) have been reported to have a close link to mast cycles. They demonstrate mast-dependent reproduction with rutting behaviors timed with flowering, resulting in dramatic populations booms during mast events (Caldecott \& Caldecott 1985, Pfeffer \& Caldecott 1986, Curran 1995). Additionally, the peak and subsequent lull in resources have been observed to result in emaciated bearded pig and sun bear (Helarctos malayanus) populations during long inter-mast periods (Curran \& Leighton 2000, Fredriksson et al. 2006). Mast-fruiting events attract an influx of nomadic frugivores able to track asynchronous 
fruiting across large landscapes (Levey 1988, Dove 1993, MacKinnon et al. 1996, Curran \& Leighton 2000, Kimura et al 2001, Kimura 2003, Granados et al. 2019). Curran and Leighton (2000) differentiated between the resource use of resident and nomadic frugivore species: proposing that resource switching occurs during mast events by resident species to reduce competition with the arrival of nomadic species that efficiently deplete mast-produced fruit supplies. While the influence of resource pulses on niche partitioning remains unknown, the fluctuating fruit availability undoubtedly affects the ecology of rainforest frugivores.

Within Borneo's rainforest ecosystems, the influence of mast-induced fluctuations in resources has been well studied, however, the ground-dwelling ungulate species have been largely overlooked (Blate et al. 1998, Knott 1999, Curran \& Leighton 2000, Webb \& Peart 2001, Felton et al. 2003, Cannon et al. 2007b, Marshall et al. 2009a, Marshall et al. 2014, Clink et al. 2017). Thus the basic ecology of Borneo's guild of ungulate species remains poorly understood despite facing encroaching threats from deforestation, poaching, and climate change. Studies of tropical ungulates are few and far between in contrast to the breadth of research on their temperate forest and grassland cousins (Ahrestani \& Sankaran 2016). This is of particular concern as tropical forest ecosystems are facing the brunt of the global extinction crisis (Wilson 1985).

Gunung Palung National Park (GPNP) in West Kalimantan, Indonesian Borneo, is a mastfruiting forest that supports 5 sympatric ungulate species across a dramatic range in body size (Table 2.1). The lesser mousedeer (Tragulus kanchil) and greater mousedeer (T. napu) are the world's smallest ungulate species with adults reaching $1.5-2.5 \mathrm{~kg}$ and $4-5.5 \mathrm{~kg}$, respectively (Nowak 1999, Matsubayashi et al. 2003). The Bornean yellow muntjac (Muntiacus atherodes) and red muntjac ( $M$. muntjak) are mid-sized cervids reaching 15 - $20 \mathrm{~kg}$ and 20 - 28kg at maturity (Heydon 1994, Phillips 2016). The bearded pig (Sus barbatus) reaches weights of between 60 - $200 \mathrm{~kg}$ when fully grown (Phillips 2016). Uncertainty remains surrounding the diets of GPNP's ungulate species as available knowledge is predominantly based on anecdotal evidence and observations. Studies of temperate ungulate ecology have found a strong relationship between ungulate body mass and diet qualityknown as the Jarman-Bell Principle (Bell 1971, Jarman 1974, Geist 1974). While debate surrounds the mechanism responsible for this trend, the decline in diet quality with larger ungulate species has been well documented (Codron et al. 2007). This principle would predict resource partitioning between the ungulates in GPNP following the body mass relationship with mousedeer species diets consisting of higher quality fruit and seed resources; muntjacs consuming a mixture of lesser-quality browse and fruit; and bearded pigs relying on varied omnivorous diet.

The presence of 7 distinct forest types within a compact area at GPNP, existing across a range of elevations and with different inherent levels of productivity provides a rare opportunity to 
simultaneously study the influence of multiple factors on patterns of habitat use. Evaluating the spatiotemporal patterns of habitat use in relation to varying levels of fruit availability, human activity, forest type, and elevation can provide insight on the spatial ecology of understudied species and partitioning among the 5 ungulates.

\subsection{Aims}

The purpose of my study was to investigate the patterns of habitat use over space and time of 5 sympatric ungulate species across a body mass continuum to inform an understanding of niche partitioning in a tropical rainforest system. Understanding the relationship between fruit availability and habitat use for each species will help inform an understanding of species-specific diets, dependence on mast resources, and will help determine if there is evidence of diet quality scaling with body mass in tropical rainforest ungulates in accordance with the Jarman-Bell Principle (Bell 1971, Jarman 1974, Geist 1974). To do so I used occupancy modelling based on camera trap data to investigate the influence of a) spatiotemporal fluctuations in fruit availability, b) human activity, c) forest type, d) elevation, and e) time on the habitat use of lesser mousedeer (T. kanchil), greater mousedeer (T. napu), the Bornean yellow muntjac (M. atherodes; yellow muntjac hereafter), red muntjac (M. muntjak), and the bearded pig (Sus barbatus). Additionally, I sought to evaluate the detection probability of each species at on and off trail camera traps to identity potential biases and inform methodology of future research. 
Table 2.1: The comparative body mass, taxonomy, and conservation status of the ungulate species observed at CPRS.

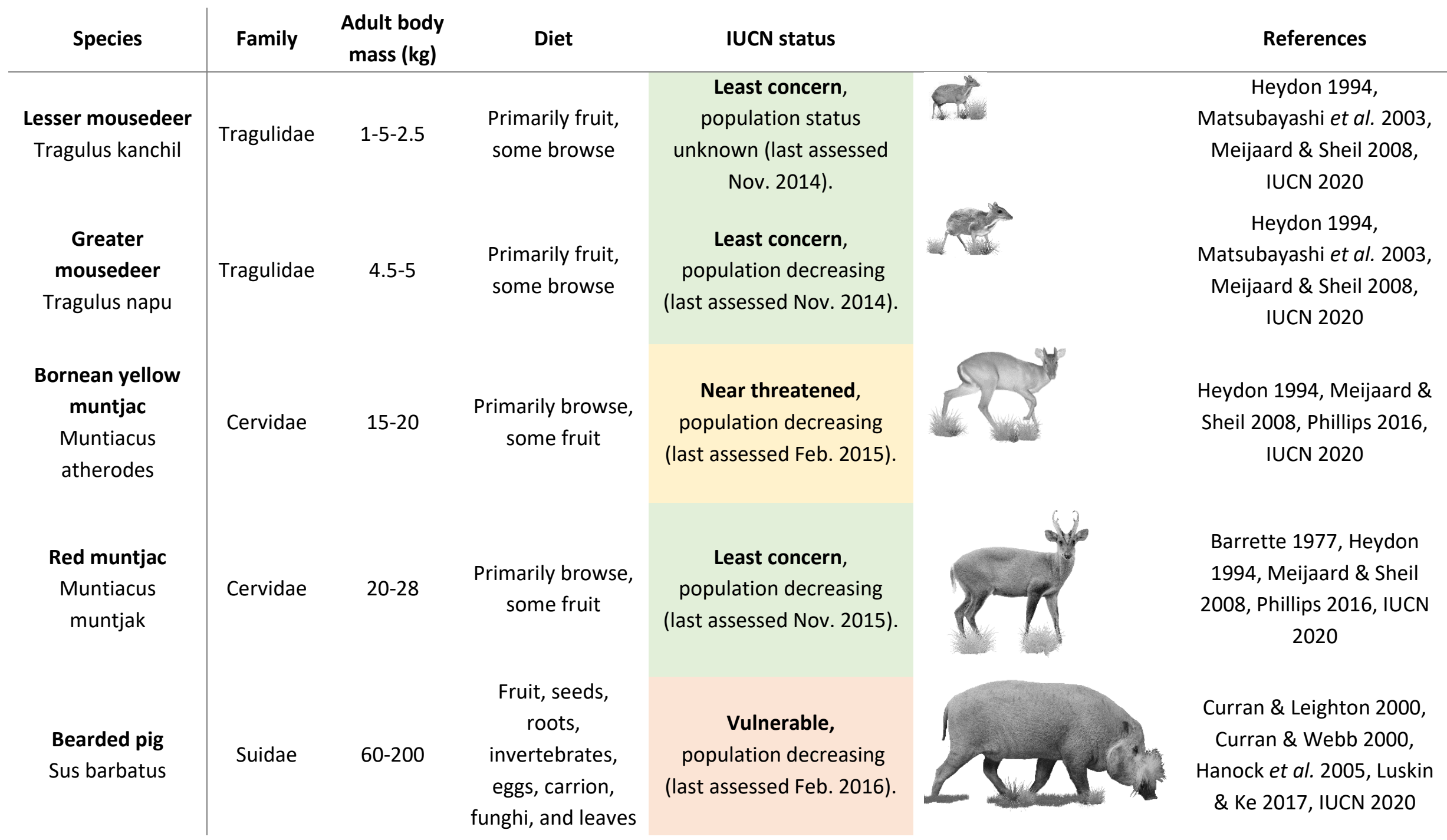




\subsection{Methods}

\subsubsection{Study Site}

The study was conducted at the Cabang Panti Research Station (CPRS) in Gunung Palung National Park (GPNP), West Kalimantan, Indonesian Borneo, as outlined in section 1.3.

\subsubsection{Data Collection}

Species detections and site-specific data were collected between July 2015 and October 2019 as outline in section 1.4 .

\section{Camera traps}

I used a network of motion-sensor activated cameras at 192 locations across a gradient of productivity, forest types, and elevation in CPRS-these were set up following a standardized camera trap protocol. Bushnell TrophyCam HD cameras were programmed to record $20 \mathrm{~s}$ video when triggered by motion, with a $10 \mathrm{~s}$ refractory period before becoming active again. All videos were analysed by a local expert in species identification. Sightings that had not been identified to a species level with confidence were omitted from the analysis.

Cameras were set up in each of the 7 distinct forest types within CPRS (Cannon et al. 2007a). However, for the purpose of this study I pool the upland granite and montane forest types into a single 'upland granite/montane' category. Pooling was necessary due to a lack of productivity data from the montane forest category for the duration of this study and justified based on and informed by past research suggesting interdigitation exists between these adjacent forest habitats (Curran \& Leighton 2000). It is possible that pooling upland granite and montane forest types may lead to an underestimation of the effect of resource availability as montane forests may have a lower level of fruit available due to stunted growth patterns from the Massenerhebung effect (Whitmore 1984). Henceforth 6 forest types will be discussed: peat swamp (PS), freshwater swamp (FS), alluvial bench $(A B)$, lowland sandstone (LS), lowland granite (LG), and upland granite/montane (UGM).

\section{Site-specific variables}

Elevation and GPS coordinates at each camera site were recorded in the field and verified using ARC ArcGIS software post-hoc. Climate and productivity data were sampled at multiple locations within each forest type monthly throughout CPRS. Fruit availability was measured at 10 randomly selected plots covering 1.5 ha in each forest type. All trees, lianas, and hemi-epiphytic figs meeting minimum size criteria were monitored and the density of stems bearing ripe fruit was recorded (see Marshall \& Leighton 2006, Marshall et al. 2010, Dillis et al. 2015 for details). Plot specific values were then combined into monthly averages for each forest type. All continuous variables were standardized using a z-score normalization. 
I separated all data into 13 sampling periods of equal duration spanning from July 2015 to October 2019. Each sampling period was 120 days and covered 4 vegetation surveys. Traditionally the term season is used in occupancy modelling, however, I chose the alternate term sampling period to avoid confusion as the timeframe in question did not reflect or align with a biological concept of a season. The study site at GPNP does not exhibit clear seasonality, therefore I chose sampling periods to reflect fluctuations in forest productivity (Figure 2.1). Henceforth I will describe the modelling seasons for this study as sampling periods.

I formatted data from camera traps and site-specific covariates into 30-day surveys. I chose a 30-day period based on the low detection rate of some species in the dataset. For effective modelling, the temporal scale of data should be chosen to optimize the balance of detections and non-detections (Mackenzie et al. 2006). If the dataset were formatted over longer surveys the data would skew towards consistent detections and if it were over shorter surveys detections would be too scarce to model.

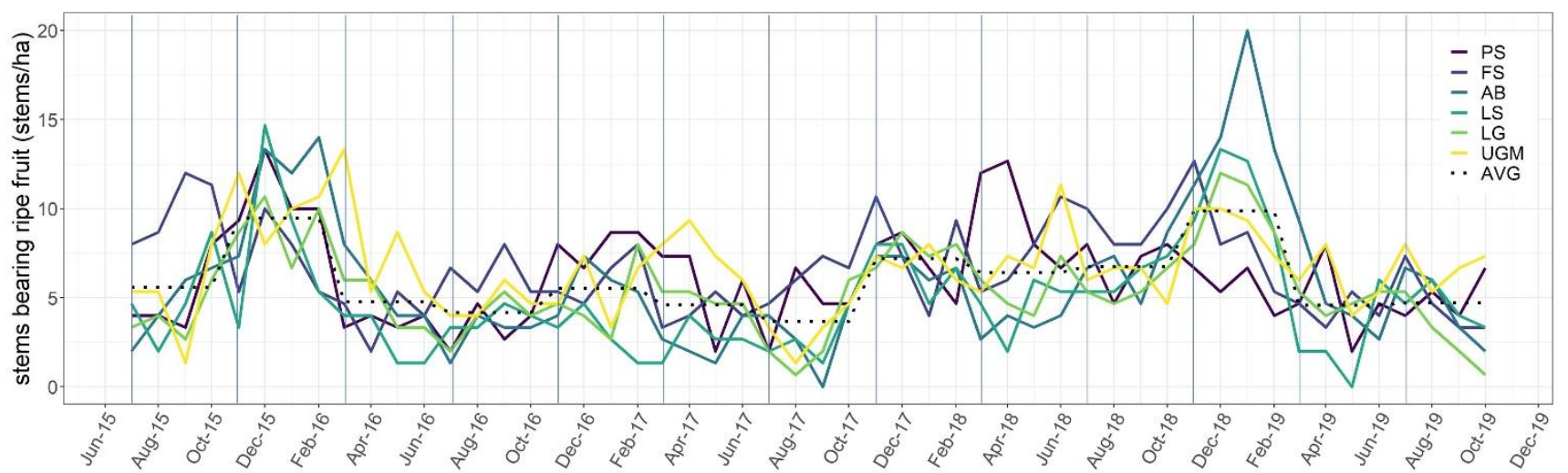

Figure 2.1: Trends in fruit availability at CPRS across 6 forest types between July 2015 and October 2019. Vertical blue lines delineate the sampling periods chosen to reflect trends in forest productivity. The dashed black line represents the density of ripe fruit per hectare averaged across habitat types and sampling periods to obtain the covariate used to represent fruit availability in my modelling.

\subsubsection{Occupancy modelling}

To assess the spatial and temporal patterns of ungulate habitat use throughout CPRS I conducted repeated single-species occupancy modelling using a variation on a single season framework. I performed all analysis in R (R Core Team 2013) and created detection histories for each of the focal species using the camtrapR package (Niedballa et al. 2016). I conducted occupancy modelling using the RPresence package developed by Mackenzie \& Hines (2018). 
Occupancy modelling is a form of analysis that uses detection/ non-detection data to obtain estimates of a species occurrence across an area by accounting for imperfect detection. The occupancy probability of a species $(\Psi)$, or the probability of a randomly selected site being occupied by the species, is estimated as a function of detection probability (p). Both occupancy and detection probability can be modelled using site-specific variables, allowing the influence of these covariates to be determined.

I used a variation on a standard simple season occupancy analysis (Mackenzie et al. 2006) to estimate habitat use and detection probabilities across the 13 sampling periods. Multi-season occupancy modelling approaches are available (Mackenzie et al. 2003); however, they require consistent resampling of each location over sampling periods. This requirement was not met as camera trapping was carried out in a rolling method across the sample site and therefore the majority of sites were not resampled across more than 2 sampling periods (see section 1.4). Multiseason approaches also involve the estimation of parameters for colonization and extinction to explain underlying relationships resulting in changes to occupancy at a site. This was not of interest to my study as the focus was on patterns of habitat use and not underlying site emigration or immigration.

Alternatively, I used a simple single-season occupancy modelling framework, with time as a covariate, to concurrently analyse habitat use and detection across multiple sampling periods without estimating extinction or colonization parameters (Fuller et al. 2016, Burnett \& Roberts 2015, Linden \& Roloff 2013). This "stacked" approach combines survey sites with all sampling periods and treats each site-period combination as a separate sampling location (Ahlering \& Merkord 2016). This approach has the advantage of extending the effective sample size and supports the assumption of open populations at each study site as the occupancy in subsequent sampling periods are independent. Additionally, this data structure can improve issues of poor model fit, although the error for parameter estimates can be subsequently underestimated (Burnett \& Roberts 2015).

Occupancy modelling functions on the assumption of closure, meaning that sites are 'closed' preventing an individual from being recorded at multiple sites during a survey. As species were able to travel between sampling sites, different terminology must be used for this study. Instead of considering the occurrence of a species at a study site as an indication of its occupancy, for this study, this can be considered as an indication of the species' use of the site (Mackenzie et al. 2006, Tan et al. 2017, Gould et al. 2019). This is a necessary distinction as the free movement of individuals violates the assumption of closure. As individuals are not prevented from leaving a site, the occupancy of the site could change throughout the sampling period. Therefore, if an individual is present, the site is instead defined as being used not occupied. 
Another assumption of occupancy modelling is that an individual is never falsely detected at a site when it was absent. This assumption was addressed by using local experts to identify species present on high-quality camera footage. Any individuals that were not identified with confidence due to poor images or uncertainty were excluded from modelling.

Table 2.2: A description of the covariates used in habitat use and detection models. All data was collected between July 2015-October 2019 at CPRS. All continuous variables are standardized using z-score normalization.

\begin{tabular}{|c|c|c|}
\hline Covariate & Measure & Range of values \\
\hline fruit & $\begin{array}{l}\text { Density of stems bearing ripe fruit / ha averaged } \\
\text { over } 120 \text {-day periods for each forest type. } \\
\text { Standardized using z-score normalization. }\end{array}$ & 2.5-14.67 stems/ha \\
\hline forest type & $\begin{array}{l}\text { Categorical covariate identifying between } 6 \\
\text { distinct forest types }\end{array}$ & $\begin{array}{l}\text { Peat Swamp (PS), Freshwater } \\
\text { Swamp (FS), Alluvial Bench } \\
\text { (AB), Lowland Sandstone (LS), } \\
\text { Lowland Granite (LG), Upland } \\
\text { granite/montane (UGM) }\end{array}$ \\
\hline elevation & $\begin{array}{l}\text { Elevation measured as distance from sea-level to } \\
\text { describe a linear relationship along an elevational } \\
\text { gradient. Standardized using z-score } \\
\text { normalization. }\end{array}$ & 6-1050 m above sea level (asl) \\
\hline$e l e v^{2}$ & $\begin{array}{l}\text { A quadratic relationship of elev }+ \text { elev }^{2} \text { to } \\
\text { describe a non-linear response to elevation. } \\
\text { Standardized using z-score normalization. }\end{array}$ & \\
\hline time & $\begin{array}{l}\text { 120-day sampling periods as a continuous } \\
\text { covariate, aligning with periodical fluctuations in } \\
\text { forest productivity (figure } 2.1 \text { ). }\end{array}$ & $1-13$ \\
\hline humans & $\begin{array}{l}\text { Index of human activity of researchers and } \\
\text { poachers at each site. Calculated as total number } \\
\text { of sightings of researchers and poachers at a site } \\
\text { during a sampling period/ sampling effort. }\end{array}$ & 0-6.93 sightings/trap night \\
\hline off-trail & $\begin{array}{l}\text { Indicator variable describing the camera } \\
\text { placement either on or off trail. }\end{array}$ & $\begin{array}{l}\text { Binary value indicated ON }(0) \\
\text { or OFF (1) trail }\end{array}$ \\
\hline effort & $\begin{array}{l}\text { The proportion of days a camera at a sampling site } \\
\text { was active during a } 120 \text {-day sampling period }\end{array}$ & $0-1$ \\
\hline
\end{tabular}




\subsubsection{Hypothesized predictors of habitat use and detection}

The influence of several spatial and temporal factors on the habitat use and detection of ungulate species within CPRS are assessed in this study (Table 2.2).

\section{Habitat use}

I predict the occurrence of ungulate species in CPRS to be differentially influenced by variation in resource availability and human activity across the study site.

A) Resource availability

The bottom-up influence of resource availability on the habitat use of ungulates across a body-size gradient was modelled using the covariates fruit, forest, elev, and elev $^{2}$. Temporal variation in fruit availability, constant within forest types, was modelled using the fruit covariate and was predicted to have a strong influence the probability of bearded pigs using a site. Bearded pigs are thought to be 'mobile specialists' able to track fruit availability across landscapes and their arrival into areas often coincides with mast events (Curran \& Leighton 2000, Yang et al. 2008, Granados et al. 2019). A mast event was recorded at GPNP in May-July 2014 prior to our study commencing, with minor fruiting events in December 2015 and January 2019, leading up to another major mast just following this study in early 2020. Distinct characteristics varying by forest type-including distinct spatial variation in productivity between forest types-was modelled using the forest covariate. According to the Jarman-Bell Principle, increasing body size in mammalian herbivores scales inversely with minimum diet quality (Bell 1970, Jarman 1974). Accordingly, I predict that reliance on high-quality fruit and browse resources available in highly productive forest types will scale inversely with body size. The probability of the smallest ungulate species using habitats (lesser mousedeer and greater mousedeer) is predicted to be strongly influenced by forest type. This would result in a positive association with highly productive habitats but no relationship with the fruit covariate as mousedeer likely stay in small ranges and do not track pulses in resources across landscapes (Nowak 1999, Yang et al. 2008, Kusuda et al. 2013). I predict that the mid-sized ungulates-yellow and red muntjacswill not show strong associations with either spatial (forest) or temporal (fruit) variation in resource availability as their diet likely consists primarily of browse (Heydon 1994, Meijaard \& Sheil 2008, Phillips 2016). Selective habitat use independent of productivity and fruit availability is represented by elev and $e^{e} \mathrm{v}^{2}$ models, describing a linear and a quadratic relationship, respectively.

B) Human activity I modelled the potential influence of human activity on the habitat use of target species using the covariate humans. This variable was calculated as an index of combined researcher and poacher sightings throughout CPRS to reflect potential negative effects associated with both lethal and nonlethal activities. Poachers were recorded on camera traps throughout the duration of the study: identified as individuals carrying guns or carcasses, and not belonging to the research teams working 
at CPRS. Sparse detections ( $n=126$ ) prevented separate analysis of the effect of poachers throughout the study site. Instead I pooled detections of researchers and poachers and calculated an index based on the total sightings of humans at a site standardized by the sampling effort (active trap nights/sampling period). Real and perceived threats of predation from natural predators may depend on the body size of herbivores (Sinclair et al. 2003, Hopcraft et al. 2012, Riginos 2014). Species with lower body mass may be more affected by a 'landscape of fear' (Lima et al. 1990, Laundre et al. 2001) and exhibit human avoidance. Based on this theory, I predict that human activity will have a negative influence on the occurrence of smaller ungulate species in CPRS and less of an effect on the larger species.

C) Population trends

Additionally, the presence of any temporal population-level trends amongst the species was assessed by modelling the covariate time which identified the sampling period, functioning as a series of time steps over the duration of the study. I used this model to determine if temporal variation in habitat use was described by a consistent linear trend over time.

\section{Detection models}

For this study, I assumed probabilities of detection to be equal among surveys, and therefore limited covariates to those describing site-specific factors influencing detectability.

I modelled changes to the detection probability of individuals due to differences in sampling effort among sites using the effort covariate. I calculated this covariate as an index of sampling effort from the number of days a camera was active in a sampling period over the length of a sampling period (120 days). I predict increased sampling effort will result in higher probabilities of detection.

I evaluated the influence of camera placement either on or off trails using the offtrail covariate. Camera trapping studies frequently place their cameras on trails to maximize the detection rate of species. Some species including large carnivores have been shown to use trail systems for easy movement throughout a territory, however, prey species may actively avoid these high-use areas to reduce the risk of predation (Harmsen et al. 2010). I predict that camera placement on vs. off-trail influences the detection probability of species, with different preferences between species. 


\subsubsection{Modelling the effects of covariates on occupancy and detection probabilities} I estimated habitat use and detection probabilities using covariates through use of a logit link function. The probability of site i being used $\left(\Psi_{\mathrm{i}}\right)$ is expressed using a logit link as a function of $\mathrm{U}$ covariates at site $\mathrm{i}\left(\mathrm{x}_{\mathrm{i} 1}, \mathrm{x}_{\mathrm{i} 2}, \ldots \mathrm{x}_{\mathrm{iU}}\right)$ :

$$
\operatorname{logit}\left(\Psi_{\mathrm{i}}\right)=\alpha_{0}+\alpha_{1} \mathrm{x}_{\mathrm{i} 1}+\alpha_{2} \mathrm{x}_{\mathrm{i} 2}+\cdots+\alpha_{\mathrm{U}} \mathrm{x}_{\mathrm{iU}},
$$

with $\alpha_{0}$ and $\alpha_{1}, \alpha_{2} \ldots \alpha_{U}$ representing the intercept or constant term, and regression coefficients for each covariate, respectively. The $\alpha$ terms are the parameters being estimated. For example, a model estimating the influence of site-specific elevation and fruit availability on site-use $\Psi$ (elevation + fruit) would be described as

$$
\operatorname{logit}\left(\Psi_{\mathrm{i}}\right)=\alpha_{0}+\alpha_{1} \text { elev }_{\mathrm{i}}+\alpha_{2} \text { fruit }_{\mathrm{i}} .
$$

Detection probability can be similarly modelled using site-specific covariates, however, as detection is not assumed to stay constant throughout a sampling period, survey-specific covariates can be included as well. Typically, this can include covariates reflecting changes in survey conditions such as observer or weather. The use of camera traps in this study for collecting detection histories removed sampling biases due to variation in observer skill associated with traditional sampling techniques. A lack of climate variation at the study site further removed the need for survey-specific covariates to account for potential factors altering detection probabilities within sampling periods. For this study, I modelled detection probabilities similarly to site occupancy and assumed detection to be constant throughout a sampling period. Detection probability at site $\mathrm{i}$ is modelled as

$$
\operatorname{logit}\left(p_{i}\right)=\beta_{0}+\beta_{1} x_{i 1}+\beta_{2} x_{i 2}+\cdots+\beta_{U} x_{i U},
$$

with $\beta_{0}$ and $\beta_{1}, \beta_{2}, \beta_{U}$ representing the intercept and regression coefficients to be estimated.

\subsubsection{Candidate models}

I created a set of $a$ priori candidate models to test the predictions outlined in Section 2.4.4 ( $\Psi \mathrm{n}=$ 19, $p n=4$, Table S.1-S.2). I designed candidate models to evaluate ecological predictions with the use of covariates described in Table 2.2. I chose not to use an exhaustive all-possible-combinations approach as this has been found to increase support for spurious variables (Anderson \& Burnham 2002). I developed the set of candidate models to assess the influence of a series of non-exclusive factors on habitat use and detection instead of mutually exclusive hypotheses. Therefore, I included models with permutations of two separate covariates to assess factors working in combination (Table S.1). I limited models to two covariates to avoid overparameterization. I only included covariates with a Spearman or Pearson correlation coefficient of $\leq 0.6$ in the same model. I also included null models in the model set. I modelled detection and habitat use, holding a parameter in a general model while estimating the other. 
I used Akaike Information Criterion (AIC) to rank candidate models, selecting for the most parsimonious fit to the data. I considered models with $\triangle \mathrm{AIC} \leq 4$ to have a substantial amount of empirical support, $\triangle \mathrm{AIC} \leq 7$ to have significantly less support, and models with $\triangle \mathrm{AIC}>7$ were deemed to have no support and were excluded from model averaging and post-hoc analysis (Burnham \& Anderson 2002).

I calculated the relative variable importance (RVI) for each covariate by summing the model weights of all models that included the covariate (Giam \& Olden 2016). RVI can be used in an information-theoretic framework to determine which covariates appear to be strong or weak predictors of occupancy or detection in relation to each other (Mackenzie et al. 2006, Giam \&Olden 2016). I tested the fit of the most parsimonious model for each species, according to AIC, using a parametric bootstrap test $(n=1,000)$. I further assessed model fit by comparing the observed and expected data using a Pearson chi-square statistic $\left(x^{2}\right)$ and calculating the overdispersion parameter (c) (Mackenzie \& Bailey 2004).

\subsubsection{Spatial overlap analysis}

I tested the model-averaged estimates of habitat use from each species, derived from models with a $\Delta \mathrm{AIC} \leq 7$, against each other using a Pearson correlation test. I interpreted the degree of correlation of habitat use estimates between species as the degree of spatial overlap with positive $r$ values greater than 0.6 indicating a significant positive association and negative $r$ values less than -0.6 indicating significant evidence of spatial avoidance. I then graphically represented the results using corrplot package in R (Wei \& Simko 2017).

\subsection{Results}

All 5 ungulate species were detected during the camera trap survey (Table S.3). Bearded pigs were detected at the most sites $(n=150)$, followed by red muntjacs $(n=106)$, yellow muntjacs $(n=96)$, and lesser mousedeer $(n=74)$. Greater mousedeer were the least detected species, detected at less than a quarter of the camera sites $(n=43)$. Bearded pigs, yellow muntjacs, and red muntjacs were detected at all six forest types (Figure 2.2). Neither lesser mousedeer or greater mousedeer were detected in the lowland granite forest type and lesser mousedeer were additionally absent from the upland granite/montane. Note that raw detection data shown in Table S.3-4 and Figure 2.2-2.3 do not account for the imperfect detection of individuals. 

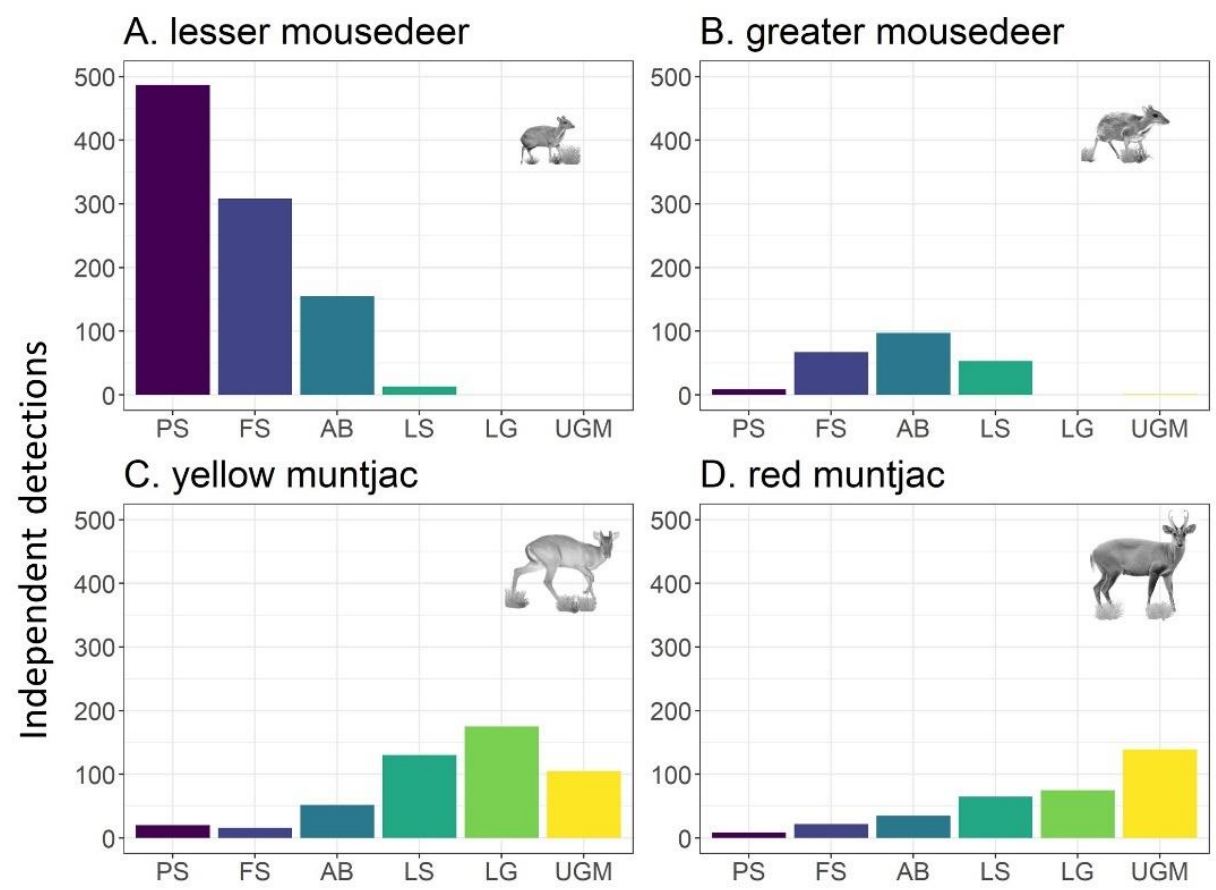

D. red muntjac

E. bearded pig

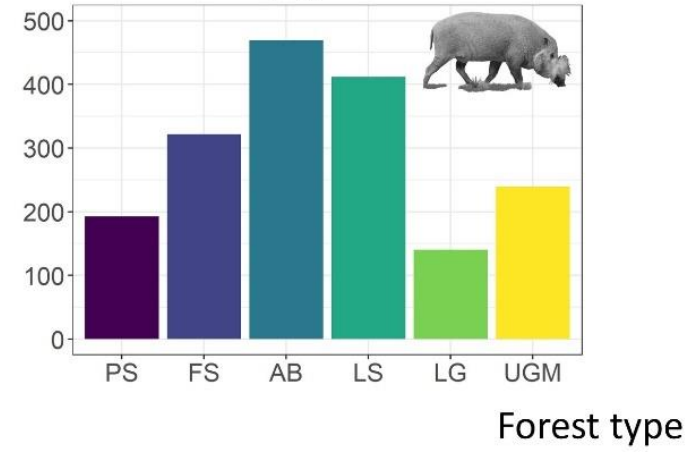

Figure 2.2: The independent detections of 5 ungulate species across forest types in CPRS recorded by motion triggered cameras between July 2015 and October 2019. Forest types in order of increasing elevational gradient are identified by the following abbreviations: Peat swamp (PS), freshwater swamp (FS), alluvial bench (AB), lowland sandstone (LS), lowland granite (LG), upland granite/montane (UGM). 


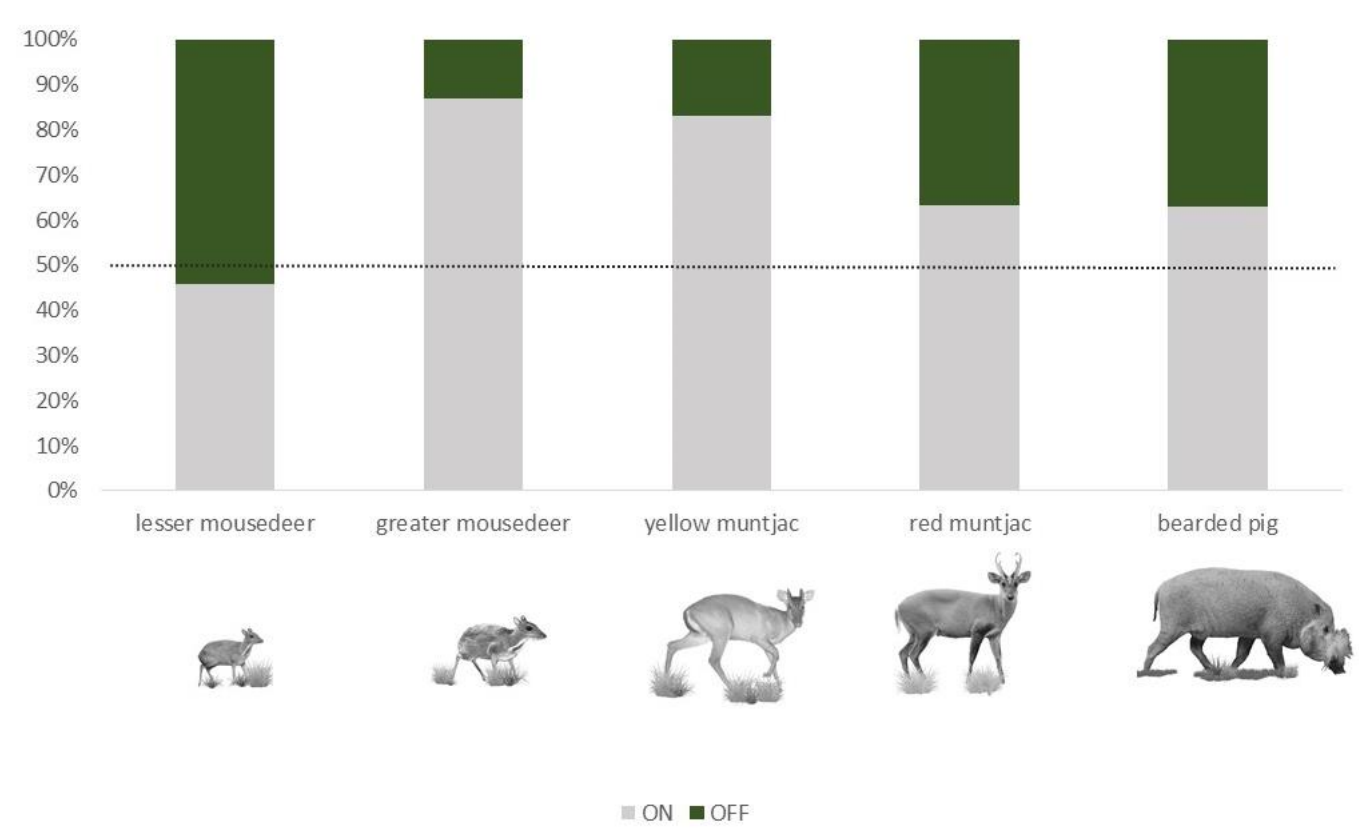

Figure 2.3: The proportion of ungulate detections at on and off trail camera locations at CPRS between July 2015 and October 2019. The number of detections was corrected for different sampling effort on $(n=134)$ and off trail $(n=58)$. Ungulate species are ordered from left to right in order of increasing body mass.

\subsubsection{Lesser mousedeer}

Forest type, human activity, and fruit availability best explained habitat use of lesser mousedeer $(\triangle \mathrm{AIC}<4$, Table 2.3). The most important variable was forest type (RVI: 0.99), followed by human activity (RVI: 0.63 ), and fruit availability (RVI: 0.22 ). Forest type was present in all top-ranked models. Habitat use of lesser mousedeer was highest in peat swamp forests $\left(\widehat{\Psi}_{P S}=0.92 \pm 0.05\right)$, followed by freshwater swamp forests $\left(\widehat{\Psi}_{F S}=0.75 \pm 0.08\right)$, alluvial bench forests $\left(\widehat{\Psi}_{A B}=0.44 \pm 0.08\right)$ and lowland sandstone forests $\left(\widehat{\Psi}_{L S}=0.11 \pm 0.04\right)$ (Figure 2.4). Lesser mousedeer were not detected in either lowland granite or upland granite/montane forests preventing the calculation of associated standard error and confidence intervals (Table 2.3). The relationship between habitat use of lesser mousedeer and human activity was positive (Figure 2.6). Fruit availability had a negative relationship with lesser mousedeer habitat use; however, this variable was associated with only $21.5 \%$ of the model weight in the top models.

Sampling effort and camera placement on or off trails were the explanatory variables present in the best performing detection probability models for lesser mousedeer (Table 2.4). Sampling effort was the most important variable (RVI: 0.97), followed by camera placement (RVI: 0.51). Sampling effort had a positive relationship with detection probability, and camera placement off trails was negatively associated with detection of lesser mousedeer $\left(p_{\text {on-trail }}=0.40 \pm 0.07\right.$, 
$p_{\text {off-trail }}=0.35 \pm 0.08$, Figure 2.5$)$, contrary to the predicted relationship evident in the raw sightings (Figure 2.3). 
Table 2.3: AIC comparisons of top ranked habitat use models ( $\triangle \mathrm{AIC}>7$ ) for ungulates at CPRS. $\triangle A I C$ is the relative difference in AIC values compared to the top ranked model, $K$ is the number of parameters in a model, $w$ is the AIC model weight, $\alpha$ is the estimated intercept or constant term, $\beta$ are they estimated regression coefficients for each parameter. Forest types are represented by the following abbreviations: freshwater swamp (FS), peat swamp (PS), lowland swamp (LS), lowland granite (LG), upland granite/montane (UGM). For all models the detection model $p$ (effort+ off-trail) was used. The null model is represented as $\Psi($.$) .$

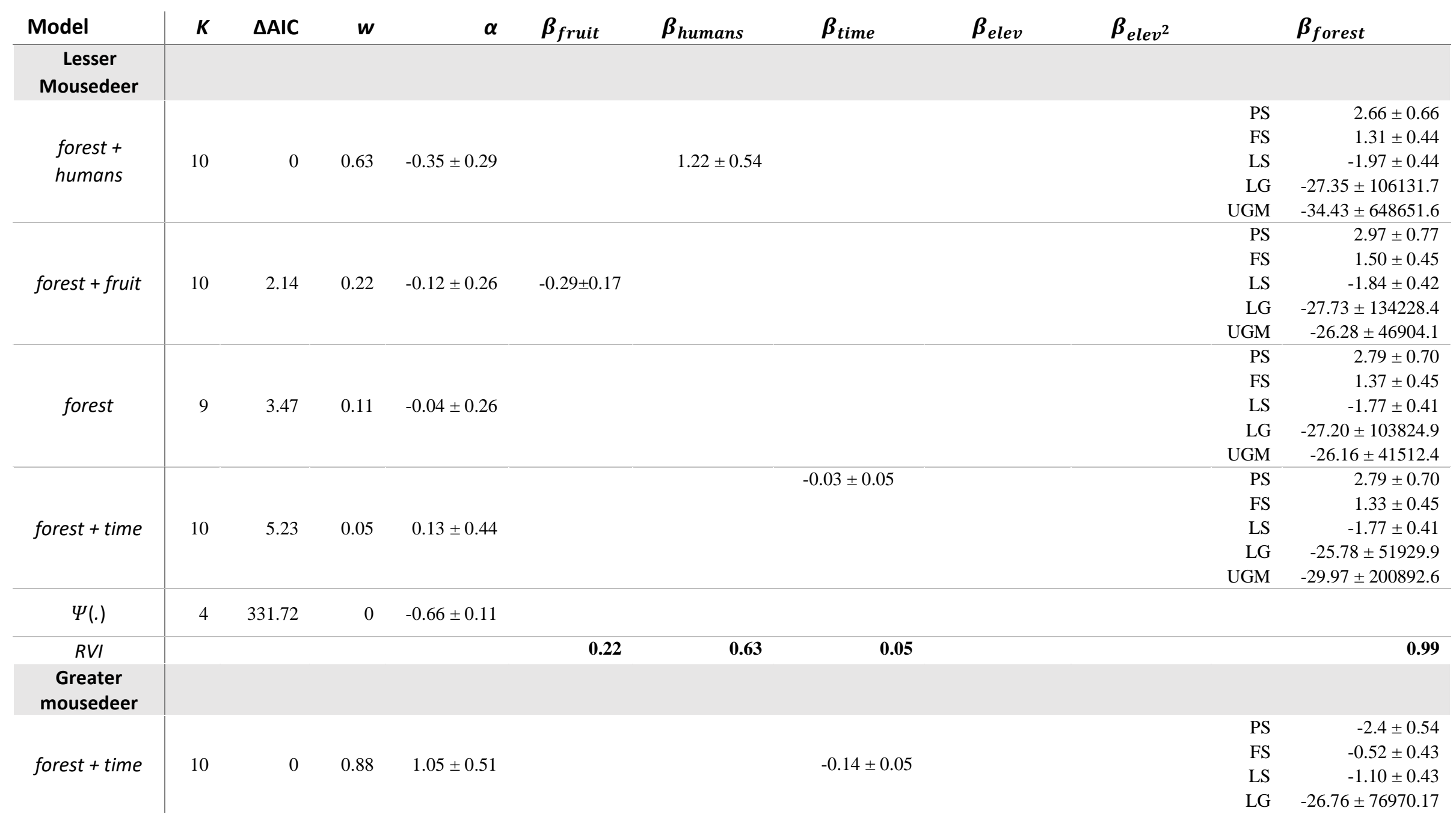




\begin{tabular}{|c|c|c|c|c|c|c|c|c|c|c|c|}
\hline Model & $K$ & $\Delta \mathrm{AIC}$ & $w$ & $\alpha$ & $\boldsymbol{\beta}_{\text {fruit }}$ & $\beta_{\text {humans }}$ & $\beta_{\text {time }}$ & $\beta_{\text {elev }}$ & $\boldsymbol{\beta}_{e l e v^{2}}$ & UGM & $\begin{array}{l}-4.28 \pm 0.79 \\
\boldsymbol{\beta}_{\text {forest }}\end{array}$ \\
\hline \multirow{5}{*}{ forest } & \multirow{5}{*}{9} & \multirow{5}{*}{5.47} & \multirow{5}{*}{0.057} & \multirow{5}{*}{$0.15 \pm 0.34$} & & & & & & PS & $-2.37 \pm 0.53$ \\
\hline & & & & & & & & & & FS & $-0.40 \pm 0.43$ \\
\hline & & & & & & & & & & LS & $-1.05 \pm 0.42$ \\
\hline & & & & & & & & & & LG & $-26.48 \pm 73612.03$ \\
\hline & & & & & & & & & & UGM & $-4.18 \pm 0.78$ \\
\hline \multirow{5}{*}{ forest + fruit } & \multirow{5}{*}{10} & \multirow{5}{*}{6.58} & \multirow{5}{*}{0.033} & \multirow{5}{*}{$0.13 \pm 0.34$} & \multirow{5}{*}{$-0.14 \pm 0.15$} & & & & & PS & $-2.35 \pm 0.53$ \\
\hline & & & & & & & & & & FS & $-0.35 \pm 0.43$ \\
\hline & & & & & & & & & & LS & $-1.09 \pm 0.43$ \\
\hline & & & & & & & & & & LG & $-26.44 \pm 71023.96$ \\
\hline & & & & & & & & & & UGM & $-4.13 \pm 0.78$ \\
\hline \multirow{5}{*}{$\begin{array}{l}\text { forest + } \\
\text { humans }\end{array}$} & \multirow{5}{*}{10} & \multirow{5}{*}{6.69} & \multirow{5}{*}{0.031} & \multirow{5}{*}{$0.08 \pm 0.35$} & & \multirow{5}{*}{$0.43 \pm 0.48$} & & & & PS & $-2.42 \pm 0.54$ \\
\hline & & & & & & & & & & FS & $-0.42 \pm 0.43$ \\
\hline & & & & & & & & & & LS & $-1.14 \pm 0.44$ \\
\hline & & & & & & & & & & LG & $-26.84 \pm 86407.31$ \\
\hline & & & & & & & & & & UGM & $-4.25 \pm 0.80$ \\
\hline$\Psi()$. & 4 & 102.81 & 0 & $-1.40 \pm 0.16$ & & & & & & & \\
\hline$R V I$ & & & & & 0.03 & 0.03 & 0.88 & & & & 0.99 \\
\hline \multicolumn{12}{|l|}{$\begin{array}{l}\text { Yellow } \\
\text { muntjac }\end{array}$} \\
\hline \multirow{5}{*}{ forest + time } & \multirow{5}{*}{10} & \multirow{5}{*}{0} & \multirow{5}{*}{0.94} & \multirow{5}{*}{$0.42 \pm 0.41$} & & & \multirow{5}{*}{$-0.15 \pm 0.04$} & & & PS & $-0.67 \pm 0.44$ \\
\hline & & & & & & & & & & FS & $-0.97 \pm 0.47$ \\
\hline & & & & & & & & & & LS & $1.87 \pm 0.52$ \\
\hline & & & & & & & & & & LG & $3.48 \pm 1.35$ \\
\hline & & & & & & & & & & UGM & $0.06 \pm 0.36$ \\
\hline & & & & & & & & & & PS & $-0.90 \pm 0.46$ \\
\hline & & & & & & & & & & FS & $-1.00 \pm 0.49$ \\
\hline forest + & 10 & 5.68 & 0.06 & $-1.02 \pm 0.36$ & & $2.37 \pm 0.86$ & & & & LS & $1.67 \pm 0.52$ \\
\hline & & & & & & & & & & LG & $4.72 \pm 5.09$ \\
\hline & & & & & & & & & & UGM & $0.09 \pm 0.38$ \\
\hline$\Psi()$. & 4 & 90.95 & 0 & $-0.03 \pm 0.14$ & & & & & & & \\
\hline$R V I$ & & & & & & 0.06 & 0.94 & & & & 0.99 \\
\hline Red muntjac & & & & & & & & & & & \\
\hline & & & & & & & & & & PS & $-0.06 \pm 0.57$ \\
\hline forest + time & & & & & & & & & & FS & $-2.08 \pm 0.64$ \\
\hline forest + tıme & 10 & 0 & 0.72 & $-1.25 \pm 0.63$ & & & $0.18 \pm 0.08$ & & & LS & $1.38 \pm 0.67$ \\
\hline & & & & & & & & & & LG & $4.456 \pm 6.57$ \\
\hline & & & & & & & & & & UGM & $2.16 \pm 0.90$ \\
\hline
\end{tabular}




\begin{tabular}{|c|c|c|c|c|c|c|c|c|c|c|}
\hline Model & $K$ & $\Delta \mathrm{AIC}$ & $w$ & $\alpha$ & $\boldsymbol{\beta}_{\text {fruit }}$ & $\beta_{\text {humans }}$ & $\boldsymbol{\beta}_{\text {time }}$ & $\boldsymbol{\beta}_{\text {elev }}$ & $\beta_{e l e v^{2}}$ & $\beta_{\text {forest }}$ \\
\hline forest + fruit & 10 & 3.36 & 0.13 & $-0.08 \pm 0.38$ & $0.32 \pm 0.20$ & & & & $\begin{array}{r}\text { PS } \\
\text { FS } \\
\text { LS } \\
\text { LG } \\
\text { UGM }\end{array}$ & $\begin{array}{r}-0.31 \pm 0.52 \\
-1.83 \pm 0.58 \\
1.54 \pm 0.68 \\
3.50 \pm 3.36 \\
1.64 \pm 0.71\end{array}$ \\
\hline forest & 9 & 4.24 & 0.09 & $-0.06 \pm 0.38$ & & & & & $\begin{array}{r}\text { PS } \\
\text { FS } \\
\text { LS } \\
\text { LG } \\
\text { UGM }\end{array}$ & $\begin{array}{r}-0.23 \pm 0.51 \\
-1.82 \pm 0.58 \\
1.35 \pm 0.65 \\
3.27 \pm 3.15 \\
1.64 \pm 0.70\end{array}$ \\
\hline $\begin{array}{l}\text { forest }+ \\
\text { humans }\end{array}$ & 10 & 4.87 & 0.06 & $0.08 \pm 0.41$ & & $-0.65 \pm 0.56$ & & & $\begin{array}{r}\text { PS } \\
\text { FS } \\
\text { LS } \\
\text { LG } \\
\text { UGM }\end{array}$ & $\begin{array}{r}-1.81 \pm 0.58 \\
-0.23 \pm 0.51 \\
1.48 \pm 0.70 \\
2.82 \pm 1.86 \\
1.61 \pm 0.68\end{array}$ \\
\hline$\Psi()$. & 4 & 57.13 & 0 & $0.52 \pm 0.24$ & & & & & & \\
\hline $\begin{array}{c}R V I \\
\text { Bearded pig }\end{array}$ & & & & & 0.13 & 0.06 & 0.72 & & & 1.0 \\
\hline fruit + forest & 10 & 0 & 0.46 & $1.83 \pm 0.45$ & $0.49 \pm 0.17$ & & & & $\begin{array}{r}\text { PS } \\
\text { FS } \\
\text { LS } \\
\text { LG } \\
\text { UGM }\end{array}$ & $\begin{array}{r}-1.14 \pm 0.52 \\
0.36 \pm 0.76 \\
-0.04 \pm 0.56 \\
-1.21 \pm 0.53 \\
-1.70 \pm 0.50\end{array}$ \\
\hline fruit + elev & 6 & 0.67 & 0.33 & $1.03 \pm 0.16$ & $0.46 \pm 0.16$ & & & $-0.62 \pm 0.12$ & & \\
\hline fruit $+e l e v^{2}$ & 7 & 2.61 & 0.12 & $1.03 \pm 0.16$ & $0.47 \pm 0.16$ & & & $-0.72 \pm 0.48$ & & \\
\hline $\begin{array}{l}\text { forest + } \\
\text { humans }\end{array}$ & 10 & 6.30 & 0.02 & $1.75 \pm 0.42$ & & $-0.82 \pm 0.38$ & & & $\begin{array}{r}\text { PS } \\
\text { FS } \\
\text { LS } \\
\text { LG } \\
\text { UGM }\end{array}$ & $\begin{array}{r}-0.91 \pm 0.49 \\
0.55 \pm 0.66 \\
0.09 \pm 0.56 \\
-1.03 \pm 0.50 \\
-1.31 \pm 0.44\end{array}$ \\
\hline elev + humans & 6 & 6.78 & 0.02 & $1.16 \pm 0.18$ & & $-0.80 \pm 0.36$ & & $-0.52 \pm 0.11$ & & \\
\hline elev + time & 6 & 6.95 & 0.02 & $1.44 \pm 0.28$ & & & $-0.07 \pm 0.03$ & $-0.53 \pm 0.11$ & & \\
\hline$\Psi()$. & 4 & 27.30 & 0 & $0.93 \pm 0.14$ & & & \multicolumn{4}{|c|}{$0.10 \pm 0.45$} \\
\hline$R V I$ & & & & & 0.92 & & 0.02 & 0.36 & 0.12 & 0.48 \\
\hline
\end{tabular}


Table 2.4: AIC comparison of the top ranked detection models ( $\triangle \mathrm{AIC}>7$ ) for ungulates at CPRS. $\triangle A I C$ is the relative difference in AIC values compared to the top ranked model, $K$ is the number of parameters in a model, $w$ is the AIC model weight, $\alpha$ is the estimated intercept or constant term, $\beta$ are they estimated regression coefficients for each parameter. For all models the occupancy model $\Psi$ (elev + time + humans + fruit) was used. The null detection model is represented as $p($.$) .$

\begin{tabular}{|c|c|c|c|c|c|c|}
\hline Model & $\kappa$ & $\triangle A I C$ & $w$ & $\alpha$ & $\boldsymbol{\beta}_{\text {off }}$ & $\beta_{\text {effort }}$ \\
\hline \multicolumn{7}{|l|}{ Lesser mousedeer } \\
\hline effort + off-trail & 8 & 0 & 0.51 & $-0.40 \pm 0.27$ & $-0.39 \pm 0.26$ & $1.06 \pm 0.34$ \\
\hline effort & 7 & 0.21 & 0.46 & $-0.49 \pm 0.27$ & & $1.11 \pm 0.34$ \\
\hline$p()$. & 6 & 7.70 & 0.01 & $0.38 \pm 0.10$ & & \\
\hline$R V I$ & & & & & 0.51 & 0.97 \\
\hline \multicolumn{7}{|l|}{ Greater mousedeer } \\
\hline$p()$. & 6 & 0 & 0.38 & 700.69 & & \\
\hline off-trail & 7 & 0.60 & 0.28 & 699.30 & $-0.71 \pm 0.55$ & \\
\hline effort + off-trail & 8 & 1.44 & 0.18 & 698.13 & $-0.96 \pm 0.57$ & $-0.63 \pm 0.60$ \\
\hline effort & 7 & 1.77 & 0.16 & 700.46 & & $-0.25 \pm 0.53$ \\
\hline$R V I$ & & & & & 0.46 & 0.34 \\
\hline \multicolumn{7}{|l|}{ Yellow muntjac } \\
\hline effort & 7 & 0 & 0.56 & $-1.37 \pm 0.27$ & & $1.09 \pm 0.31$ \\
\hline effort + off-trail & 8 & 0.53 & 0.43 & $-1.29 \pm 0.28$ & $-0.35 \pm 0.29$ & $1.04 \pm 0.31$ \\
\hline$p()$. & 6 & 10.13 & 0 & $-0.48 \pm 0.11$ & & \\
\hline$R V I$ & & & & & 0.43 & 0.99 \\
\hline \multicolumn{7}{|l|}{ Red muntjac } \\
\hline effort + off-trail & 8 & 0 & 0.75 & $-1.92 \pm 0.23$ & $0.53 \pm 0.20$ & $0.62 \pm 0.27$ \\
\hline off-trail & 7 & 3.36 & 0.14 & $-1.45 \pm 0.09$ & $0.43 \pm 0.20$ & \\
\hline$p()$. & 6 & 6.00 & 0.04 & $-1.38 \pm 0.08$ & & \\
\hline$R V I$ & & & & & 0.89 & 0.75 \\
\hline \multicolumn{7}{|l|}{ Bearded pig } \\
\hline effort & 7 & 0 & 0.40 & $-0.28 \pm 0.20$ & & $0.39 \pm 0.23$ \\
\hline$p()$. & 6 & 0.68 & 0.29 & $0.027 \pm 0.07$ & & \\
\hline effort + off-trail & 8 & 1.80 & 0.17 & $-0.25 \pm 0.21$ & $-0.08 \pm 0.17$ & $0.37 \pm 0.24$ \\
\hline off-trail & 7 & 2.08 & 0.14 & $0.05 \pm 0.08$ & $-0.13 \pm 0.17$ & \\
\hline$R V I$ & & & & & 0.31 & 0.57 \\
\hline
\end{tabular}



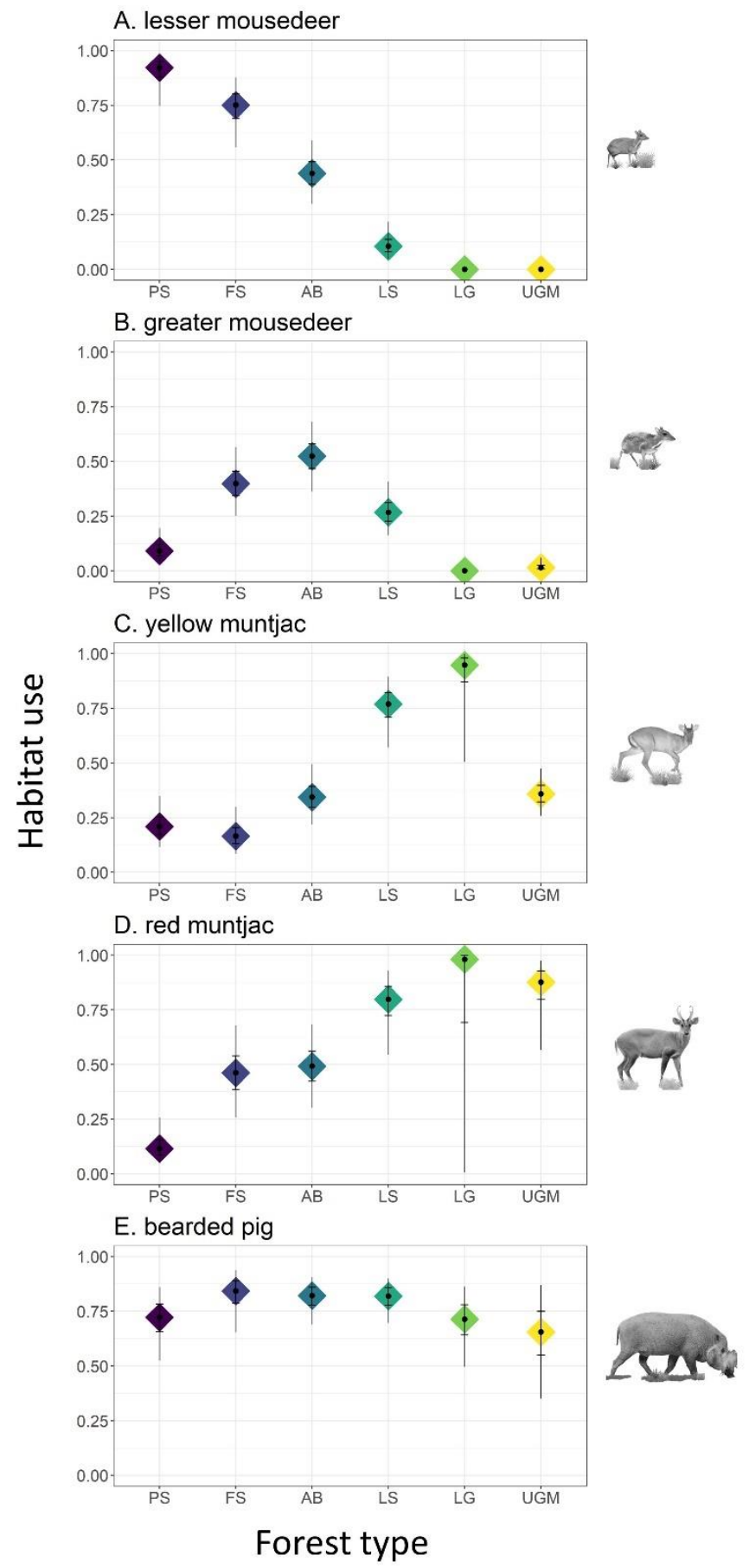

Figure 2.4: Model-averaged estimates of ungulate habitat use $(\widehat{\Psi})$ across 6 forest types at CPRS. Vertical bars illustrated the model averaged $95 \%$ confidence interval and whiskers define the $50 \%$ confidence intervals. Forest types are represented in order of increasing elevation, identified by the following abbreviations; peat swamp (PS), freshwater swamp (FS), alluvial bench (AB), lowland sandstone (LS), lowland granite (LG), and upland granite/montane (UGM). 
A. lesser mousedeer

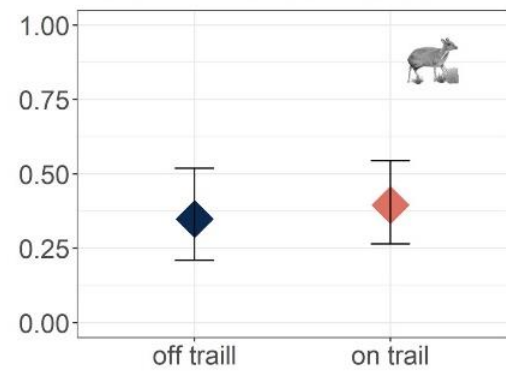

C. yellow muntjac

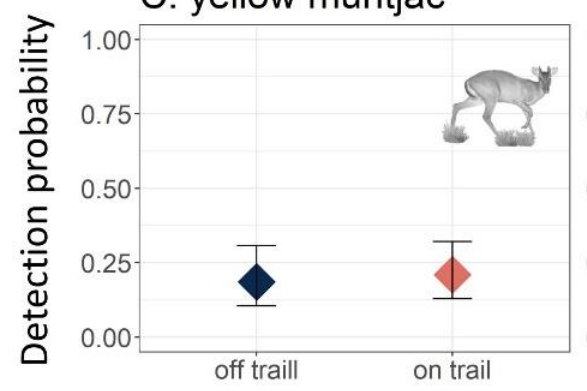

E. bearded pig

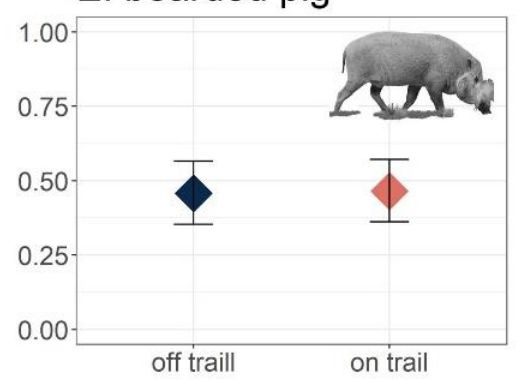

Camera placement
B. greater mousedeer

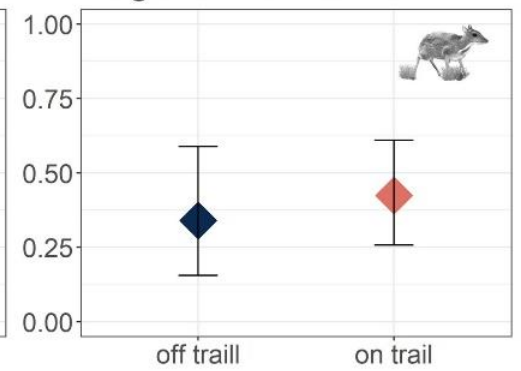

D. red muntjac

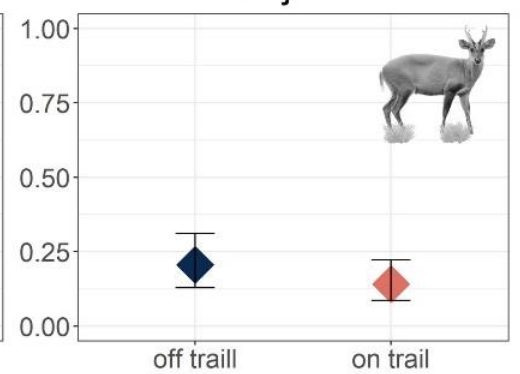




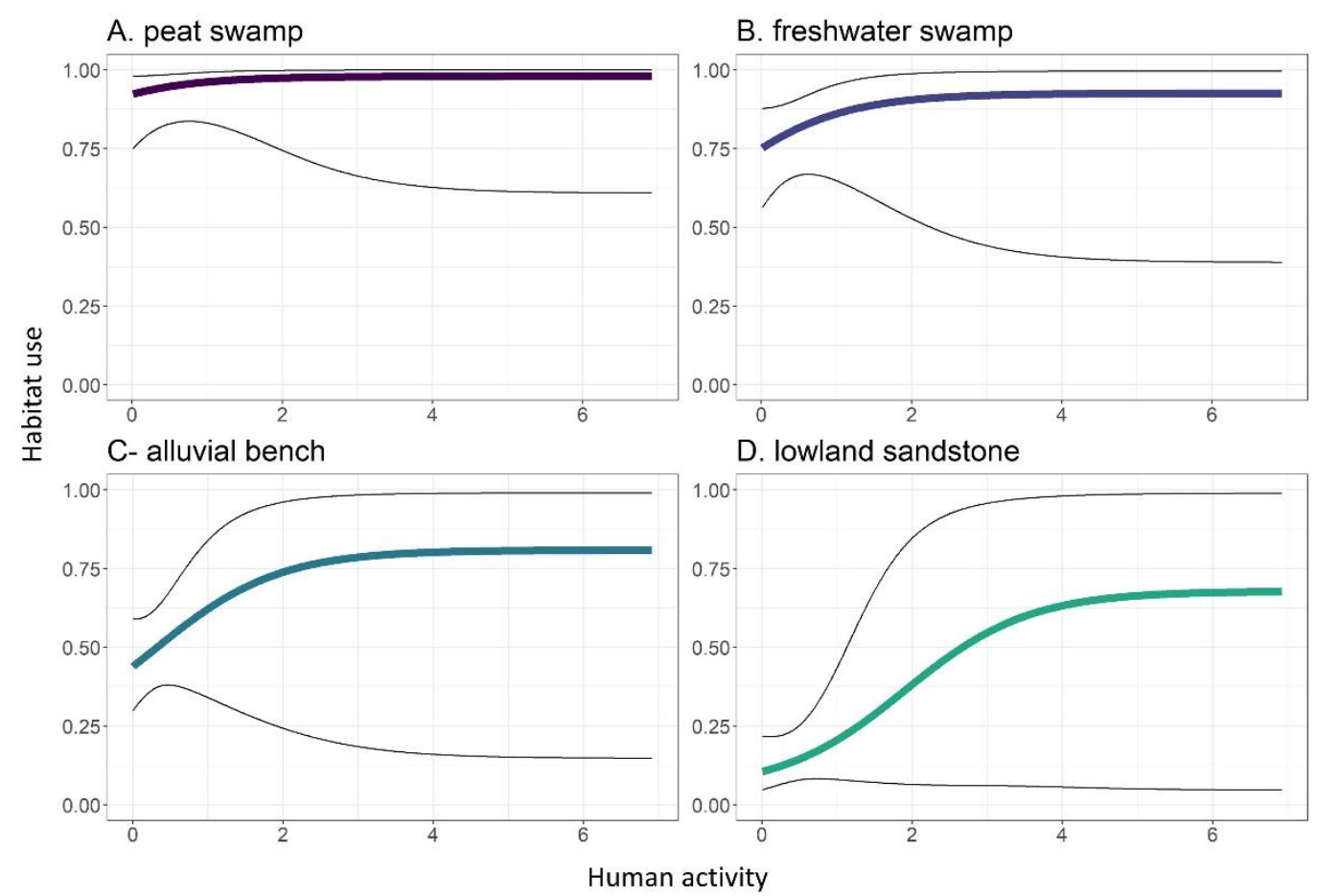

Figure 2.6: The relationship between human activity and habitat use of lesser mousedeer using modelaveraged estimates of habitat use $(\widehat{\Psi})(\triangle A I C>7)$. The relationship is shown for each forest type (A-D) with lowland granite and upland granite/montane omited due to non-detection in those forest types. The black lines illustrate the model averaged 95\% confidence intervals.

\subsubsection{Greater mousedeer}

Forest type and time best explained habitat use of greater mousedeer ( $\triangle \mathrm{AIC}<4$, Table 2.3). Only one model, $\Psi$ (forest +time), was considered to have substantial support. Forest type was the most important covariate, present in all the models with $\triangle \mathrm{AIC}<7$ (RVI: 0.99). Habitat use of greater mousedeer was highest in alluvial bench forests $\left(\widehat{\Psi}_{A B}=0.52 \pm 0.08\right)$, followed by freshwater swamp forests $\left(\widehat{\Psi}_{F S}=0.40 \pm 0.08\right)$, lowland sandstone forests $\left(\widehat{\Psi}_{L S}=0.27 \pm 0.06\right)$, peat swamp forests $\left(\widehat{\Psi}_{P S}=\right.$ $0.09 \pm 0.04)$, and upland granite/montane forests $\left(\widehat{\Psi}_{U G M}=0.02 \pm 0.01\right.$, Figure 2.4). Greater mousedeer were not detected in lowland granite forests. An extremely small amount of detections in upland granite/montane forests $(n=1)$ prevented successful calculation of associated standard errors. Variation in habitat use of greater mousedeer was also explained by time was (RVI: 0.88) with a negative trend of habitat use over time (Figure 2.7). Fruit availability and human activity were explanatory variables alongside forest type in models with little support $(\triangle \mathrm{AIC}<7)$ with a combined model weight of only 0.06 (Table 2.3). Both models performed worse than the $\psi$ (forest) model, meaning these covariates did not 
significantly explain further variation in habitat use. Elevation had no support as an explanatory variable for greater mousedeer habitat use.

All candidate models for detection probability of greater mousedeer, including the null model, had a delta $\mathrm{AIC}<2$, indicating that they cannot be differentiated in importance. Camera positioning on or off trails explained some variability (RVI: 0.46$)$ with detection probability at off-trail sites estimated to be slightly lower than on-trail sites $\left(\hat{p}_{O N}=0.4 \pm 0.09, \hat{p}_{O F F}=0.34 \pm 0.12\right.$, Table 2.4 , Figure 2.5$)$. Sampling effort (RVI: 0.34) appeared to have a negative influence on detection, however, the standard error overlaps zero indicating that the direction of the relationship cannot be determined with confidence.
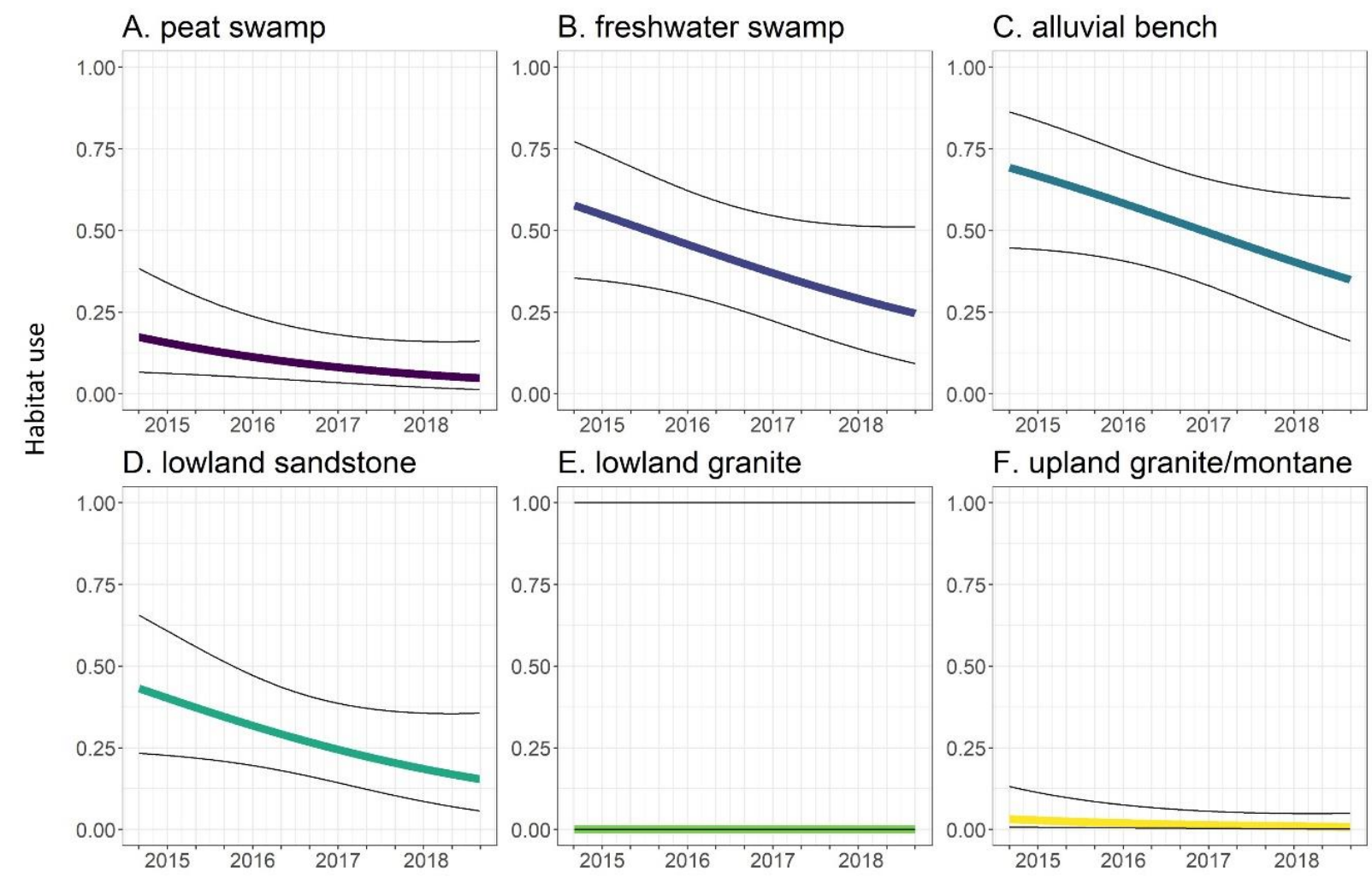

Figure 2.7: The relationship of habitat use of greater mousedeer over time using model-averaged estimates of habitat use $(\widehat{\Psi})(\triangle A I C>7)$. The relationship is shown for each forest type $(A-F)$. The black lines illustrate the model averaged $95 \%$ confidence intervals. 


\subsubsection{Yellow muntjac}

Forest type (RVI: 0.99) and time (RVI: 0.94) best explained habitat use of yellow muntjacs. $\triangle$ AIC values of all other candidate models were $>4$, and therefore had considerably less support. Habitat use of yellow muntjacs was highest in lowland granite forests $\left(\widehat{\Psi}_{L G}=0.95 \pm 0.07\right)$, followed by upland granite/montane forests $\left(\widehat{\Psi}_{U G M}=0.36 \pm 0.06\right)$, lowland sandstone forests $\left(\widehat{\Psi}_{L S}=0.77 \pm 0.08\right)$, alluvial bench forests $\left(\widehat{\Psi}_{A B}=0.34 \pm 0.07\right)$, peat swamp forests $\left(\widehat{\Psi}_{P S}=0.21 \pm 0.06\right)$, and freshwater swamp forests $\left(\widehat{\Psi}_{F S}=0.17 \pm 0.05\right.$ ) (Table 2.3, Figure 2.4). Time negatively influenced the probability of use across all forest types over the study period (Figure 2.8). Human activity, fruit availability, and elevation were absent from the top-ranked models.

Both sampling effort (RVI: 0.99) and camera positioning (RVI: 0.43) explained the detection probability of yellow muntjacs (Table 2.4). Sampling effort had a positive effect on detection probabilities, while camera positioning off-trail had a negative effect on detection probabilities $\left(p_{O N}=\right.$ $\left.0.21 \pm 0.05, p_{O F F}=0.19 \pm 0.05\right)$ (Figure 2.5).

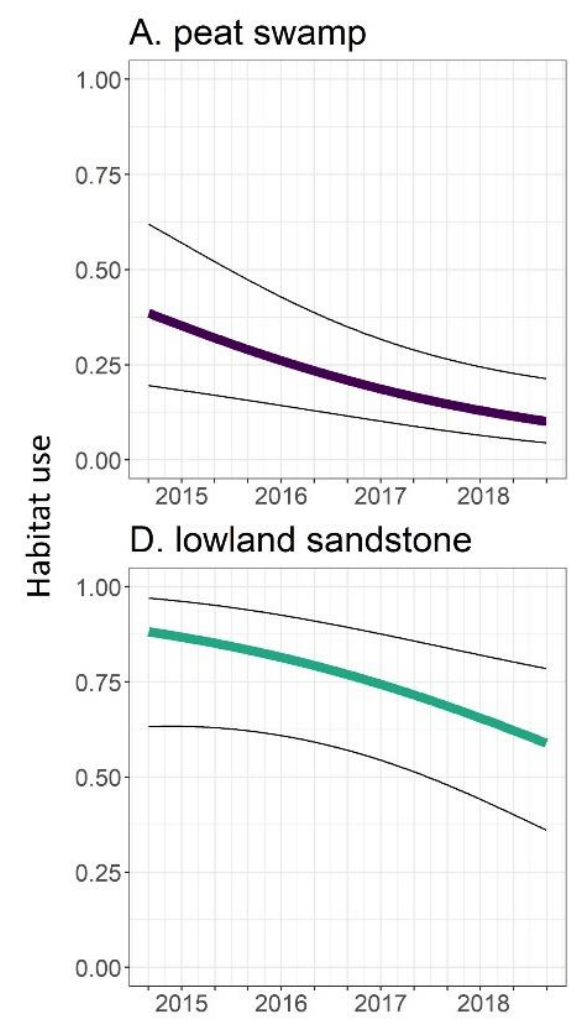

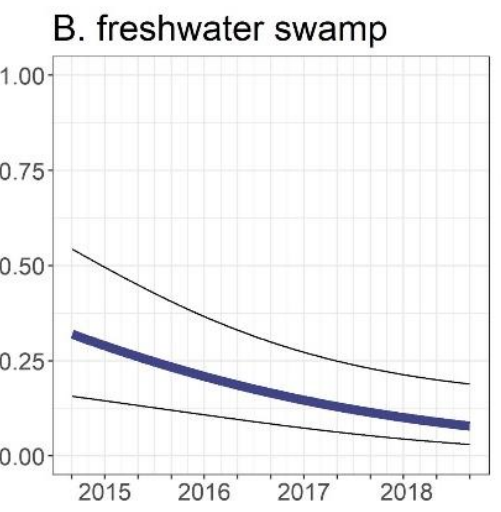

\section{C. alluvial bench}

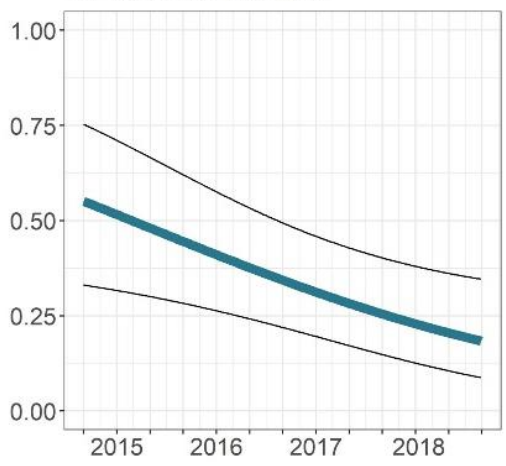

E. lowland granite

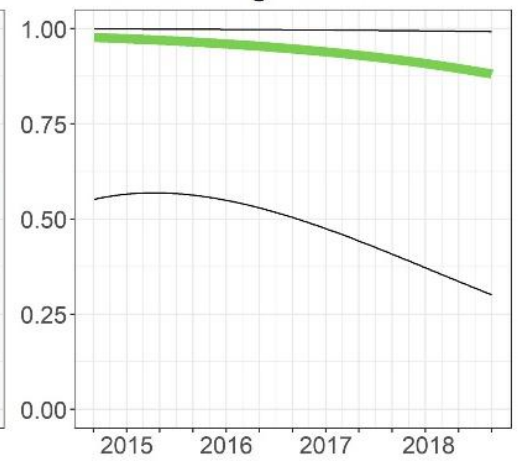

F. upland granite/montane

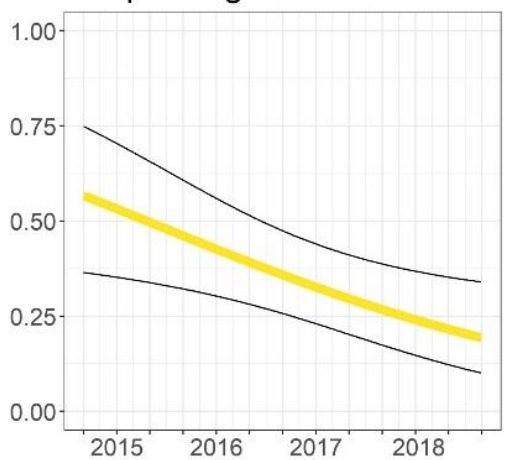

Figure 2.8: The relationship between time and the probability of yellow muntjac using sites, using model-averaged estimates of habitat use $(\widehat{\Psi})(\Delta \mathrm{AIC}>7)$. The relationship is shown for each forest type (A-F). The black lines illustrate the model averaged 95\% confidence intervals. 


\subsubsection{Red muntjac}

Forest type (RVI: 1 ) and time (RVI: 0.72 ) best explained habitat use of red muntjacs. The forest type covariate was present in all 4 top models, which performed significantly better than all other models including the null model (Table 2.3). Habitat use of red muntjacs was highest in lowland granite forests $\left(\widehat{\Psi}_{L G}=0.98 \pm 0.09\right)$, followed by upland granite/montane forests $\left(\widehat{\Psi}_{U G M}=0.88 \pm 0.09\right)$, lowland sandstone forests $\left(\widehat{\Psi}_{L S}=0.80 \pm 0.09\right)$, alluvial bench forests $\left(\widehat{\Psi}_{A B}=0.90 \pm 0.10\right)$, freshwater swamp forests $\left(\widehat{\Psi}_{F S}=0.46 \pm 0.11\right)$, and finally peat swamp forests $\left(\widehat{\Psi}_{P S}=0.12 \pm 0.05\right.$, Figure 2.4$)$. The next most important explanatory variable was time which had a positive effect on habitat use (Figure 2.9). Fruit availability was a covariate in the set of top-performing models (RVI: 0.06) with a positive effect on habitat use. Human activity was not present in the best performing models ( $\triangle \mathrm{AIC}<4$ ), however, there was some support (RVI: 0.06) that it negatively influenced habitat use of red muntjacs. Models containing elevation as a covariate did not reach acceptable convergence and were omitted from findings.

Both camera placement (RVI: 0.89) and sampling effort (RVI: 0.75) explained the detection probability of RM (Table 2.4). Red muntjacs had higher detection probabilities off-trail ( $\hat{p}_{O N}=0.14 \pm$ $0.03, \hat{p}_{O F F}=0.21 \pm 0.05$ ) and at cameras operated for longer periods of time (Figure 2.5). The increased detection probability off-trails is in contrast to the predicted relationship evident in the raw sightings (Figure 2.3). 

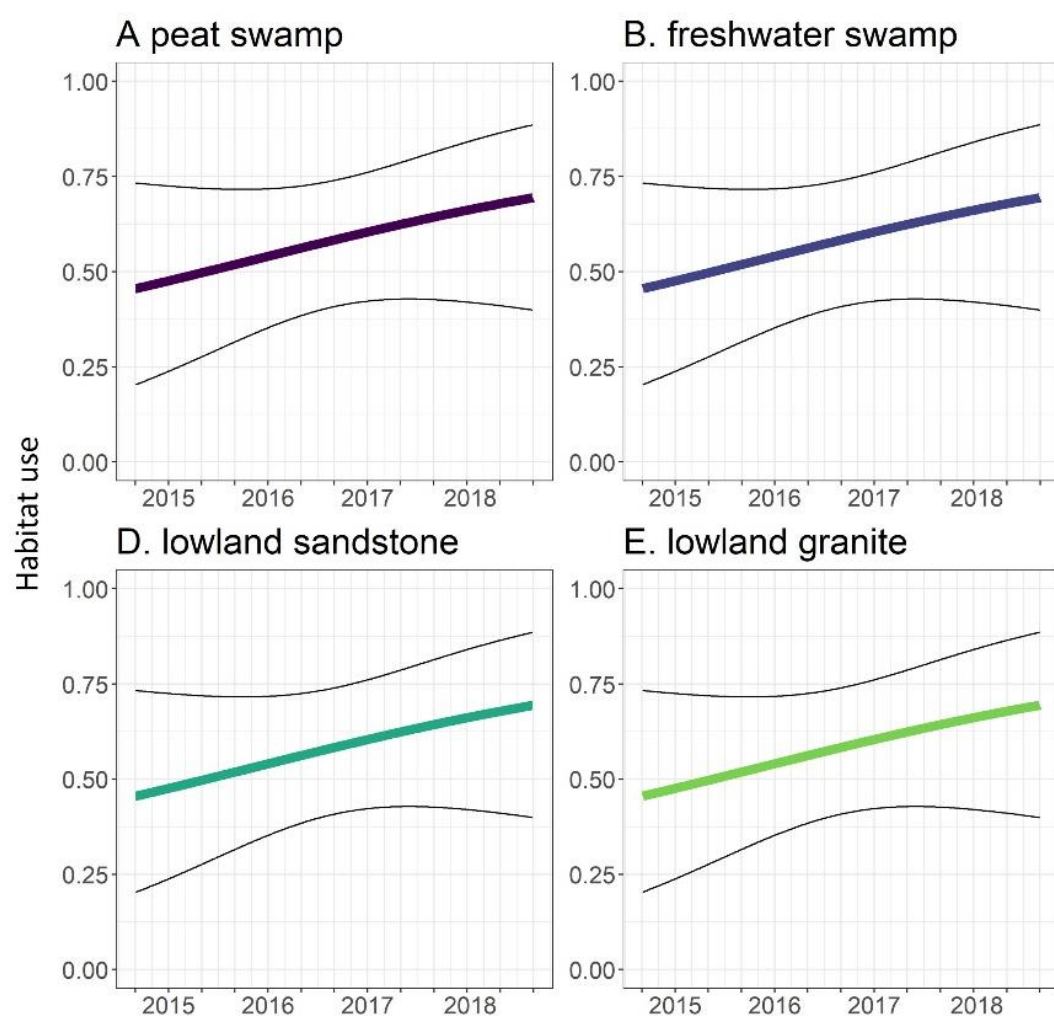

C. alluvial bench
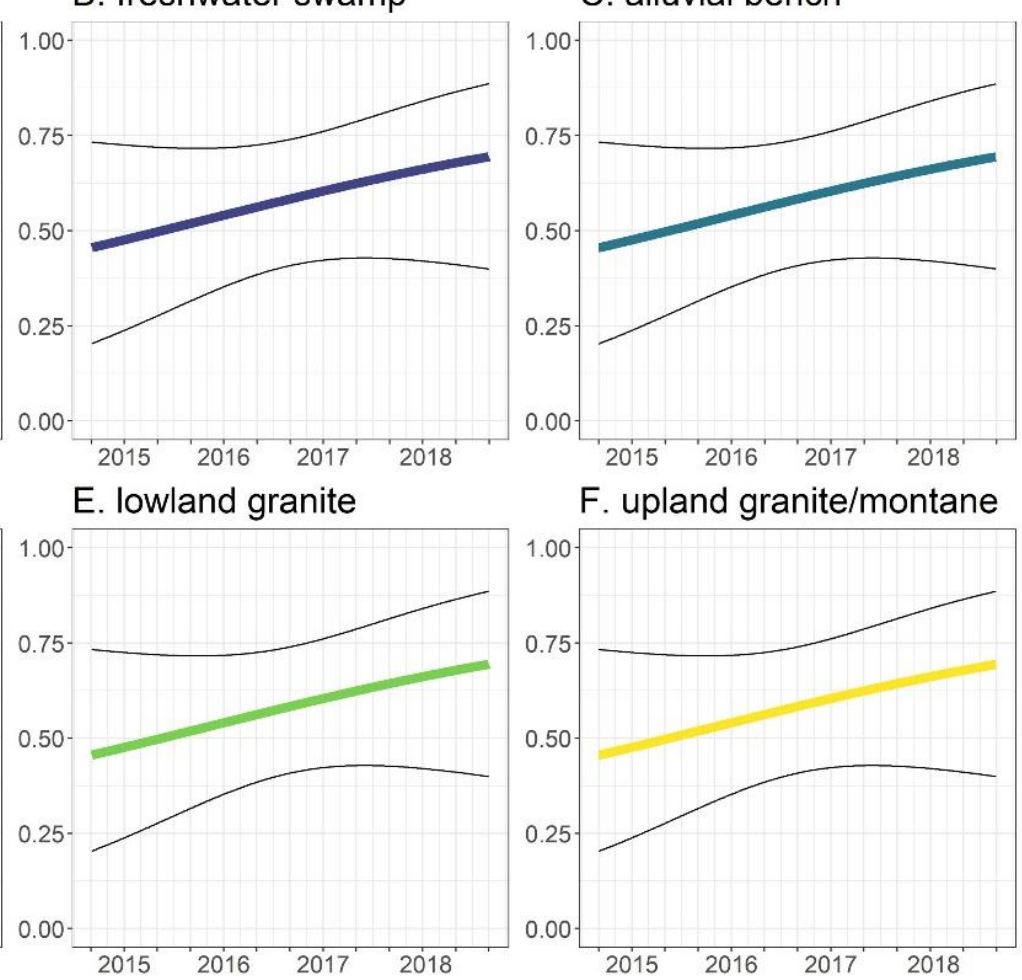

Figure 2.9: The relationship of habitat use of red muntjacs over time using model-averaged estimates of habitat use $(\widehat{\Psi})(\triangle A I C>7)$. The relationship is shown for each forest type $(A-F)$. The black lines illustrate the model averaged $95 \%$ confidence intervals.

\subsubsection{Bearded pig}

Fruit availability best explained habitat use of bearded pigs (RVI: 0.92). The fruit covariate was present in all top models (Table 2.3) and had a positive influence on habitat use (Figure 2.10). Forest type (RVI: 0.48 ) and elevation ( $\mathrm{RVI}_{\text {elev }}: 0.36, \mathrm{RVI}_{\text {elev2: }}$ 0.12) further explained habitat use of bearded pigs. Habitat use of bearded pigs was highest in freshwater swamp forests $\left(\widehat{\Psi}_{F S}=0.84 \pm 0.07\right.$ ), followed by alluvial bench and lowland sandstone forests $\left(\widehat{\Psi}_{A B, L S}=0.82 \pm 0.05\right)$, peat swamp forests $\left(\widehat{\Psi}_{P S}=0.72 \pm 0.09\right)$, lowland granite forests $\left(\widehat{\Psi}_{L G}=0.71 \pm 0.10\right)$, and upland granite/montane forest forests $\left(\widehat{\Psi}_{U G M}=\right.$ $0.65 \pm 0.14$, Figure 2.4). Elevation had a negative linear relationship with habitat use in the second-best model indicating greater use of low elevations. Human activity and time were absent from the best models suggesting a comparatively insignificant relationship with habitat use of bearded pigs.

All candidate models for detection probability of bearded pigs, including the null model, had a delta $\mathrm{AIC}<2$, indicating that they cannot be differentiated in importance (Table 2.4). Sampling effort 
(RVI: 0.57) appeared to have a slight positive effect on detection. No clear relationship was evident with camera placement $\left(\hat{p}_{O N}=0.47 \pm 0.05, \hat{p}_{O F F}=0.46 \pm 0.05\right.$, Figure 2.5$)$.

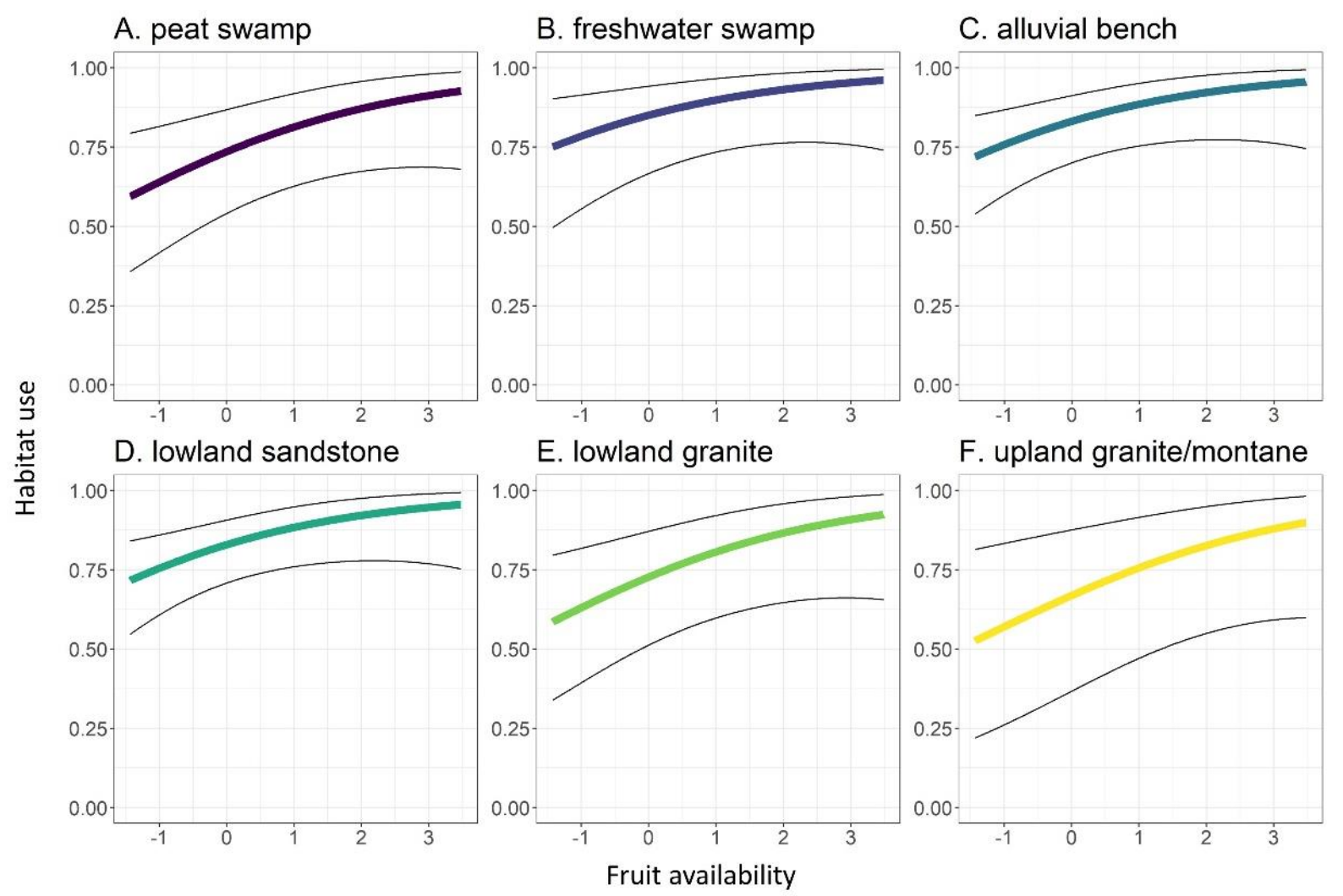

Figure 2.10: The relationship of fruit availability and habitat use of bearded pig at CPRS using modelaveraged estimates of habitat use $(\widehat{\Psi})(\Delta A I C>7)$. Fruit availability was measured as the density of ripe fruit per ha in each forest type on a monthly basis. The relationship is shown for each forest type (A-F). The black lines illustrate the model averaged 95\% confidence intervals.

Table 2.5: Estimates from null models of habitat use and detection assuming constant estimates among sites.

\begin{tabular}{l|cc}
\multicolumn{1}{c|}{ Species } & $\Psi($.$) estimate of habitat use$ & $p($.$) estimate of detection$ \\
probability & probability \\
\hline Lesser mousedeer & $0.34 \pm 0.02$ & $0.59 \pm 0.02$ \\
Greater mousedeer & $0.20 \pm 0.03$ & $0.39 \pm 0.04$ \\
Yellow muntjac & $0.49 \pm 0.04$ & $0.38 \pm 0.03$ \\
Red muntjac & $0.63 \pm 0.06$ & $0.20 \pm 0.03$ \\
Bearded pig & $0.72 \pm 0.03$ & $0.51 \pm 0.02$
\end{tabular}




\subsubsection{Model fit}

Model fit for both habitat use and detection probabilities was further assessed for the top preforming general model for each species based on overdispersion ( $\hat{c}$, Table 2.6). All $\hat{c}$ values were greater than 1 , indicating overdispersion, however, values were below commonly accepted thresholds of $\hat{c}<3$ (Lebreton et al. 1992).

Table 2.6: The dispersion parameter ( $\hat{c})$ for the best performing general habitat use and detection models for each species. The goodness of fit was calculated using a parametric bootstrap $(n=1,000)$. $\hat{c}>$ 1 indicates overdispersion, and $\hat{c}<1$ indicates under dispersion. $\hat{c}<3$ are considered acceptable (Lebreton et al. 1992).

\begin{tabular}{|c|c|c|}
\hline Species & Top model & $\hat{\mathbf{c}}$ \\
\hline \multirow[t]{2}{*}{ Lesser mousedeer } & $\Psi$ (forest + humans) & 2.24 \\
\hline & $p($ effort + off-trail) & 2.13 \\
\hline \multirow[t]{2}{*}{ Greater mousedeer } & $\Psi($ forest + time $)$ & 1.40 \\
\hline & $p($ effort + off-trail) & 1.45 \\
\hline \multirow[t]{2}{*}{ Yellow muntjac } & $\Psi($ forest + time $)$ & 1.51 \\
\hline & $p($ effort + off trail) & 1.58 \\
\hline \multirow[t]{2}{*}{ Red muntjac } & $\Psi($ forest + time $)$ & 1.09 \\
\hline & $p(e f f o r t+o f f$-trail) & 1.79 \\
\hline \multirow[t]{2}{*}{ Bearded pig } & $\Psi$ (forest + fruit) & 1.89 \\
\hline & $p$ (effort) & 2.06 \\
\hline
\end{tabular}

\subsubsection{Spatial overlap analysis}

Patterns of spatial avoidance and overlapping habitat use were evident from spatial overlap analysis.

The greatest spatial overlap in model-averaged habitat use was between bearded pigs and greater mousedeer $(r=0.68, p<0.05$, Figure 2.11). The strongest evidence of spatial avoidance was between lesser mousedeer and red muntjacs $(r=-0.85, p<0.05)$ and lesser mousedeer and yellow muntjacs $(r=-$ $0.62, p<0.05)$. All Pearson correlation coefficients had $p$ values below 0.05 . Correlation coefficients below a threshold of 0.6 were not considered to have biologically significant effect sizes. 


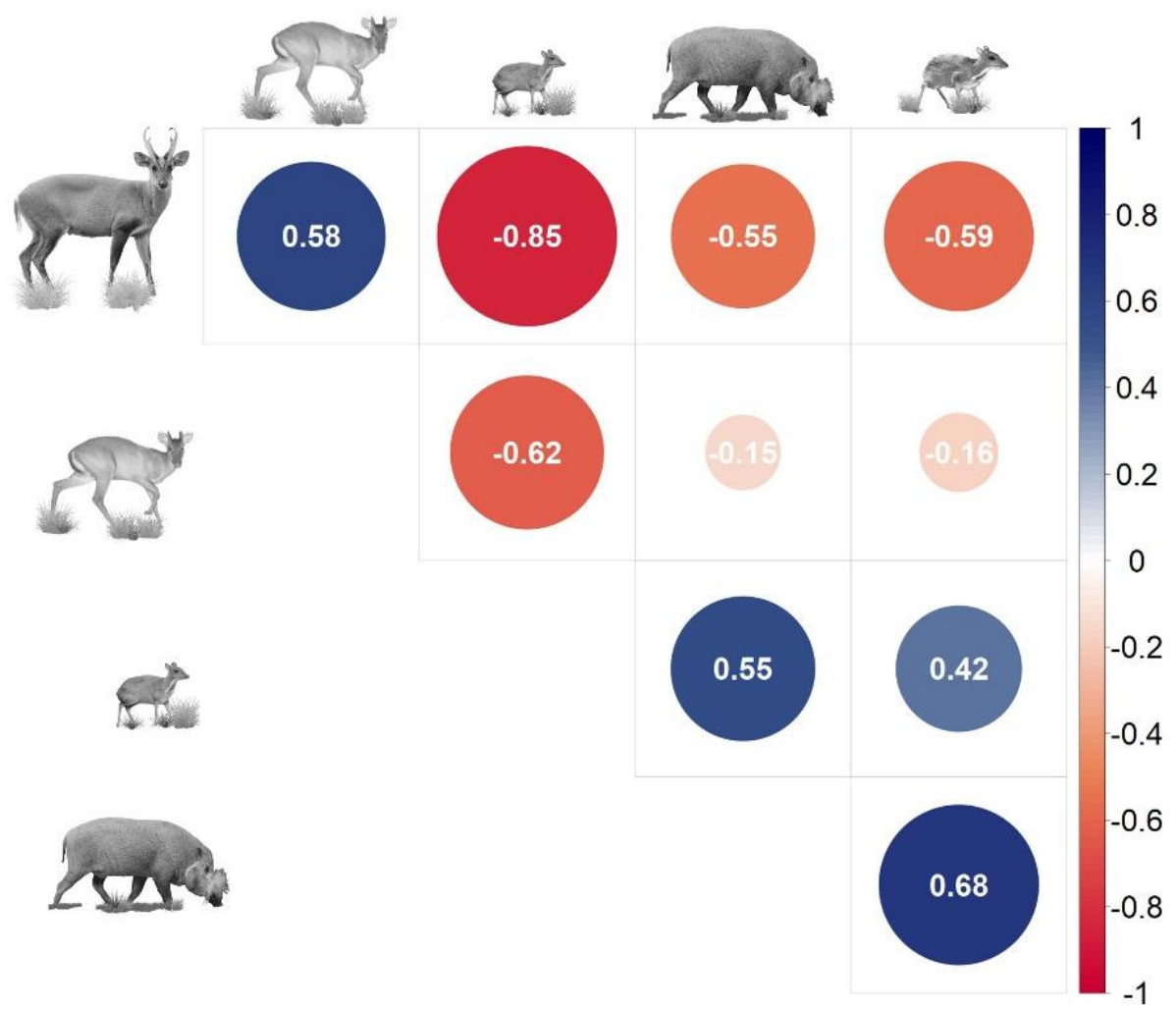

Figure 2.11: The correlation (Pearson) between the model-averaged habitat use estimates of ungulates species at CPRS. Positive correlations indicate spatial overlap between species (blue, $r>0.6)$. Significant negative correlations indicate spatial avoidance between species in the Cabang Panti Research Station (red, $r<-0.6)$.

\subsection{Discussion}

My results provide insight into the influence of spatial and temporal factors on habitat use and niche partitioning of an understudied tropical ungulate guild. My findings suggest that habitat use of ungulates in a Bornean lowland rainforest ecosystem are influenced by forest type, temporal variation in fruit availability, and human activity. As predicted, habitat partitioning was evident within the ungulate guild with habitat use for each species peaking in different forest types.

\section{Forest type and spatial niche partitioning}

Forest type was a strong predictor for the habitat use of all 5 ungulate species with clear evidence of species-specific habitat preference.

Habitat partitioning was evident between the sympatric mousedeer species as peak habitat use estimates were observed in distinct forest types, with estimates dropping off in adjacent habitats. The pattern of overlapping habitat use with spatially separate peaks suggest habitat partitioning has occurred. The spatial separation of high-use areas suggests that each species may have specialized in 
resources specific to different forest types to reduce competition. This pattern of habitat partitioning may be a product of the distinct floral species assemblages, and thus a distinct array of fruit and seeds, present in each forest type (Table 1.1).

According to the study of forest composition at CPRS conducted by Cannon \& Leighton (2004), the peat swamp forest, for which I estimated the highest habitat use of lesser mousedeer, is predominantly composed of plant species that produce fleshy fruits and legumes (20\% Myrtaceae, $13 \%$ Sapotaceae, 6\% Fabaceae). The alluvial bench forest, where greater mousedeer habitat use estimates peaked, is predominately composed of masting dipterocarp species (20\%), as well as plants producing dry starching fruits and seeds (9\% Myristicaceae, $8 \%$ Euphorbiaceae). The consistently high level of fruit resources in the peat swamp forest (Table S.5) supports the prediction that the smallest ungulate in this study system, the lesser mousedeer, would be associated with a forest type providing consistent highquality diet resources. As an ungulate with a very small body mass, the lesser mousedeer would have a limited ability to buffer the effects of low resources during periods of low fruit-availability. In contrast, the slightly larger greater mousedeer (Table 2.1), was associated with habitat where many plants only produce fruit during masts, leaving a potentially lower proportion of fruit consistently available. A less dependable level of fruit and seed resources supports the prediction that greater mousedeer would similarly have high-quality fruit and seed-based diets with the possible addition of some browse or other resources in times of low fruit availability.

A clear pattern of habitat partitioning was less evident between yellow and red muntjacs. Habitat use of both species appears to peak in lowland granite forests. However, the large uncertainty of this estimate for red muntjacs along with the trend evident from the raw detection data suggests that red muntjacs may actually peak in upland granite/montane forests (Figures 2.2 and 2.3). Overlapping habitat use of yellow and red muntjacs could arise if the sympatric species have specialized to share habitat by consuming separate food resources. Both lowland and upland granite/montane forests are composed predominantly of masting dipterocarp species ( $20 \%$ for lowland granite and upland granite, respectively). While non-mast fruit and seed resources remain available in these forest types, the drop in availability during inter-mast periods indicates yellow and red muntjacs may have fallback foods they rely on during low seed and fruit availability. Fallback foods have become increasingly recognized in tropical mast-systems where the dramatic fluctuations in resources require species to switch to different diets when their preferred food is unavailable (Hanya \& Bernard 2012, Marshall et al. 2009b).

Bearded pigs used all forest types at CPRS and exhibited relatively low variation in habitat use estimates in each forest type. The relative homogeneity of bearded pig habitat use, overlapping all other 
ungulates at CPRS, suggests a lack of niche differentiation on a spatial dimension. As bearded pigs are thought to primarily consume fruit resources, similarly to the other ungulates in this study, niche differentiation to reduce competition is most likely evident along another dimension.

\section{Temporal variation in fruit availability}

As predicted, temporal variation in fruit availability was an important explanatory variable for bearded pigs which showed a positive relationship with fruit availability. This suggests that their habitat use is more strongly influenced by temporal patterns in resources than spatial patterns. This finding supports previous research that has described the ability of bearded pigs to track spatially and temporally variable fruit resources (Curran \& Leighton 2000, Dove 1993, MacKinnon et al. 1996). Previously tracking of resources has been recorded during long-distance migrations during mast events, however, little is known about their resource use during inter-mast periods. The timing of this study immediately followed a significant mast event, encompassed one small mast event, and ended at the onset of another large mast. The link between bearded pig habitat use during the inter-mast period at CPRS and fruit availability indicates that resource tracking may additionally occur on a smaller spatial scale between mast events. Ideally, the habitat use of bearded pigs should be studied over a longer timeframe that encapsulates both mast and inter-mast periods to better understand this relationship. In contrast, lesser mousedeer had a negative relationship with fruit availability. Lesser mousedeer habitat use was best predicted by forest type, with the highest estimates of use in the peat and freshwater swamp forest types which had high fruit productivity over the study period (Figure 2.1, S.5). This suggests that habitat use for this species is primarily dictated by spatial distributions of fruit resources and additionally influenced by temporal trends of fruiting. The negative relationship with temporal fruiting patterns indicates that lesser mouse deer actively avoid masting areas that attract bearded pigs when fruit availability is high. Spatial avoidance during periods of high fruit availability supports the theory by Curran \& Leighton (2000) that resident frugivore species switch to other fruit resources during masts and avoid mast-produced resources that attract nomadic frugivores.

The results of this study provide further evidence that bearded pigs are dependent on temporal fluctuations in fruit resources associated with mast events in tropical dipterocarp forests. Other species that track available fruit resources have been found to have negative energetics during inter-mast periods and rely on the abundant fruit during mast events for reproduction (Knott 1998, Fredriksson et al. 2006). Past observations of widely emaciated pigs during long inter-mast periods suggest that bearded pig populations are similarly not sufficiently supported by non-mast resources alone (Curran \& 
Leighton 2000) highlighting conservation concerns for bearded pigs trapped in small, isolated forest fragments. Increasing forest fires, deforestation, and climate change threatening dipterocarp forests has already had serious consequences for other species reliant on mast resources in Bornean rainforests. For example, Fredriksson et al. (2006) recorded an $~ 80 \%$ reduction in sun bear (Helarctos malayanus) densities following 1997-1998 forest fires that wiped out a large proportion of the mast produced fruit the bears were dependent on.

\section{Human activity}

Human activity was an important explanatory variable for lesser mousedeer habitat use, accounting for $63 \%$ of model weight. For the remaining species, models including human activity were only marginally supported (3-6\% of model weight). In contrast to my prediction, human activity had a positive influence on lesser mousedeer habitat use. Although comparatively insignificant, the influence on yellow muntjacs was also positive, while bearded pig and red muntjac habitat use showed a negative relationship with human activity. The positive association of human activity across CPRS and lesser mousedeer habitat use may be a result of a 'human-shield effect' (Nowak et al. 2014). Researchers have had a consistent presence at CPRS for the past few decades and regularly visited and maintained the camera grid throughout the study area. The natural predators of mousedeer are likely primarily the members of the local felid guild composed of 5 obligate carnivore species (Brodie \& Giordano 2013). Additionally, mousedeer are a prey of preference for local poachers (Bernard et al. 2013). The presence of researchers may deter both poachers, wanting to avoid detection, and inherently avoidant natural predators. To further test this possibility and quantify any shielding effect of researchers, future studies could compare densities of both ungulates and predators within CPRS and elsewhere in the national park.

\section{Diet}

Patterns of niche partitioning evident among the 5 ungulate species provide some information about their likely diet preferences. The smallest bodied ungulate, lesser mousedeer, was associated with a high-fruit forest habitat. Additionally, the larger-bodied ungulates (greater mousedeer, yellow muntjacs, red muntjacs) were linked to masting forest habitats where fruit and seed availability varies substantially, indicating these species' diets consist to a larger degree of other more reliable food sources, such as browse. Ungulates associated with masting forest types may be a result of the wealth of seedlings produced following mast events and not a direct link to fruit availability. For example, 
habitat use of bearded pigs was not focused in a distinct habitat and may indicate a lack of habitat preference, travelling to benefit from resources across all forest types. These findings support the prediction that diet quality scales negatively with body mass in ungulates at CPRS, in keeping with the Jarman-Bell Principle (Bell 1970, Jarman 1974).

\section{Time}

An overall temporal trend in habitat use was evident in greater mousedeer, yellow muntjacs and red muntjacs. The probability of greater mousedeer and yellow muntjacs using sites declined over the study, suggesting a possible decline in the local population. The probability of red muntjacs using sites increased and may similarly be explained by a change in the local density of red muntjacs. These temporal trends are reported here with caution for a couple reasons. The first being that inferences about abundance should be drawn with caution due to the failure of the assumption of closure. Secondly, the 4.5-year duration of this study may be sufficient to indicate population trends. However, a longer study period is necessary to exclude possible fluctuations in density occurring naturally from either regular population cycles (i.e. due to movements) or changes in life-history parameters (i.e. birth and deaths).

\section{Detection probability}

Lesser mousedeer had the highest estimates of detection probability despite being the smallest-bodied ungulate-a potential disadvantage for detection by camera traps (Anile \& Devillard 2016). This was followed by bearded pigs, then yellow muntjacs, greater mousedeer, and red muntjacs with the lowest detection probabilities (Table 2.12).

For greater mousedeer and bearded pigs, the variation provided by detection covariates did not supply sufficient explanation for the data compared to the null model. This suggests that the detection probability of greater mousedeer and bearded pigs remained constant across sites and sampling periods

$\left(p_{G M D}=0.39 \pm 0.04, p_{B P}=0.51 \pm 0.018\right)$. Sampling effort was an important covariate that positively influenced the detection probability of lesser mousedeer, red muntjacs, and yellow muntjacs. Camera position on or off trails was a strong predictor for the detection probabilities of lesser mousedeer, yellow muntjacs, and red muntjacs. lesser mousedeer and yellow muntjacs' detection were higher on trails while red muntjacs' detection was higher at off-trail sites.

The inclusion of covariates to explain heterogeneity in detection probability across the study improves estimates of detection and habitat use, however, large error values associated with detection 
covariates in this study indicate that other variables that were not measured may better explain heterogeneity in detection probabilities.

\section{Study limitations}

Limitations of this study that may reduce the strength of inferences should be considered. Logistical constraints prevented a more thorough sampling of sites throughout CPRS. Improved coverage of sites, combining to sample a greater proportion of the total study area, as well as more consistent resampling, would improve the confidence of model estimates. Furthermore, the patterns of habitat partitioning among distinct forest types observed in this study may be the result of additional characteristics unique to each forest type (other than fruit availability) that were not measured in this study (i.e. forest structure). Future research should account for other forest specific variables that could provide alternative explanations for the patterns I observed.

Occupancy modelling was used to account for imperfect detection by estimating detection probabilities, however, logistical constraints limited the inclusion of more variables potentially influencing detection. Unexplained heterogeneity in detection probability remained despite using sampling effort and camera placement to improve estimates.

The detection probabilities may differ between species as the motion-triggered cameras have a detection bias towards larger body mass. Accordingly, the habitat use of smaller-bodied ungulates may be underestimated. Additionally, a regularly serviced camera trap framework has the potential for detection bias against human-avoidant species if scent traces are left from regular servicing visits. Occupancy modelling on a fine temporal scale could test for this bias by estimating different detection probabilities over additional surveys following the servicing of cameras.

\section{Conclusion \& future directions}

The results from my study demonstrate a pattern of habitat and resource partitioning of an understudied guild of 5 sympatric ungulates in a tropical rainforest system. Furthermore, my findings indicate differential use of resources among five ungulate species with the smaller mousedeer species relying on forest habitats with consistent fruit resources to provide high-quality nutrition; muntjac species using higher elevation forest habitats that provide opportunistic availability of mast resources; and bearded pigs following temporal patterns of fruiting across CPRS. This study provides support for extending the Jarman-Bell Principle (Bell 1970, Jarman 1974) to ungulates in tropical ecosystems. The partitioning of resources between consistent non-mast and variable pulses in mast resources provide an additional 
dimension for niche partitioning, reducing intraguild competition. Human activity in the research station did not appear to negatively impact ungulate species and in contrast, a human-shield effect may benefit smaller species. The inferences from these findings could be further tested through long-term studies of bearded pig abundance paired with GPS collaring to understand movement patterns of this fruittracking species. 
Chapter 3.

\section{Spatiotemporal habitat use patterns of Sunda clouded leopard (Neofelis diardi) in a mast-fruiting rainforest: influence of forest type, prey occurrence, humans, and fluctuations in fruit resources.}

\subsection{Abstract}

The spatial ecology of Borneo's top predator - the Sunda clouded leopard (Neofelis diardi)-remains poorly understood despite accelerating deforestation reducing available rainforest habitats. I sought to contribute insight into factors that influence the habitat use of clouded leopards, to better inform range predictions, habitat suitability, and conservation planning. I used camera trap data from $4 \frac{1}{2}$ years and a single-season occupancy modelling approach, with time as a covariate, to estimate the influence of sitespecific covariates on the habitat use of clouded leopards over space and time, while accounting for imperfect detection. Habitat use was quantified across 6 distinct forest types and along gradients of human activity, prey occurrence, elevation, and temporal fluctuations in fruit resources in Gunung Palung National Park, West Kalimantan, Indonesian Borneo. I found the habitat use of clouded leopards was strongly influenced by forest type, negatively associated with areas of high human activity, and positively associated with temporal fluctuations in fruit availability and bearded pig occurrence. Habitat use differed significantly between forest types and was highest in the lowland granite forest $\left(\widehat{\Psi}_{L G}=0.87\right.$ $\pm 0.09)$, moderate in the upland granite/montane forests $\left(\widehat{\Psi}_{U G}=0.41 \pm 0.07\right)$, low in both lowland sandstone and peat swamp forests $\left(\widehat{\Psi}_{P S}=0.14 \pm 0.05, \widehat{\Psi}_{L S}=0.11 \pm 0.05\right)$ and remained undetected in the freshwater swamp and alluvial bench forests. High estimates of habitat use associated with bearded pig occurrence and fruiting events suggest that bearded pigs are an important prey of clouded leopards and fruiting may act as a cue, signaling available prey for the top carnivore. Areas of high researcher and poacher activity were associated with lower estimates of habitat use, indicating a possible 'landscape of fear'. My findings contribute new information on the spatial ecology of clouded leopards and factors influencing habitat use that can be applied to improve the efficacy of conservation efforts.

\subsection{Introduction}

Exhibiting the fastest rates of deforestation and land-conversion worldwide, the natural landscape of Indonesian Borneo (Kalimantan) has undergone an alarming transformation since the 1970's with potentially catastrophic consequences for native wildlife (Curran et al. 2004, Hansen et al. 2013, 
Ocampo-Penuela et al. 2020). The increasingly fragmented landscape and reduction in the size of forested areas puts carnivores under further pressure (Noss et al. 1996, Woodroffe \& Ginsberg 1998, Macdonald et al. 2018). The Sunda clouded leopard (Neofelis diardi; subsequently referred to as the clouded leopard) is the apex predator in Borneo's rainforest ecosystems and among the world's most vulnerable, elusive, and poorly understood felid species (IUCN 2020). The medium sized felid, 15-25 kg, is considered a semi-arboreal species and is largely restricted to forested areas with dense canopy cover (Hearn et al. 2016, 2018a). A 50\% loss of forested areas on the island of Borneo between 1973 and 2015 (Ocampo-Penuela et al. 2020), and increasingly degraded 'protected' areas (Curran et al. 2004), have restricted clouded leopards into remnant forest fragments resulting in populations $26 \%$ over carrying capacity (Kaszta et al. 2019).

Effective conservation planning to protect the Sunda clouded leopard is reliant on a thorough understanding of factors influencing their habitat use and distribution. Determining environmental and physical factors (i.e. elevation, climate, forest type) associated with habitat use is fundamental in identifying suitable habitats for protection and achieving functional connectivity across wider landscapes. The rainforest ecosystems in Borneo experience mast-fruiting and consequently dramatic fluctuations of fruit resources. The resource pulses are thought to have considerable 'bottom-up' influence on frugivore populations (Ostfeld \& Keesing 2000, Wong et al. 2005, Kanamori et al. 2017, Chapter 2). This elicits considerable ecological response from consumer populations, the response of clouded leopards to fluctuations in fruit resources through changes in prey populations remains unknown and merits investigation. Furthermore, the influence of anthropogenic disturbance on the spatial ecology of clouded leopards is increasingly important to consider as few areas remain unaffected by encroaching settlements and infrastructure development. Human activities may influence clouded leopard distribution and habitat use through direct effects of poaching or through developing a 'landscape of fear' (Lima et al. 1990, Laundre et al. 2001, Oriol-Cotterill et al. 2005) further restricting effective ranges. Additionally, the occurrence of prey species is a useful predictor for habitat use of carnivore species and may help identify important species interactions shaping patterns of clouded leopard spatial ecology (Burton et al. 2012, Ross et al. 2013, Wisz et al. 2013).

A growing body of research has sought to shed light on clouded leopard ecology in Borneo, but insight has been limited due to challenges studying an elusive low-density carnivore species across difficult terrain (Hearn et al. 2013,2019). A low number of detections frequently inhibit solid inferences despite extensive sampling efforts (Bernard et al. 2013, Cheyne et al. 2016). Hearn et al. (2016) used questionnaires to link researchers' observations of clouded leopards to habitat types, finding the highest 
apparent suitability in lowland and upland forests, while montane and mangrove habitats were associated with the least detections. Additionally, the influence of landscape-scale factors was investigated by Macdonald et al. (2018) on clouded leopards in both Sumatra and Borneo, finding negative influences from nearby human population, forest loss, and plantations. Positive correlations were found between clouded leopard sightings and canopy cover, forest connectivity, and degree of lowland forests present (Macdonald et al. 2018). Poaching and live-trade of clouded leopards in Borneo (D'Cruze \& Macdonald 2015, Nijam et al. 2019), as well as evidence of clouded leopards avoiding deforested and human-altered areas suggests a negative impact from human disturbance (Macdonald et al. 2018, Hearn et al. 2019), however, clouded leopards' response to human activity within a forest landscape has not yet been studied. Additionally, the influence of prey occurrence on clouded leopard habitat use and distribution is not yet understood as the diet and prey preference of clouded leopards are undetermined. Anecdotal observations and co-occurrence patterns indicate Sambar deer (Rusa unicolor), muntjacs (Muntiacus spp.), mousedeer (Tragulus spp.), and bearded pigs (Sus barbatus) may be important prey species but further research is needed to substantiate this possibility (Rabinowitz et al. 1987, Ross et al. 2013, Hearn et al. 2018b).

In recent years camera traps have become a popular research tool that amass enough data to evaluate densities (Wilting et al. 2012), activity patterns (Cheyne \& Macdonald 2011, Hearn et al. 2013), abundance (Wearn et al. 2013), and behavioral observations (Allen et al. 2016) in an efficient, costeffective, and easily replicated manner. Large amounts of presence/absence data from camera traps provide an effective foundation for modelling the occurrence of elusive species while accounting for imperfect detection (Rolland et al. 2011, Galvez et al. 2016, Li et al. 2018). The combination of occupancy modelling and motion-triggered cameras have been effectively used to study factors influencing the habitat use of other large felid species including lynx (Lynx lynx) (Rolland et al. 2011), leopards (Panthera pardus) (Burton et al. 2012, Edwards et al. 2018), bobcats (L. rufus), and pumas (Puma concolor) (Lewis et al. 2015).

\subsection{Aims}

The goal of my study was to examine the influence of site-specific characteristics, human activity, and prey occurrence on spatiotemporal patterns of clouded leopard habitat use in an ecologically intact mast-fruiting rainforest system. Habitat use estimates from occupancy modelling of five ungulate species across a body size gradient (1.5-200 kg; Chapter 2)-identified as potential prey for clouded leopards-were directly incorporated to model habitat use of clouded leopards. Additionally, I used 
phenological data describing temporal variation in fruit availability among 6 forest types to determine the influence of mast-induced resource variation. Analyses were based on a long-term extensive camera trapping effort from July 2015-October 2019 and single-species occupancy modelling to evaluate the influence of site-specific covariates. Gaining a more comprehensive understanding of the spatial ecology of Borneo's top predator is vital to inform effective conservation planning and reverse the decline of this charismatic species.

\subsection{Methods}

\subsubsection{Study site}

This study was based within the Cabang Panti Research Station (CPRS) located in Gunung Palung National Park (GPNP), West Kalimantan, Indonesian Borneo (Section 1.3). CPRS is an approximately 34 $\mathrm{km}^{2}$ site covering 7 distinct forest types along an altitudinal gradient from sea level to $\sim 1,100 \mathrm{~m}$ (Figure 1.1). GPNP exhibits strong pulses in resource availability during mast-events and the occurrence of 7 distinct forest types, within a compact area, make it a prime location to study responses to fluctuating fruit resources. The study site remains relatively undisturbed by humans although there is an extensive trail system frequently used by researchers.

\subsubsection{Data collection}

Data were collected between July 2015 and October 2019 at 192 camera sites throughout CPRS. Sites were chosen randomly along trail and off trails in all 7 forest types covering the available elevational gradient. The presence or absence of species were assessed at each site using motion-triggered cameras. To maintain independence among detections, multiple subsequent detections at a site were pooled on a daily basis. Camera traps (Bushnell TrophyCam) were used in preference to more invasive methods such as capturing and fitting individual clouded leopards with GPS collars and to maximize the detection of a wide range of species. Cameras were programmed to record $20 \mathrm{~s}$ videos when triggered, followed by a $10 \mathrm{~s}$ refractory period. Due to resource limitation, cameras were rotated between sites to sample as large of a portion of the study site as possible. On average, 31.8 sites were sampled during a survey with a minimum of 4 active camera locations maintained in each forest type. Cameras were regularly serviced to ensure batteries were charged and cameras remained active. Cameras were placed along trails $(n=134)$ as well as off-trail $(n=58)$ to test for differences in detection rates from camera placement. 
Species

To understand the effect of prey on habitat use of clouded leopards, I used data from 5 possible ungulate prey species across a body size gradient (Table 2.1) as covariates-lesser mousedeer (Tragulus kanchil, LMD), greater mousedeer (T. napu, GMD), Bornean yellow muntjac (Muntiacus atherodes, YM), red muntjac (M. muntjak, RM), and bearded pig (Sus barbatus, BP) (Chapter 2).

\section{Site-specific covariates}

Several site-specific covariates were measured at each camera-location for inclusion in occupancy and detection modelling. Elevation was measured as meters above sea level and was standardized using a zscore normalization.

Forest type was classified for each site and was included in analysis as a categorical covariate. Seven distinct forest types are present in CPRS (Table 1.1). I pooled the upland granite and montane forest types together in this study as there was a lack of phenological data available for the montane forest type during the study period. The upland granite and montane forests exhibit considerable interdigitation and share similar floral composition and productivity, therefore I believe pooling these forest types to be reasonable if inferences are treated with caution. The forest types I include in this study are peat swamp (PS), freshwater swamp (FS), alluvial bench (AB), lowland sandstone (LS), lowland granite (LG) and upland granite/montane (UGM).

I used phenology data, collected by Dillis et al. (2015), to determine temporal variation in fruit availability in each forest type over the sampling period. The density of stems bearing ripe fruit was measured from all trees with stems larger than $14.5 \mathrm{~cm} \mathrm{dbh}$, lianas larger than $3.5 \mathrm{~cm} \mathrm{dbh}$, and all hemiepiphytic figs with roots touching the ground. Measurements were taken on a monthly basis from 10 randomly selected sampling plots, covering 1.5 ha of each forest type. Values were averaged to obtain one monthly estimate per forest type. I standardized values using a z-score normalization before analysis.

I used site-specific estimates of habitat use for each of the 5 potential prey species from singlespecies occupancy models (Section 2.5) to described prey occurrence. To avoid confounding influence of covariates, I took data from the conditional estimates from the null occupancy model to describe the occurrence of each species while only accounting for imperfect detection. No covariates are used to model habitat use in the null model, resulting in conditional habitat use estimates with values of either ' 1 ' when a species was detected, or a probability value reflecting the chance of presence when there was no detection. 
I calculated human activity as an index of all human detections at each site standardized by the sampling effort (trap nights/sampling period). Human activity was a combination of researcher and poacher sightings. Although poachers were detected consistently throughout the study period, the sparse frequency of detections prevented the influence of poachers to be determined separately. I used the index approach instead of occurrence estimates from occupancy models as researchers were detected at a high frequency, reducing the level of variation between sites.

\subsubsection{Occupancy modelling}

A simple single-species occupancy modelling approach (Mackenzie et al. 2006) was used to model habitat use of clouded leopards across CPRS and evaluate the influence of site-specific covariates on habitat use and detection. All analyses were conducted in R (R Core Team 2013) using the RPresence package (Mackenzie \& Hines 2018).

Traditionally, occupancy modelling is based on the assumption of closure, meaning species cannot move between sampling sites during a survey. In relation to the spatial scale of this study, I believe this assumption is not met as clouded leopards may have home ranges as large as $16 \mathrm{~km}^{2}$ for females and $>50 \mathrm{~km}^{2}$ for males (Hearn et al. 2013, Mohamed et al. 2019). Occupancy at a site can thus not be determined as an individual detected at one site may be able to travel and be detected a separate site within a survey. Alternatively, the use of a site can be estimated using the same approach. Accordingly, in this study I estimate the habitat use $(\Psi)$ and detection probability $(p)$.

I created detection histories for each sampling site using the camtrapR package (Niedballa et al. 2016). I broke continuous histories into 30-day survey periods starting July $1^{\text {st }}, 2015$. I grouped four consecutive surveys, totaling to a period of 120 days, into sampling periods. In this study, I will be using the term sampling period instead of the traditional sampling season as there are no climatic seasons at CPRS. Instead of aligning with the occurrence of climatic seasons I designed the sampling periods to align with fluctuations in fruit availability (Figure 2.1).

I formatted all data into distinct camera location $x$ sampling period combinations and subsequently treated these as distinct sites $(n=2,496)$. This data structure permitted me to estimate clouded leopard habitat use across CPRS with limited temporal replication, and without estimating site emigration and immigration. This approach also allowed me to estimate the influence of fluctuations in fruit availability without using a multi-season approach typically used with temporal covariates. Using this approach, sometimes referred to as a stacked single-season approach, the occupancy at a site is estimated independently of previous or consecutive sampling periods (Fuller et al. 2016). I believe this 
to be acceptable for the purpose of this study as the interest is in estimating habitat use and not siteoccupancy.

I modelled the detection of clouded leopards at $i=1, \ldots, 2496$ site-periods during $j=1, \ldots, 4$ surveys as $y_{i j} \sim$ Bernoulli $\left(z_{i} \times p_{i j}\right) . z_{i}$ is the latent variable indicating if site $i$ is used or not by a species (1 or 0$)$ and $p_{i j}$ is the site and survey-specific probability of detection given an individual is present. The site-specific probability of use by clouded leopards is described by $\left(\Psi_{i}\right)$ and latent states of use as $z_{i}^{\sim}$ Bernoulli $\left(\Psi_{i}\right)$.

I modelled the effects of covariates on habitat use and detection using logit-link functions. The probability of a site being used by clouded leopards was modelled as logit $\left(\Psi_{i}\right)=\alpha_{0}+\alpha_{1} \mathrm{x}_{\mathrm{ij}}$, and the probability of detection was modelled as $\operatorname{logit}\left(p_{i}\right)=\beta_{0}+\beta_{1} \mathrm{x}_{\mathrm{ij}}$, where the covariate at site $i$ and survey $j$ is represented by $x_{i j}$, and $\beta_{1}$ and $\alpha_{1}$ are the associated regression coefficients. The intercept or constant term (for categorical variables) is represented by $\beta_{0}$ or $\alpha_{0}$.

I modelled occupancy as a function of forest type (with lowland sandstone as the constant), temporal variation in fruit availability as a site $\mathrm{x}$ sampling period specific variable, elevation (both as a linear and quadratic terms), human activity represented as an index of human detections per trap night, sampling period, and as a function of occurrence of each of the 5 ungulate species using conditional habitat use estimates from the standard model. I modelled detection as a function of sampling effort (the proportion of days a camera was active at the site during a sampling period), and as a function of camera placement-a categorical covariate identifying placement either on or off trails.

Using the site-specific covariates, I designed a set of a priori candidate models for modelling habitat use and detection probability $(\Psi n=204, p n=4)$. I tested all possible combinations of covariates that described biologically relevant hypotheses, with a maximum of three covariates in a model to prevent over parameterization and avoid non-convergence issues. I assessed any correlation between variables and omitted correlated covariates $(r>0.6)$ from the same model.

I used a two-step approach for model fitting, focussing on modelling habitat use first as it is the primary parameter of interest for this study. Modelling habitat use first with a general model for detection enabled me to assess inferences about habitat use without a confounding influence from the constraints applied to detection probability (MacKenzie et al. 2006). Following this first step, I then modelled detection probability using the best performing model for habitat use. I checked models following the first two steps by fitting all top habitat use models with all detection models to confirm the selection process. Using a parametric bootstrap $(n=1,000)$ to compare the observed and expected data 
$\left(x^{2}\right)$ for the most general model, I assessed model fit and calculated the overdispersion parameter ( $\left.\hat{c}\right)$ (Mackenzie \& Bailey 2004).

I used Aikake's Information Criterion (AIC) to rank models and determine the most parsimonious model with the best fit to the data. I included models with significant support $(\triangle \mathrm{AIC}<7)$ in model selection tables and model-averaging (Burnham \& Anderson 2002). I graphically represented all results using the ggplot2 package (Wickham 2016) in R and using the viridis colour scale designed for colourblindness (Garnier 2018).

\subsection{Results}

Between July 2015 and October 2019, a total of 42,610 trap nights across 192 sites at CPRS resulted in 276 independent detections of clouded leopards. Clouded leopards were detected at $22 \%$ of the sites, with the highest amount of detections in the lowland granite forests (Table 3.1). There were no detections of clouded leopards in the freshwater swamp or alluvial bench forests during the study period despite a combined 12,020 trap nights. Without the influence of covariates clouded leopards had a naïve detection probability of $0.21 \pm 0.02$.

Table 3.1: Detections of clouded leopards across CPRS by forest type between July 2015-October 2019.

\begin{tabular}{l|ccc} 
Forest type & Detections & Trap nights & Detections per trap night \\
\hline Peat swamp (PS) & 8 & 6575 & 0.001 \\
Freshwater swamp (FS) & 0 & 5747 & 0 \\
Alluvial bench (AB) & 0 & 6273 & 0 \\
Lowland sandstone (LS) & 15 & 7084 & 0.002 \\
Lowland granite (LG) & 156 & 5514 & 0.028 \\
Upland granite/montane (UGM) & 97 & 11417 & 0.009 \\
TOTAL & $\mathbf{2 7 6}$ & $\mathbf{4 2 6 1 0}$ & $\mathbf{0 . 0 0 7}$
\end{tabular}

\subsubsection{Habitat use}

Habitat use of clouded leopards was best described by forest type and bearded pig occurrence, which were consistently present in all top performing models ( $\triangle \mathrm{AIC}<7$; Table 3.2 ). Fruit availability was present in two of the top nine models. The inclusion of the fruit covariate in the top model allowed for more variation in the data to be explained despite the penalty associated with increased parameterization. 
The highest estimates of habitat use were associated with the lowland granite forest $\left(\widehat{\Psi}_{L G}=0.87\right.$ \pm 0.09 , Figure 3.1), followed by the upland granite/montane forest $\left(\widehat{\Psi}_{U G M}=0.41 \pm 0.07\right)$. Clouded leopards used peat swamp $\left(\widehat{\Psi}_{P S}=0.14 \pm 0.05\right)$ and lowland sandstone forests $\left(\widehat{\Psi}_{L S}=0.11 \pm 0.05\right)$ less frequently. Alluvial bench and freshwater swamp forests were associated with a strong negative relationship on clouded leopard habitat use as there were no detections in these habitats during the study period. The complete lack of detections prevented accurate estimation of standard errors and habitat use estimates approached zero.

Bearded pig occurrence had a strong positive association with clouded leopard habitat use (Figure 3.2). The $\beta$ values associated with the $B P$ covariate remained $\sim 1.5$ across all models, indicating that clouded leopards were between 4.3-4.8 times more likely to use sites where bearded pigs were detected.

The availability of ripe fruit had a positive relationship with clouded leopard habitat use. The probability of clouded leopards using a site increased 1.46 times for every 1-unit increase in density of ripe fruit available at the site.

Human activity had a negative effect of on the probability of clouded leopards using sites. The human covariate was present in one of the top models ( $\triangle \mathrm{AIC}<2$ ) which should be considered to have support insignificantly different from the $1^{\text {st }}$ and $2^{\text {nd }}$ ranked models (Burnham \& Anderson 2002). The associated $\hat{\beta}$ values (Table 3.1) indicate that clouded leopards are 1.27 times less likely to use a site for every 1-unit increase in human activity. The lesser mousedeer ( $L M D)$, greater mousedeer (GMD), yellow muntjac ( $Y M)$ and red muntjac (RM) covariates appeared in the set of best performing models, however, the standard error associated with the beta values overlapped zero. Accordingly, the influence of mousedeer and muntjac occurrence cannot be reported with any confidence.

The time covariate was present in two of the best performing models and described a slight negative trend in the probability of clouded leopards using habitats over the duration of the study. Habitat use was estimated to decline by 1.07 - 1.08 times with each sampling period. 


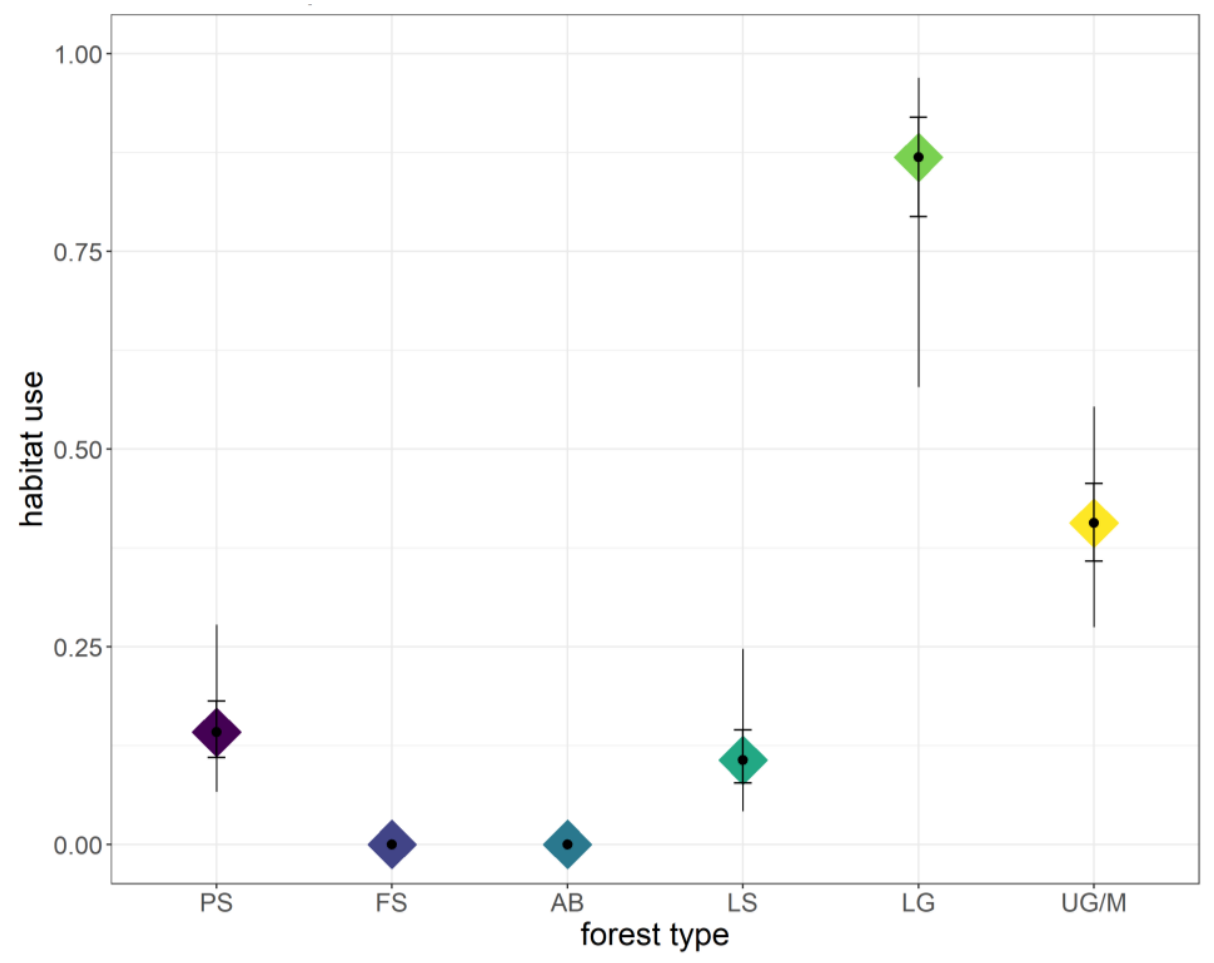

Figure 3.1: Clouded leopard habitat use by forest type at CPRS. Habitat use estimates are modelaveraged $(\triangle \mathrm{AIC}<7)$. Forest types are ordered along an increasing elevational gradient and identified by the following abbreviations: Peat swamp (PS), freshwater swamp (FS), alluvial bench (AB), lowland sandstone (LS), lowland granite (LG) and upland granite/montane (UGM). Vertical lines represent the $95 \%$ confidence interval and whiskers demonstrate the $50 \%$ confidence interval. 


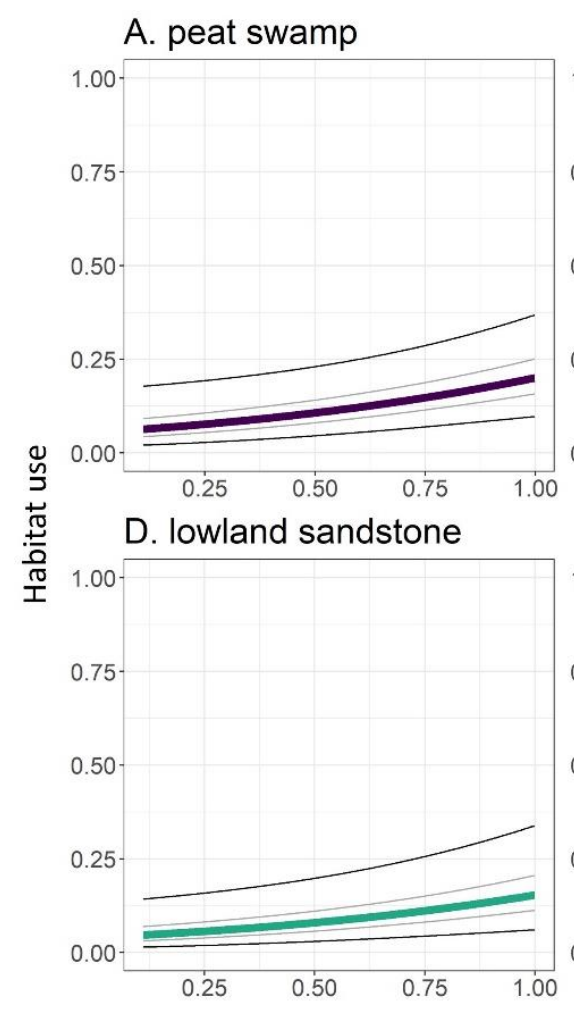

B. freshwater swamp

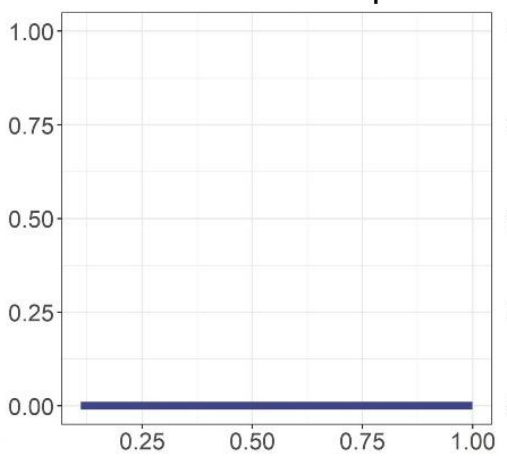

E. lowland granite

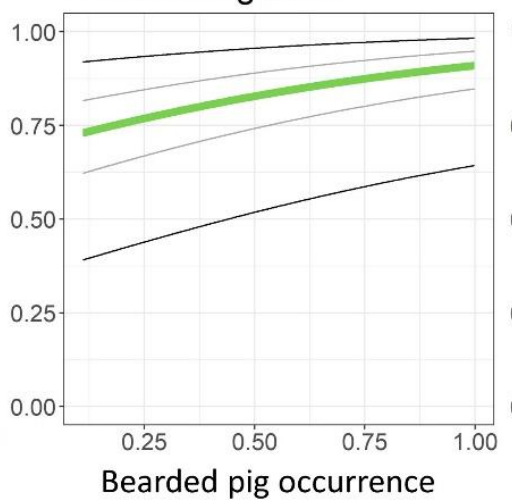

C. alluvial bench

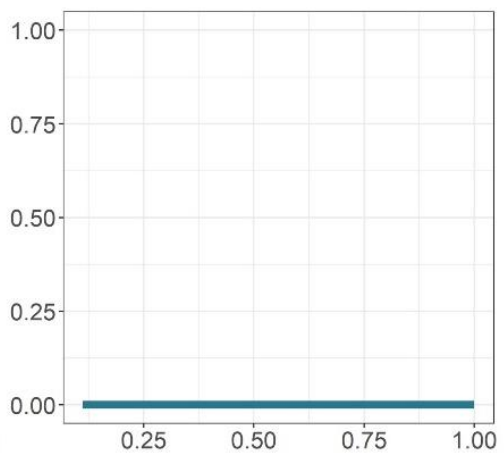

F. upland granite/montane

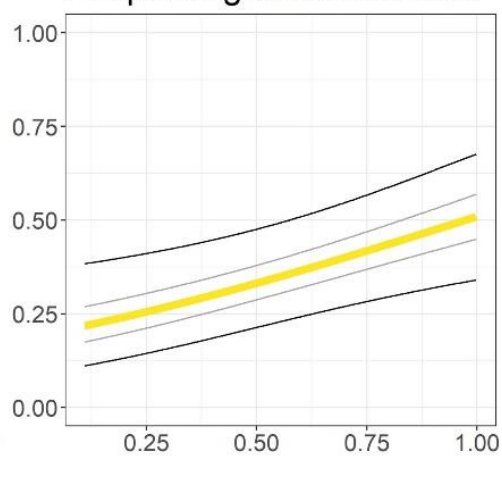

Figure 3.2: The relationship between bearded pig occurrence and clouded leopard habitat use across forest types in CPRS. Clouded leopard habitat use estimates are model averaged ( $\mathrm{AIC}<7)$. Black boundaries represent the model-averaged $95 \%$ confidence interval and grey boundary lines represent the model-averaged $50 \%$ confidence interval.

\subsubsection{Detection}

The detection probability of clouded leopards was best described by both effort and off-trail covariates (Table 3.3). Sampling effort had a positive relationship with detection probability, while camera placement off-trail had a strong negative relationship (Figure 3.3). The odds of detecting a clouded leopard were 13-15 times higher at on-trail sites than off-trail. The off-trail covariate best described the heterogeneity in detection probability between sites, evident from the strong $\hat{\beta}$ value as well as the performance of the $p$ (off-trail) model $\triangle A I C=1.34$, indicating that its performance was comparable with the top model (Burnham \& Anderson 2002). 


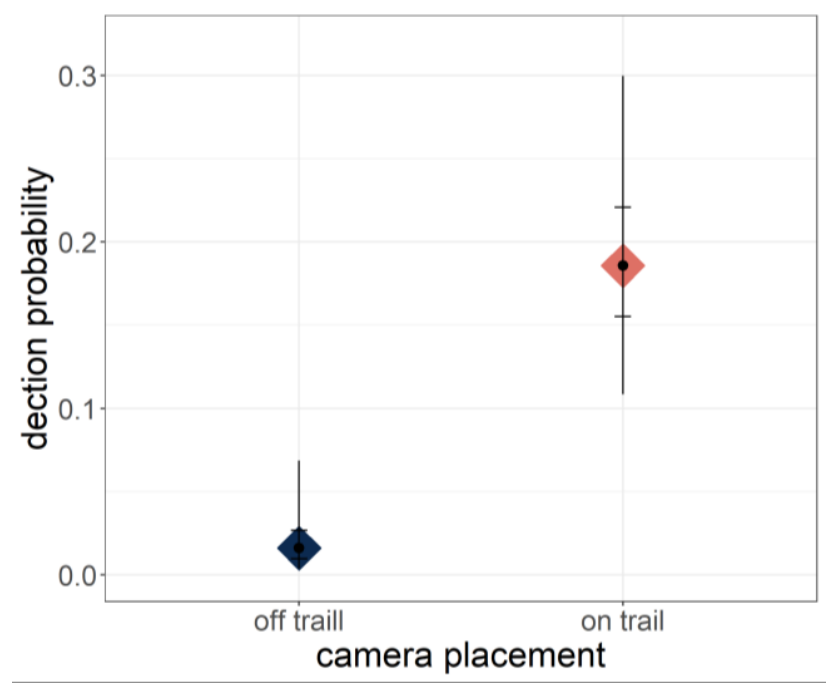

Figure 3.3: The probability of detecting Sunda clouded leopards at camera stations on and off trails given presence at the camera site. Estimates of detection probability are model-averaged ( $\triangle \mathrm{AIC}>7)$. Vertical bars illustrate the $95 \%$ confidence interval and whiskers identify the $50 \%$ confidence interval.

\subsubsection{Model fit}

Model fit was assessed using a parametric bootstrap for the most general model $\Psi$ (fruit + forest $+B P$ ), $p($ effort + off-trail). The dispersion parameter $(\hat{c})$ was calculated to be 1.93 , indicating slight overdispersion and suggesting that some variation in the data remains unexplained. A dispersion parameter value below 3 is considered acceptable (Lebreton et al. 1992), and further influence from additional factors is probable as I limited models to include a maximum of 3 covariates. 
Table 3.2: AIC comparison of top ranked habitat use $(\Psi)$ models $(\triangle \mathrm{AIC}<7)$ for the Sunda clouded leopard. Habitat use was modelled with general detection model $p$ (effort + off-trail). The null model is represented as $\Psi(.) . \Delta \mathrm{AIC}$ is the relative difference in AIC values compared to the top ranked model, $K$ is the number of parameters in a model, $\mathrm{w}$ is the AIC model weight, $\alpha$ is the estimated intercept or constant term, $\beta$ are the estimated regression coefficients for each covariate on the logit scale. Forest types are represented by the following abbreviations: freshwater swamp (FS), peat swamp (PS), lowland swamp (LS), lowland granite (LG), upland granite/montane (UGM). The values reported in grey represent models that did not reach convergence.

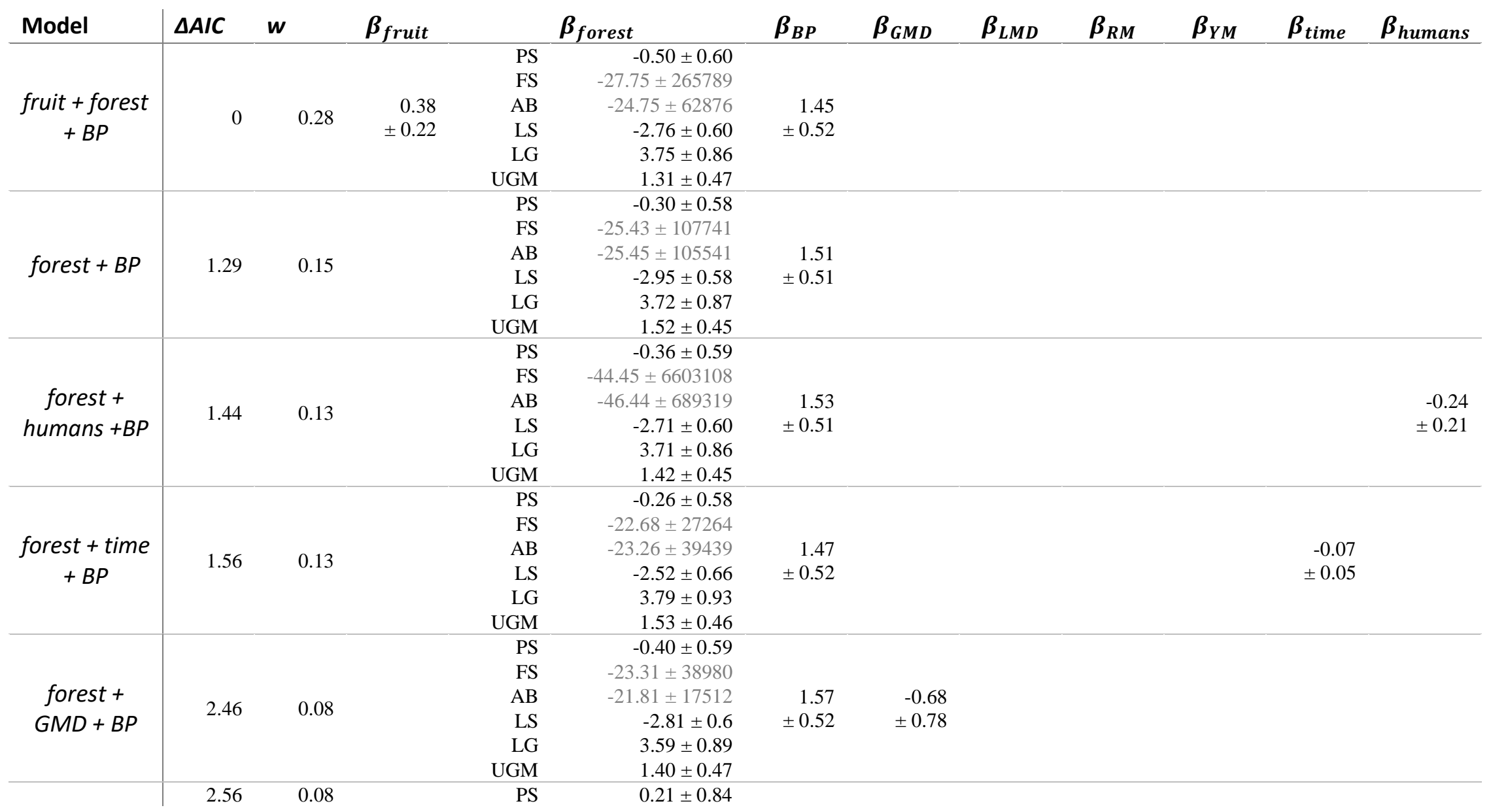




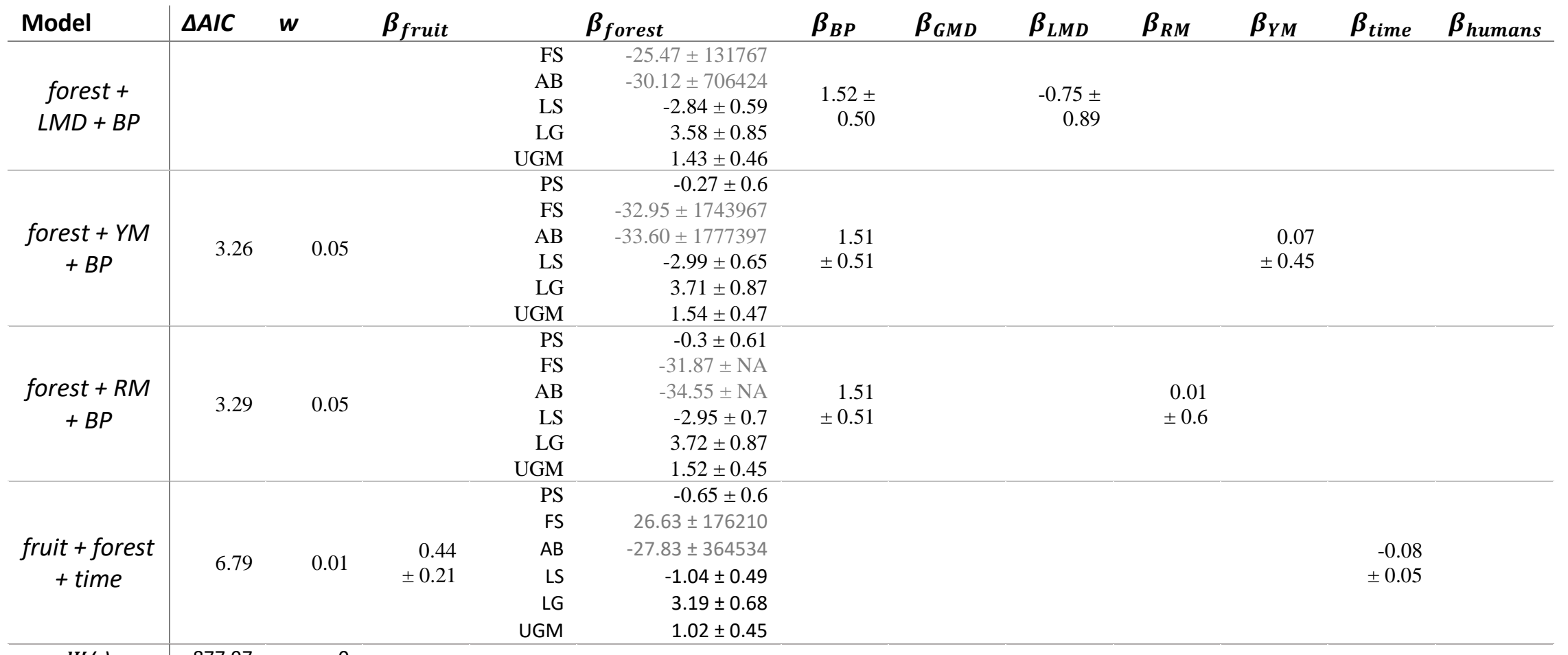


Table 3.3: AIC comparison of top ranked models of Sunda clouded leopard detection $(p)(\triangle \mathrm{AIC}<7)$. Habitat use was modelled with general model $\Psi$ (elev + fruit + time). $\triangle \mathrm{AIC}$ is the relative difference in AIC values compared to the top ranked model, $K$ is the number of parameters in a model, $w$ is the AIC model weight, $\alpha$ is the estimated intercept or constant term, $\beta$ are the estimated regression coefficients for each covariate on the logit scale. $e^{\beta}$ represents the back-transformed $\beta$ estimate describing the odds associated with the covariate.

\begin{tabular}{r|rrrrrrr} 
Model & \multicolumn{1}{|c}{$\boldsymbol{\Delta A I C}$} & $\boldsymbol{w}$ & $\boldsymbol{\alpha}$ & $\boldsymbol{\beta}_{\text {effort }}$ & $\boldsymbol{e}^{\boldsymbol{\beta}_{\text {effort }}}$ & $\boldsymbol{\beta}_{\text {off-trail }}$ & $\boldsymbol{e}^{\boldsymbol{\beta}_{\text {off-trail }}}$ \\
\hline effort + off-trail & 0 & 0.66 & $-1.66 \pm 0.29$ & $0.61 \pm 0.34$ & 1.84 & $-2.6 \pm 0.73$ & -13.46 \\
off-trail & 1.34 & 0.34 & $-1.18 \pm 0.1$ & & & $-2.71 \pm 0.72$ & -15.03
\end{tabular}

\subsection{Discussion}

My results demonstrate clear spatiotemporal patterns of habitat use of the Sunda clouded leopard in CPRS. Using an occupancy modelling framework enabled habitat use to be quantified among camera sites while accounting for imperfect detection. The habitat use of clouded leopards in the Bornean rainforest ecosystem was strongly influenced by forest type and bearded pig occurrence, and, to a lesser degree, human activities, and temporal fluctuations in fruit availability.

\section{Forest type}

Clouded leopard habitat use patterns showed clear preferences for distinct forest types at CPRS. The lowland granite forest (200-400 m asl) was the most frequently used habitat followed by the upland granite/montane (350-800 m asl) with moderate use. Containing a large portion of dipterocarp species, both the lowland and upland granite forests exhibit considerable pulses in fruit resources during mastevents (Cannon \& Leighton 2004). These forests also have a high density of both large and small trees which may facilitate any arboreal behaviours of clouded leopards (Table 1.1). The presence of ridgelines in these forests, which have been linked with large-scale movement patterns of male clouded leopards (Macdonald et al. 2018), may further explain high estimates of habitat use.

Highest occurrences of clouded leopards in lowland and upland forests was similarly reported by Hearn et al. (2016) from a questionnaire of researchers that found habitat suitability peaked in lowland and upland forests and dropped off at higher elevation montane forests. By pooling the higher elevation montane forest with the upland granite forest in this study, any disparity between habitat use of clouded leopards in upland granite and montane forests is lost and may have resulted in underestimates 
of habitat use in the upland granite forest. Of the 93 detections in the pooled 'upland granite/montane' forest (Table 3.1), 44 were detections of clouded leopards in the montane forest habitat and 53 were at sites in the upland granite forest. Habitat use was not estimated separately for montane forests due to a paucity of fruit availability data, however the number of detections suggest a slight decline of habitat use in upper montane forests.

Previous studies have reported increased occurrence of clouded leopards at higher elevations (Allen et al. 2016, Tan et al. 2017), however I found that elevation was not a good predictor for habitat use. Describing clouded leopard occurrence by elevation oversimplified patterns of habitat use, as clouded leopards used the low-lying peat swamp forests and habitat use may decline at higher elevations. Habitat use should be used to inform and prioritize protection efforts, however, habitats that demonstrate low levels of use should not be dismissed as unimportant. Fallback foods, a concept used to describe resources that are critical to a species during periods of food scarcity, may drive species to travel outside common habitats and alter their ranges (Marshall et al. 2009b). Although used comparably less than other forest types, the low elevation peat swamp and lowland sandstone forests may provide key resources vital to population persistence. Clouded leopards were not detected in either the freshwater swamp forest and lowland sandstone forest over $4 \frac{1}{2}$ years. The low-density of trees in the freshwater swamp or lowland sandstone forests may make these forest habitats unsuitable for clouded leopards. If unsuitable for hunting or other key behaviours, the low-density forests may still function to maintain connectivity to other key habitats.

\section{Prey occurrence}

The occurrence of bearded pigs was a strong predictor of habitat use of clouded leopards across CPRS, indicative of a predator-prey relationship between clouded leopards and bearded pigs. Bearded pigs have been recorded travelling in large groups during mast-events, arriving at mast-fruiting areas in the 100's (Curran \& Leighton 2000, Dove 1993, MacKinnon et al. 1996). Pulses in occurrence, in combination with a hunting strategy distinct from most mid-sized felids may enable clouded leopards to predate on bearded pigs when available. Clouded leopards are adept at climbing trees and their unique canine morphology is indicative of a hunting strategy of dropping from above and delivering a nape bite to sever the spinal column (Christiansen 2007, 2008). Although some studies have suggested bearded pigs could be a potential prey species for clouded leopards (Ross et al. 2013), others have dismissed this possibility due to the disparity in body size of an adult bearded pig (up to $200 \mathrm{~kg}$ ) and clouded leopards (15-25 kg) (Mohamed et al. 2015). Carbone et al. (1999) described the energetic constraints of 
carnivores and predicted that carnivores with body mass $<21.5 \mathrm{~kg}$ would feed primarily on small prey $(<$ $45 \%$ of carnivore mass). Sunda clouded leopards straddle the distinction between small and large prey based on energetic constraints. High availability of large prey could lead to favorable trade-off between energy expenditure from hunting and gains from successful kills.

A large degree of sexual dimorphism between females $(\sim 12 \mathrm{~kg})$ and males ( $\sim 24 \mathrm{~kg})$ may differentially influence choice in prey species. Based on energetic constraints, smaller females may differ from males by predating primarily on small prey (Carbone et al. 1999). Hearn et al. (2018) used temporal overlap to inform predator-prey associations and found female clouded leopards were associated with mousedeer while male clouded leopards were associated with sambar deer (Rusa unicolor). My research did not identify clouded leopards by sex and most-likely disproportionately describes habitat use patterns of male clouded leopards, as females have extremely low detection rates possible due to a more arboreal hunting behaviour (Cheyne \& Macdonald 2011, Sollmann et al. 2014).

\section{Fluctuations in fruit resources}

Pulses in fruit availability in GPNP may act as a cue for clouded leopards indicating high occurrence of prey. This novel finding links bottom-up effects of resource availability to an apex predator in a mastfruiting rainforest system. High fruit availability attracts frugivore species (Moegenburg \& Levey 2003) and I previously showed bearded pigs track available fruit across large areas (Chapter 2). Additionally, mast events create periods of high resources suitable for reproduction and can lead to population growth of frugivore species (Ostfeld \& Keesing 200, Hessen et al. 2013). Reproduction of bearded pigs is thought to be timed to coincide with mast events as mating behavior is observed during the flowering period and piglets are observed only during fruiting events (Curran \& Webb 2000). The appearance of large numbers of bearded pigs and their young as well as other species capable of tracking food resources, is marked by fruiting events that occur at slightly different times across large landscapes (Caldecott 1991). The coincidence of fruiting and a rise in available prey enables clouded leopards to use fruit availability as a cue for conditions ideal for hunting. The link between mast events and clouded leopard habitat use emphasizes the importance of preserving the dipterocarp forests in Borneo. Protecting these quickly disappearing forests is vital to maintaining suitable habitats for clouded leopards, as well as the innumerable species dependent on mast-fruiting resources. 


\section{Human activity}

Human activity was associated with a reduction in clouded leopards habitat use, indicative of a potentially negative influence of passive human activity on this apex predator within the National Park. The index of human activity recorded at sampling sites throughout the park included both researchers and poachers. I was unable to assess the impact of poaching on clouded leopards due to sparse detections of poachers, however, direct impact on clouded leopards is considered to be low as poachers in Borneo are thought to primarily target ungulate species (Corlett 2007, Bernard et al. 2013). A negative influence on clouded leopards from passive human activity exists through the formation of a 'landscape of fear' (Lima et al. 1990, Laundre et al. 2001). The perceived threat from human activity can alter carnivore behavior, leading to increased vigilance, reduction in time hunting, and avoidance (Griffiths \& Van Schaik 1993, Buij et al. 2007, Ciuti et al. 2012a, b). Ultimately the perceived threat from humans can result in extirpation from an area or reduced fitness of individuals (Ciuti et al. 2012a).

Although direct impacts from poachers is thought to be minimal, poaching may indirectly impact clouded leopards through competition for prey species and should be investigated. Detections of poachers declined with elevation (Figure S.1), most likely a result of increasingly difficult terrain and distance from entry points. Sambar deer may have been extirpated from the area from over-hunting as there were no sightings throughout CPRS between 2015-2019, and it is possible that other prey species are under similar threat. Poaching may also push affected species to higher elevations to seek refuge and result in clouded leopards following prey to low-disturbance areas.

\section{Detection probability}

The probability of detecting Sunda clouded leopards was substantially higher along trails in accordance with previous research on clouded leopards (Cheyne \& Macdonald 2011, Cheyne et al. 2016). Camera trap studies for large mammals frequently deploy cameras along trails and ridgelines to increase the probability of detecting low-density species (Williams et al. 2002). Movement patterns associated with patrolling and scent-marking behaviors in clouded leopards may be facilitated by wildlife trails, humanmade trails, and ridgelines (Wilting et al. 2006, Gordon \& Stewart 2007, Allen et al. 2016). Although my finding of higher detections of clouded leopards on trails suggests camera trap methodology employed to increase detections of felids would be successful with clouded leopards, studies should avoid an entirely on-trail setup that may lead to biased detections between species or sexes (Wearn et al. 2013, Kolowski \& Forrester 2017, O'Connor et al. 2017). Female clouded leopards, often sighted with young, were found to have different fine-scale habitat use, and possibly avoid encountering males that use 
roads and ridgelines for long-distance movements (Hearn et al. 2018). Different fine-scale habitat use between sexes may explain consistently low detections of females in clouded leopard studies. Increased arboreality or avoidance of trails by females would result in underestimates of females from studies using only on-trail cameras.

\section{Conclusion}

My findings build on previous research to indicate bearded pigs are an important prey species for the Sunda clouded leopard, and demonstrates a novel link between fruiting events, bearded pig occurrence, and Sunda clouded leopard habitat use possibly suggesting that fruiting is used as a cue for prey occurrence. Additionally, my results show the importance of lowland and upland granite/montane forests, necessitating protection as key habitats for the Sunda clouded leopard. Lastly, I found human activity to be linked with lower levels of habitat use, indicating a possible 'landscape of fear'. Together, these findings provide novel insight into factors influencing the habitat use of the Sunda clouded leopard and can be applied to better inform range predictions, habitat suitability models, and conservation planning. The rate at which the forests of Borneo are disappearing and remaining paucity of information about its rainforest ecosystems necessitates a swift and effective move to conserve this charismatic felid. Conservation efforts targeting the Sunda clouded leopard will likely benefit innumerable other species that share dependencies on similar habitats and resources. More research is urgently needed to further refine our understanding of clouded leopard diet, threats, and sexdependent differences in habitat and resource use. 
The purpose of my research was to shed light on the spatial ecology of understudied ungulates and a top predator in a mast-fruiting Bornean rainforest. In Chapter 2, I provided evidence of niche partitioning among 5 sympatric ungulate species along a fruit resource gradient. Mousedeer (Tragulus kanchil, and T. napu) and muntjac (Muntiacus atherodes and M. muntjak) species differentially used distinct forest types, indicating different foraging strategies: with smaller bodied mousedeer using forests with high-quality resources and larger muntjacs differentiating by using forests with more variable resources. However, bearded pigs (Sus barbatus) did not select for any forest types but instead appeared to track pulses of abundant fruit across the landscape. These findings describe, for the first time, niche partitioning among the ungulates present at Cabang Panti Research Station (CPRS) and more generally improve our understanding of resource use of an ungulate guild varying in body size from 1.5 to $200 \mathrm{~kg}$ in a mast-fruiting rainforest. In chapter 3, I used data on forest type, ungulate prey occurrence, fluctuation fruit resources, and human activity throughout CPRS as predictors of habitat use of Sunda clouded leopard (Neofelis diardi; clouded leopard hereafter). Habitat use of clouded leopards was strongly influenced by forest type, indicating differences in suitability that should be accounted for when assessing potential habitat. Occurrence of bearded pigs and, to a lesser degree, fruit availability also explained spatial and temporal variability in habitat use of clouded leopards. In the absence of detailed data on diet composition and prey preference, I interpreted these findings as evidence that bearded pigs are likely an important prey species and clouded leopards may use fruiting events as a cue for their availability.

\section{Hunting strategy}

The hunting strategy of clouded leopards remains unobserved, however past research together with my findings illustrates a possible hunting strategy enabling clouded leopards to target large prey feeding in areas with high fruit availability. Clouded leopards, particularly females, have been well-documented to be skilled at climbing trees and moving through canopies, resulting in their description as a semiarboreal species (Brodie \& Giordano 2013, Sollmann et al. 2014, Macdonald et al. 2018). Additionally, multiple studies on felid tooth morphology have identified clouded leopards as an outlier with considerably long and narrow 'blade-like' canines (Freeman \& Lemen 2007, Christiansen 2006, 2007, 2008). The canine morphology is inconsistent with typical allometric scaling and possibly indicative of a hunting strategy of dropping from above and delivering a nape bite to sever the spinal column 
(Christiansen 2007, 2008). Furthermore, a paralyzing bite would enable large prey to be quickly incapacitated, allowing clouded leopards to target species that would be considered too large based on energetic constraints (Christiansen 2007, Carbone et al. 1999). The spatiotemporal association between clouded leopards, bearded pigs, and fruiting that I describe in Chapter 3 indicates that bearded pigs may be an important prey for clouded leopards and that clouded leopards track bearded pigs through their association with fruiting events. To my knowledge, there have been no direct observations of clouded leopards hunting ungulates, however, their skill climbing trees, tooth morphology, and spatial association with both bearded pigs and fruiting events indicates a possible strategy of waiting in fruiting trees and dropping down to predate on bearded pigs below.

\section{Forest type}

The influence of forest type on habitat use was evident for both mousedeer and muntjac species, as well as the clouded leopards. The distinct forest types present in CPRS exhibit clear differences in forest structure, floral composition, soil type, and productivity. The variation occurring among forest types inside Borneo's rainforests necessitates incorporating forest type into species conservation in Borneo. Predicting current ranges and suitable habitat are important steps in assessing populations and planning conservation efforts. Physical and environmental covariates known to influence the habitat use of a species can be applied to models that can predict use across a larger landscape-eliminating the need to directly survey large areas. Currently, range and habitat suitability models for ungulates and clouded leopards on Borneo have been limited to regional assessments or coarse models on a landscape-scale based on elevation, canopy cover and human-altered landscapes (Hearn et al. 2016, 2018b, 2019, Macdonald et al. 2018, Kaszta et al. 2019). My findings of forest type preference should be applied to refine current estimates of range and the remaining habitat across Borneo. Classifying forested areas in Borneo by forest type would increase the accuracy of these estimates. This would most likely lead to a reduction in range estimates and remaining suitable habitat. With little research informing current models in Borneo, estimates likely overestimate the extent of remaining suitable habitat which could have serious consequences for threatened populations. Further modelling is required to incorporate my findings into predictions of habitat suitability and range across Borneo.

\section{Baseline for further research}

My evaluation of the current habitat use of ungulates and the clouded leopards at CPRS provides a baseline and steppingstone to further research that is needed to inform effective conservation. Long- 
term research is needed to identify any changes in habitat use paired with abundance estimates over time to better quantify species' response to threats. Climate change, land-use conversion, and poaching threaten to push ungulates and clouded leopards out of low-lying forests, shifting their ranges up an elevational gradient and further compressing distributions into less suitable habitats. Land-use conversion disproportionately affects lowland forests (Curran et al. 2004) and access into forests by poachers is facilitated by logging roads and proximity to forest edge (Laurance et al. 2006, Mohd-Azlan \& Lading 2006). My research provides a snapshot of current habitat use of ungulates and clouded leopards in GPNP, however, the reported distributions function as a baseline to be compared over time and among populations. Additionally, my research has uncovered avenues that merit further investigation regarding the movement patterns of bearded pigs and clouded leopards across the landscape. The association of both bearded pigs and clouded leopards with fruiting across CPRS was evident in my research, however, radio-collaring could be used to solidify this finding and better understand this relationship. Furthermore, I was unable to evaluate differences in habitat use or detection between male and female clouded leopards but a rising levels of evidence indicates sexdependant differences in habitat use and prey selection (Cheyne \& Macdonald 2011, Wilting et al. 2012, Hearn et al. 2018b). Substantially higher detection rates of male clouded leopards are creating a research base that may disproportionately describe male-specific findings and overlook insight on females vital to effective conservation. Lastly, my research demonstrates patterns of habitat partitioning between sympatric ungulate species and linked clouded leopard habitat use to bearded pig occurrence-shedding light on the previously understudied diets of these species. However, further research focusing on feeding ecology of clouded leopards is needed to compile comprehensive dietary assessments.

\section{Mast resources}

My research provides evidence of the bottom-up effects of mast-induced fluctuations in fruit availability having a permeating influence across trophic levels in a Bornean rainforest. Habitat and resource partitioning found amongst the ungulate species indicated the presence of different resource strategies. The mousedeer and muntjac species appear to differentially use specific forest types and did not follow spatiotemporal patterns of fruiting. In contrast, bearded pigs did not appear to differentiate among forest types. Instead, habitat use was closely tied to patterns of fruit availability, suggesting an ability to track resources across a large area. Large groups of bearded pigs, often containing over 100 individuals, have been described following mast events and travelling long-distances to arrive in a masting area 
(Curran \& Leighton 2000, Dove 1993, MacKinnon et al. 1996). This strategy of utilizing the concentrated and short-lived resources from fruiting events has trade-offs as the timing of such events can be irregular. In the past, long inter-mast periods have resulted in populations of bearded pigs and sun bears (Helarctos malayanus), who are similarly associated with mast resources, becoming emaciated and numerous individuals were found to have died from apparent starvation (Wong et al. 2005). Dependence on a variable resource leaves species highly vulnerable to disruptions in fruiting patterns.

The bottom-up influence of fruit availability is not limited to consumers like bearded pigs or sun bear. The link between bearded pig occurrence and clouded leopard habitat use that I outline in Chapter 3 describes the mechanism by which the top carnivore is influenced by cycles of fruit availability. Furthermore, bearded pig reproduction has been linked to significant mast events that provide enough resources to support lactating females (Oliver 1993, Hancock 2005, Luskin \& Ke 2017). The abundance of available prey as bearded pigs and their young coinciding with fruiting events creates an indirect association between clouded leopards and fruit availability.

The dependence on mast-fruiting resources, either directly (bearded pigs) or indirectly (clouded leopards), leaves species increasingly vulnerable as climate change and human disturbance (i.e. logging) impact the timing and availability of mast resources. Although the timing and triggering of mast-fruiting events are not fully understood, the El Nino Southern Oscillation (ENSO) cycles are thought to be a significant factor (Wich \& Schaik 2000). A growing pool of evidence suggests that climate change is altering the nature of El Nino events (Yeh et al. 2009), their frequency (Trenberth \& Hoar 1997), and subsequently affects fruiting (Chapman et al. 2005). Additionally, climate change and reduction in forest cover (McAlpine et al. 2018) are resulting in a drier hotter climate in Borneo that has led to an increase in forest fires decimating remaining habitats (Goldammer \& Seibert 1990). A further nail in the coffin is the ongoing deforestation occurring in Borneo due to logging and conversion into plantations (Curran et al. 2004, Hansen et al. 2013, Ocampo-Penuela et al. 2020). In combination, these threats are reducing the extent of remaining dipterocarp forests in Borneo and altering the timing of fruiting events. Increasingly arhythmic mast-events in diminishing forest fragments are eliminating key resources that could trigger cascading effects throughout rainforest ecosystems. Reduced and unpredictable fruiting resources could have dire consequences for both bearded pigs and the clouded leopards - as well as innumerable other species for whom the link to mast-fruiting has not yet been identified. The findings of my research underscore the need for more rigorous protection of the dipterocarp forests in Borneo, further research expanding our understanding of the vulnerable mast-fruiting forest communities, and 
refinement of estimates of species' range and suitable habitats integrating information from ongoing research into efficacious conservation plans. 


\section{REFERENCES}

Ahlering, M.A., C.L. Merkord (2016). Cattle grazing and grassland birds in the northern tallgrass prairie. The Journal of Wildlife Management. 80(4):643-654.

Ahrestani, F.S., M. Sankaran (2016). The ecology of large herbivores in South and Southeast Asia. Ecological Studies (Analysis and Synthesis), vol 225. Springer, Dordrecht.

Ahumada, J.A., C.E.F. Silva, K. Gajapersad, C. Hallam, J. Hurtado, E. Martin, A. McWilliam, B. Mugerwa, T. O’Brien, F. Rovero, D. Sheil, W.R. Spironello, N. Winarni, S. J. Andelman (2011). Community structure and diversity of tropical forest mammals: data from a global camera trap network. Philosophical Transactions of the Royal Society B 366(1578).

Ahumada, J.A., J. Hurtado, D. Lizcano (2013). Monitoring the status and trends of tropical forest terrestrial vertebrate communities from camera trap data: a tool for conservation. PIOS ONE, 8(9): e73707.

Alamgir, M., M.J. Campbell, S. Sloan, A. Suhardiman, J. Supriatna, W.F. Laurance (2019). High-risk infrastructure projects pose imminent threats to forests in Indonesian Borneo. Scientific Reports 9(140).

Albert, A., A.G. Auffret, E. Cosyns, S.A.O. Cousins, B. D’hondt, C. Eichberg, A.E. Eycott, T. Heinken, M. Hoffman, B. Jaroszewicz, J.E. Malo, A. Marell, M. Mouissie, R.J. Pakeman, M. Picard, J. Plue, P. Poschlod, S. Provoost, K.A. Schulze, C. Baltzinger (2015). Seed dispersal by ungulates as an ecological filter: a trait-based meta-analysis. Oikos 124(9):1109-1120.

Albrecht, M., N.J. Gotelli (2001). Spatial and temporal niche partitioning in grassland ants. Oecologia 126:134-141.

Allen, B.L., L.R. Allen, H. Andren, G. Ballard, L. Boitani, R.M. Engeman, P.J.S. Fleming, A.T. Ford, P.M. Haswell, R. Kowalczyk, J.D.C. Linnell, L.D. Mench, D.M. Parker (2017). Can we save large carnivores without losing large carnivore science? Food Webs 12:64-75. 
Allen, M.L., H.U. Wittmer, E. Setiawan, S. Jaffe, and A.J. Marshall (2016). Scent marking in Sunda clouded leopard (Neofelis diardi): novel observations close a key gap in understanding felid communication behaviors. Scientific Reports 6, 35433.

Anderson, D., K. Burnham (2002). Avoiding Pitfalls When Using Information-Theoretic Methods. The Journal of Wildlife Management 66(3), 912-918.

Anile, S., S. Devillard (2016). Study design and body mass influence RAls from camera trap studies: evidence from the Felidae. Animal Conservation, 19(1):35-45.

Ashton, P.S., T.J. Givnish, S. Appanah (1988). Staggered flowering in the dipterocarpaceae: new insights into floral induction and the evolution of mast fruiting in the aseasonal tropics. The American Naturalist. 132(1):44-66.

Austin, K.G., M. Gonzalez-Roglich, D. Schaffer-Smith, A.M. Schwantes, J.J. Swenson (2017). Trends in size of tropical deforestation events signal increasing dominance of industrial-scale drivers. Environmental Research Letters 12(5): e079601.

Barlow, J., F. França, T.A. Gardner, C.C. Hicks, G.D. Lennox, E. Berenguer, L. Castello, E.P. Economo, J. Ferreira, B. Guenard, C.G. Leal, V. Isaac, A.C. Lees, C.L. Parr, S.K. Wilson, P.J. Young, N.A.J. Graham (2018). The future of hyperdiverse tropical ecosystems. Nature 559, 517-526.

Barrette, C. (1977). Some aspects of the behaviour of muntjacs in Wilpattu National Park. Mammalia 41(1):1-34.

Beccari, O. (1904). Wanderings in the great forests of Borneo travels and researches of a naturalist in Sarawak. London, Constable.

Bell, R. (1970). The use of the herb layer by grazing ungulates in the Serengeti. In 'Animal Populations in Relation to Their Food Resources'. (Ed. A. Watson.) pp. 111-124.

Bell, R. (1971). A Grazing Ecosystem in the Serengeti. Scientific American. 225(1): 86-93.

Bernard, H., A.H. Ahmad, J. Brodie, A.J. Giordano, M. Lakim, R. Amat, S. Koh Pei Hue, L. Shan Khee, D. Lim-Hasegawa, Y. Sau Wai, and W. Sinun (2013). Camera trapping survey of mammas in and 
around Imbak Canyon conservation area in Sabah, Malaysian Borneo. The Raffles Bulletin of Zoology 61(2):861-870.

Berry, N.J., O.L. Phillips, S.L. Lewis, J.K. Hill, D.P. Edwards, N.B. Tawatao, N. Ahmad, D. Magintan, C.V. Khen, M. Maryati, R.C. Ong, K.C. Hamer (2010). The high value of logged tropical forests: lessons from northern Borneo. Biodiversity and Conservation 19: 985-997.

Blate, G.M., D.R. Peart, M. Leighton (1998). Post-dispersal predation on isolated seeds: A comparative study of 40 tree species in a Southeast Asian rainforest. Oikos 82 (3): 522-538.

Blundel, A.G (1996). A preliminary checklist of mammals at Cabang Panti Research Station, Gunung Palung National Park, West Kalimantan. Tropical Biodiversity 3(3):251-259.

Bodmer, R.E., R.J. Mather, and D.J. Chivers (1991). Rain forests of central Borneo--threatened by modern development. Oryx 25(1):21-26

Bogdziewicz, M., R. Zwolak, E, E. Crone (2016). How do vertebrates respond to mast seeding? Oikos, 125(3):300-307.

Brodie, J.F. (2009). Is research effort allocated efficiently for conservation? Felidae as a global case study. Biodiversity and Conservation.18:2927-2939.

Brodie, J.F., A.J. Giordano (2013). Lack of trophic release with large mammal predators and prey in Borneo. Biological Conservation. 163: 58-67.

Brodie, J.F., A.J. Giordano, E.F. Zipkin, H. Bernard, J. Mohd-Azlan (2014). Correlation and persistence of hunting and logging impacts on tropical rainforest mammals. Conservation Biology 29(1):110-121.

Brookfield, H., Y. Byron (1990). Deforestation and timber extraction in Borneo and the Malay Peninsula: the record since 1965. Global Environmental Change, 1(1): 42-56.

Buij, R., McShea, W. J., Campbell, P., Lee, M. E., Dallmeier, F., Guimondou, S., J.D. Nichols (2007). Patchoccupancy models indicate human activity as major determinant of forest elephant Loxodonta cyclotis seasonal distribution in an industrial corridor in Gabon. Biological Conservation. 135(2): 189-201. 
Burivalova, Z., E.T. Game, B. Wahyudi, Ruslandi, M. Rifqi, E. MacDonald, S. Cushman, M. Voigt, S. Wich, D.S. Wilcove (2020). Does biodiversity benefit when the logging stops? An analysis of conservation risks and opportunities in active versus inactive logging concessions in Borneo. Biological Conservation 241:108369.

Burnett, R.D., L. J. Roberts (2015). A quantitative evaluation of the conservation umbrella of spotted owl management areas in the Sierra Nevada. PLOS ONE 10(4): e0123778.

Burnham, K. P., D.R. Anderson (2002). A practical information-theoretic approach. Model selection and multimodel inference, 2nd ed. Springer, New York.

Burton, A.C., M.K. Sam, C. Balangtaa, J.S. Brashares (2012). Hierarchical multi-species modeling of carnivore responses to hunting, habitat and prey in a West African protected area. PLOS ONE 7(5): e38007.

Burton, A.C., E. Neilson, D. Moreira, A. Ladle, R. Steenweg, J.T. Fisher, E. Bayne, S. Boutin (2015). Wildlife camera trapping: a review and recommendations for linking surveys to ecological processes. Journal of Applied Ecology 52: 675-685.

Caldecott, J., \& Caldecott, S. (1985). A horde of pork. New Scientist. 107(1469): 32-35.

Caldecott, J. (1991). Eruptions and migrations of bearded pig populations. Bongo 18:233-243.

Cannon, C.H., L.M. Curran, A.J. Marshall, M. Leighton (2007a). Long-term reproductive behaviour of woody plants across seven Bornean forest types in the Gunung Palung National Park (Indonesia): Suprannual synchrony, temporal productivity and fruiting diversity. Ecology Letters 10:956-969.

Canon, C.H., L.M. Curran, A.J. Marshall, M. Leighton (2007b). Beyond mast-fruiting events: community asynchrony and individual dormancy dominate woody plant reproductive behavior across seven Bornean forest types. Current Science 93(11):1558-1566.

Cannon, C.H., M. Leighton (2004). Tree species distributions across five habitats in a Bornean rain forest. Journal of Vegetation Science 15(2):257-266.

Carbone, C., G.M. Mace, S.C. Roberts, D.W. Macdonald (1999). Energetic constraints on the diet of terrestrial carnivores. Nature 402:286-288. 
Chapman, C., L.J. Chapman, T. Struhsaker, A. Zanne, C. Clark, J. Poulsen (2005). A Long-Term Evaluation of Fruiting Phenology: Importance of Climate Change. Journal of Tropical Ecology, 21(1): 31-45

Cheyne, S.M., S.J. Husson, R.J. Chadwick, and D.W. Macdonald (2010). Diversity and activity of small carnivores of the Sabangau peat-swamp forest, Indonesian Borneo. Small Carnivore Conservation 43:1-7.

Cheyne, S.M., D.W. Macdonald (2011). Wild felid diversity and activity patterns in Sabangau peat-swamp forest, Indonesian Borneo. Oryx 45(1):119-124.

Cheyne, S. M., W.J. Sastramidjaja, Muhalir, Y. Rayadin, D.W. Macdonald (2016). Mammalian communities as indicators of disturbance across Indonesian Borneo. Global Ecology and Conservation 7:157-173.

Christiansen, P. (2006). Sabertooth characters in the clouded leopard (Neofelis nebulosa Griffiths 1821). Journal of Morphology, 267(10):1186-1198.

Christiansen, P. (2007). Canine morphology in larger Felidae: implications for feeding ecology. Biological Journal of the Linnean Society 91(4):573-592.

Christiansen, P. (2008). Evolutionary convergence of primitive sabretooth craniomandibular morphology: the clouded leopard (Neofelis nebulosa) and Paramachairodus Ogygia compared. Journal of Mammalian Evolution 15:155-179.

Ciuti, S., J.M. Northrup, T.B. Muhly, S. Simi, M. Musiani, J.A. Pitt, \& M.S. Boyce (2012a). Effects of humans on behaviour of wildlife exceed those of natural predators in a landscape of fear. PloS ONE. 7(11): e50611.

Ciuti, S., T.B. Muhly, D.G. Paton, A.D. McDevitt, M. Musiani, M.S. Boyce (2012b). Human selection of elk behavioral traits in a landscape of fear. Proceedings of the Royal Society B. 279:4407-4416.

Clink, D.J., C. Dillis, K.L. Fellen, L. Beaudrot, A.J. Marshall (2017). Dietary diversity, feeding selectivity, and responses to fruit scarcity of two sympatric Bornean primates (Hylobates albibarbis and Presbytis rubicunda rubida). PLOS ONE 12(3): e0173369. 
Codron, D., J.A. Lee-Thorp, M. Sponheimer, J. Codron, D. De Ruiter, J.S. Brink (2007). Significance of diet type and diet quality for ecological diversity of African ungulates. Journal of Animal Ecology, 76(3), 526-537.

Corlett, R.T. (2007). The impact of hunting on the mammalian fauna of tropical Asian forests. bioTropica 39(3):292-303.

Corley, R. H. V. (2009). How much palm oil do we need? Environ. Sci. Policy 12:134-139

Curran, L. M. (1995). The ecology and evolution of mast-fruiting in Bornean Dipterocarpaceae: A general ectomycorrhizal theory. PhD. 1994. Princeton University

Curran, L.M, M. Leighton (2000). Vertebrate responses to spatiotemporal variation in seed production of mast-fruiting Dipterocarpaceae. Ecological Monographs. 70(1): 101-128.

Curran, L.M., S.N. Trigg, A.K. McDonald, D. Astiani, Y.M. Hardiono, P. Siregar, I. Caniago, E. Kasischke (2004). Lowland forest loss in protected areas of Indonesian Borneo. Science, 303(5660):10001003.

Cushman, S.A., E.A. Macdonald, E.L. Landguth, Y. Malhi, D.W. Macdonald (2017). Multiple-scale prediction of forest loss risk across Borneo. Landscape Ecology 32: 1581-1598.

D'Cruze, N., D.W. Macdonald (2015). Clouded in mystery: the global trade in clouded leopards. Biodiversity Conservation 24(14): 3505-3526.

de Bruyn, M., B. Stelbrink, R.J. Morley, R. Hall, G.R. Carvalho, C.H. Cannon, G. van den Bergh, E. Meijaard, I. Metcalfe, L. Boitani, L. Maiorano, R. Shoup, T. von Rintelen (2014). Borneo and Indochina are major evolutionary hotspots for Southeast Asian biodiversity. Systematic Biology 63(6):879-901.

Dillis, C., L. Beaudrot, K.L. Fellen, D.J. Clink, H.U. Wittmer, A.J. Marshall (2015). Modelling the ecological and phenological predictors of fruit consumption by gibbons (Hylobates albibarbis). Biotropica 47(1):85-93.

Dirzo, R., H.S. Young, M. Galetti, G. Ceballos, N.J.B. Isaac, B. Collen (2014). Defaunation in the Anthropocene. Science 345(6195):401-406. 
Dove, M. R. (1993). The responses of Dayak and bearded pig to mast-fruiting in Kalimantan: An analysis of nature-culture analogies. Man and the Biosphere Series. 13:113-113.

Edelman A, A. Gelding, E. Konovalov, R. McComiskie, A. Penny, N. Roberts, S. Templeman, D. Trewin,M. Ziembicki,B. Trewin,R. Cortlet,J. Hemingway,J. Isaac, S. Turton (2014). State of the Tropics 2014 report. Report. Cairns, James Cook University.

Edwards, S., S. Cooper, K. Uiseb, M. Hayward, B. Watcher, J. Melzheimer (2018). Making the most of bycatch data: Assessing the feasibility of utilising non-target camera trap data for occupancy modelling of a large felid. African Journal of Ecology 56(4):885-894.

Fawzi, N.I, V.N. Husna, J.A. Helms (2018). Measuring deforestation using remote sensing and its implication for conservation in Gunung Palung National Park, West Kalimantan, Indonesia. IOP Conf. Series: Earth and Environmental Sciences 149: 012038.

Felton, A.M., L.M. Engstrom, A. Felton, C.D. Knott (2003). Orangutan population density, forest structure and fruit availability in hand-logged and unlogged peat swamp forests in West Kalimantan, Indonesia. Biological Conservation 114(1):91-101.

Fragoso, J.M.V., T. Levi, L.F.B. Oliveira, J.B. Luzar, H. Overman, J.M. Read, K.M. Silvius (2016). Line transect surveys underdetect terrestrial mammals: Implications for the sustainability of subsidence hunting. PLOS ONE 11(4): e0152659.

Fredriksson, G.M., L.S. Danielsen, J.E. Swenson (2006). Impacts of EL Nino related drought and forest fires on sun bear fruit resources in lowland dipterocarp forest of East Borneo. Biodiversity and Conservation. 16: 1823-1838.

Freeman, P. W., C.A Lemen (2007). The trade-off between tooth strength and tooth penetration: predicting optimal shape of canine teeth. Journal of Zoology, 273(3):273-280.

Fritz, H., P. Duncan, I.J. Gordon, A.W. Illius (2002). Megaherbivores influence trophic guilds structure in African ungulate communities. Community Ecology 131:620-625.

Fuller, A. K., D. W. Linden, J.A. Royle (2016). Management decision making for fisher populations informed by occupancy modelling. Wildlife Management 80(5):794-802. 
Fuller, D.O., T.C. Jessup, A. Salim (2004). Loss of forest cover in Kalimantan, Indonesia, since 1997-1998 El Nino. Conservation Biology 18(1):249-254.

Galvez, N., G. Guillera-Arroita, B.J.T. Morgan, Z.G. Davies (2016). Cost-efficient effort allocation for camera-trap occupancy surveys of mammals. Biological Conservation. 204(B):350-359.

Garnier, S. (2018). Viridis: Default Color Maps from 'matplotlib'. R package version 0.5.1. https://CRAN.R-project.org/package=viridis

Gaveau, D.L.A., D. Sheil, Husnayaen, M.A. Salim, S. Arjasakusuma, M. Ancrenaz, P. Pacheco, E. Meijaard (2016). Rapid conversions and avoided deforestation: examining four decades of industrial plantation expansion in Borneo. Scientific Reports 6: e32017.

Gaveau, D.L.A, S. Sloan, E. Molidena, H. Yaen, D. Sheil, N.K. Abram, M. Ancrenaz, R. Nasi, M. Quinones, N. Wielaard, E. Meijaard (2014). Four decades of forest persistence, clearance and Logging on Borneo. PLoS ONE 9(7): e101654.

Geist, V. (1974). On the Relationship of Social Evolution and Ecology in Ungulates. American Zoologist. 14(1):205-220.

Giam, X., J.D. Olden (2016). Quantifying variable importance in a multimodel inference framework. Methods in Ecology and Evolution 7: 388-397.

Goldammer J.G., Seibert B. (1990) The Impact of Droughts and Forest Fires on Tropical Lowland Rain Forest of East Kalimantan. In: Goldammer J.G. (eds) Fire in the Tropical Biota. Ecological Studies (Analysis and Synthesis), vol 84. Springer, Berlin, Heidelberg

Gordon, C.H., A.M.E. Stewart (2007). The use of logging roads by clouded-leopards. CAT News 47:12-13.

Gosselink, T., T. Van Deelen, R. Warner, M. Joselyn (2003). Temporal Habitat Partitioning and Spatial Use of Coyotes and Red Foxes in East-Central Illinois. The Journal of Wildlife Management, 67(1):90103.

Gould, M.J., W.R. Gould, J.W. Cain III, G.W. Roemer (2019). Validating the performance of occupancy models for estimating habitat use and predicting the distribution of highly mobile-species: A case study using the American black bear. Biological Conservation 234:28-36. 
Granados, A., H. Bernard, J.F. Brodie (2019). The influence of logging on vertebrate responses to mast fruiting. Journal of Animal Ecology 88(6):892-902.

Griffiths, M. and C.P. Van Schaik (1993). The impact of human traffic on the abundance and activity patterns of Sumatran rainforest wildlife. Conservation Biology 7(3):623-626.

Hampton, S.E. (2004). Habitat overlap of enemies: temporal patterns and the role of spatial complexity. Oecologia 138:475-484.

Hancock, P.A., E.J. Milner-Gulland, M.J. Keeling (2005). An individual based model of bearded pig abundance. Ecological Modelling 181(2-3):123-137.

Hansen, M.C., P.V. Potapov, R. Moore, M. Hancher, S.A. Turubanova, A. Tyukavina, D. Thau, S.V. Steman, S.J. Goetz, T.R. Loveland, A. Kommareddy, A. Egorov, L. Chini, C.O. Jusice, J.R.G. Townshend (2013). High-resolution global maps of $21^{\text {st }}$ century forest cover change. Science 342(6160):850853.

Hanya, G., H. Bernard (2012). Fallback foods of red leaf monkeys (Presbytis rubicunda) in Danum valley, Borneo.

Harmsen, B.J., R.J. Foster, S. Silver, L. Ostro, C.P. Doncaster (2010). Differential use of trails by forest mammals and the implications for camera trap studies: a case study from Belize. Biotropica 42(1):126-133.

Hawkins, B.A. (2001). Ecology's oldest pattern? Trend's in Ecology \& Evolution 16(8):470.

Hearn, A.J., J. Ross, D. Pamin, H. Bernard, L. Hunter, D.W. Macdonald (2013). Insights into the spatial and temporal ecology of the Sunda clouded leopard Neofelis diardi. The Raffles Bulletin of Zoology 61(2):871-875.

Hearn, A.J., J. Ross, D.W. Macdonald, G. Bolongon, S.M. Cheyne, A. Mohamed, H. Samejima, J.F. Brodie, A. Giordano, R. Alfred, et al. (2016). Predicted distribution of the Sunda clouded leopard Neofelis diardi (Mammalia: Carnivora: Felidae) on Borneo. Raffles Bulletin of Zoology, S33: 149-156. 
Hearn, A.J., J. Ross, H. Bernard, S.A. Bakar, B. Goossens, L.T.B. Hunter, D.W. Macdonald (2017). Responses of Sunda clouded leopard Neofelis diardi population density to anthropogenic disturbance: refining estimates of its conservation status in Sabah. Oryx 53(4):643-653.

Hearn, A.J., S.A. Cushman, B. Goossens, E. Macdonald, J. Ross, L.T.B. Hunter, N.K. Abram, D.W. Macdonald (2018a). Evaluating scenarios of landscape change for Sunda clouded leopard connectivity in a human dominated landscape. Biological Conservation 222:232-240.

Hearn, A.J., S.A. Cushman, J. Ross, B. Goossens, L.T.B. Hunter, D.W. Macdonald (2018b). Spatio-temporal ecology of sympatric felids on Borneo. Evidence for resource partitioning? PLOS ONE 13(7): e0200828.

Hearn, A.J., J. Ross, H. Bernard, S.A. Bakar, B. Goossens, L.T.B. Hunter, D.W. Macdonald (2019). Responses of Sunda clouded leopard Neofelis diardi population density to anthropogenic disturbance: refining estimates of its conservation status in Sabah. Oryx 53(4):643-653.

Heithaus, M. R. (2001). Habitat selection by predators and prey in communities with asymmetrical intraguild predation. Oikos, 92(3):542-554.

Hessen, M., S. Rogahn, J.Ostner, O. Schulke (2013). Food abundance affects energy intake and reproduction in frugivorous female Assamese macaques. Behavioral Ecology and Sociobiology 67: 1053-1066.

Heydon, M.J (1994). The ecology and management of rain forest ungulates in Sabah, Malaysia: Implications of forest disturbance. Institution of Tropical Biology.

Hill, H \& T. Shiraishi (2007). Indonesia after the Asian Crisis. Asian Economic Policy Review 2(1):123-141.

Hiller, M.A., B.C. Jarvis, H. Lisa, L.J. Paulson, E.H.B. Pollard, S.A. Stanley (2004). Recent trends in illegal logging and a brief discussion of their causes. Journal of Sustainable Forestry 19(1-3):181-212.

Holt, R. (1987). On the Relation between Niche Overlap and Competition: The Effect of Incommensurable Niche Dimensions. Oikos 48(1):110-114. 
Hopcraft, J.G.C., T.M. Anderson, S. Perez-Vila, E. Mayemba, H. Olff (2012). Body size and the division of niche space: food and predation differentially shape the distribution of Serengeti grazers. Animal Ecology 81(1):201-213.

Hutchinson, G. E. (1957). Cold Spring Harbor Symposium on Quantitative Biology. Concluding Remarks.

Hutchinson, G. E. (1959). Homage to Santa Rosalia or why are there so many kinds of animals? The American Naturalist, 93(870):145-159.

IUCN (2020). The IUCN Red list of threatened species. Version 2020-1. https://www.iucnredlist.org downloaded April 5, 2020.

Janzen, D. H. (1971). Seed predation by animals. Annual Review of Ecology and Systematics 2(1):465492.

Jarman, P. (1974). The social organisation of antelope in relation to their ecology. Behaviour 48(1-4): 215-267.

Jensen, K.A., I. Das (2008). Cultural exploitation of freshwater turtles in Sarawak, Malaysian Borneo. Chelonian Conservation and Biology 7(2):281-285.

Johnson, A.E., C.D. Knott, B. Pamungkas, M. Pasaribu, A.J. Marshall (2005). A survey of the orangutan (Pongo pygmaeus wurmbii) population in and around Gunung Palung National Park, West Kalimantan, Indonesia based on nest counts. Biological Conservation 121(4):495-507.

Kanamori, T., N. Kuze, H. Bernard, T.P. Malim, S. Kohshima (2017). Fluctuations of population density in Bornean orangutans (Pongo pygmaeus morio) related to fruit availability in the Danum Valley, Sabah, Malaysia: a 10-year record including two mast fruitings and three other peak fruitings. Primates 58:225-235.

Kaszta, Z., S.A. Cushman, A.J. Hearn, D. Burnham, E.A. Macdonald, B. Goossens, S.K.S.S. Nathan, D.W. Macdonald (2019). Integrating Sunda clouded leopard (Neofelis diardi) conservation into development and restoration planning in Sabah (Borneo). Biological Conservation. 235:63-76.

Kellner, K.F., R.K. Swihart (2014) Accounting for imperfect detection in ecology: a quantitative review. PLOS ONE 9(10): p. e111436. 
Kerr, J.T., T.V. Burkey (2002). Endemism, diversity, and the threat of tropical moist forest extinctions. Biodiversity \& Conservation 11:695-704.

Kimura, K., T. Yumoto, K. Kikuzawa (2001). Fruiting Phenology of Fleshy-Fruited Plants and Seasonal Dynamics of Frugivorous Birds in Four Vegetation Zones on Mt. Kinabalu, Borneo. Journal of Tropical Ecology, 17(6):833-858.

Kimura, K. (2003). A tropical montane forest in Borneo as a source of fruit supply for frugivorous birds. Global Environmental Research 7(1):113-122.

Knott, C.D. (1998). Changes in Orangutan caloric intake, energy balance, and ketones in response to fluctuations fruit availability.

Knott, C.D. (1999). Reproductive, physiological and behavioural responses of orangutans in Borneo to fluctuations in food availability. Doctoral Dissertation, Harvard University.

Kolowski, J.M., T.D. Forrester (2017). Camera trap placement and the potential for bias due to trails and other features. PLoS ONE 12(10): e0186679.

Krebs, C.J. (1972). The experimental analysis of distribution and abundance. Ecology. New York, Harper and Row. 1-14.

Kusuda, S., I. Adachi, K. Fujioka, M. Nakamura, N. Amano-Hanzawa, N. Goto, S. Furuhashi, O. Doi (2013). Reproductive characteristics of female lesser mouse deer (Tragulus javanicus) based on fecal progestogens and breeding records. Animal Reproductive Science 137(1-2):69-73.

Laman, T.G. (1996). Rain forest bird diversity in Gunung Palung National Park, West Kalimantan, Indonesia. Tropical Biodiversity 3: 281-296.

Laundré, J. W., Hernández, L., \& Altendorf, K. B. (2001). Wolves, elk, and bison: re-establishing the" landscape of fear" in Yellowstone National Park, USA. Canadian Journal of Zoology. 79(8):14011409.

Laurance, W. F., B. M. Croes, L. Tchignoumba, S. A. Lahm, A. Alonso, M. E. Lee, P. Campbell, C. Ondzeano (2006). Impacts of roads and hunting on central African rainforest mammals. Conservation Biology 4: 1251-1261. 
Lebreton, J. D., K.P. Burnham, J. Clobert, D.R. Anderson (1992). Modeling survival and testing biological hypotheses using marked animals: a unified approach with case studies. Ecological Monographs. 62(1):67-118.

Lechowicz, M.J. (1995). Seasonality of flowering and fruiting in temperate forest trees. Canadian Journal of Botany 73(2):175-182.

Levey, D. J. (1988). Spatial and temporal variation in Costa Rican fruit and fruit-eating bird abundance. Ecological Monographs, 58(4):251-269.

Lewis, J.S., K. A. Logan, M.W. Alldredge, L.L. Bailey, S. VandeWoude, K.R. Crooks (2015). The effects of urbanization on population density, occupancy, and detection probability of wild felids. Ecological Applications 25(7):1880-1895.

Li, X., W.V. Bleisch, X. Jiang (2018). Using large spatial scale camera trap data and hierarchical occupancy models to evaluate species richness and occupancy of rare and elusive wildlife communities in southwest China. Diversity and Distributions. 24(11):1560-1572.

Lima, S. L., \& Dill, L. M. (1990). Behavioral decisions made under the risk of predation: a review and prospectus. Canadian Journal of Zoology. 68(4):619-640.

Linden, D.W., G.J. Roloff (2013). Retained structures and bird communities in clearcut forests of the pacific Northwest, USA. Forest Ecology \& Management. 310: 1045-1056.

Loreau, M., C. De Mazancourt (2013). Biodiversity and ecosystem stability: a synthesis of underlying mechanisms. Ecology Letters, 16:106-115.

Luskin, M. S., A. Ke (2017). Bearded pig Sus barbatus (Müller, 1838). Ecology, conservation and management of wild pigs and peccaries, 175-183.

Macdonald, E.A., S.A. Cushman, E.L. Landguth, A.J. Hearn, Y. Malhi, D.W. Macdonald (2018). Simulating impacts of rapid forest loss on population size, connectivity and genetic diversity of Sunda clouded leopards (Neofelis diardi) in Borneo. PLoS ONE 13(9): e0196974.

Mackenzie, D.I., J.D. Nichols, G.B. Lachman, S. Droege, J.A. Royle, C.A. Langtimm (2002). Estimating site occupancy rates when detection probabilities are less than one. Ecology 83(8):2248-2255. 
Mackenzie, D.I., L.L. Bailey (2004). Investigating species co-occurrence patterns when species are detected imperfectly. British Ecological Society 73(3):546-555.

Mackenzie, D.I., J. Hines (2018). RPresence: R interface for program PRESENCE. R package version 2.12.31.

Mackenzie, D.I., J.D. Nichols, J.E. Hines, M.G. Knutson, A.D. Franklin (2003). Estimating site occupancy, colonization and local extinction probabilities when a species is not detected with certainty. Ecology 84: 2200-2207.

MacKenzie D.I., J.D. Nichols, J.A. Royle, K.H. Pollock, LL. Bailey, J.E. Hines (2006) Occupancy estimation and modeling: Inferring patterns and dynamics of species occurrence. San Diego: Elsevier. 344 p.

MacKinnon, K., G. Hatta, A. Mangalik, H. Halim (1996). The ecology of Kalimantan (Vol. 3). Oxford University Press.

Malins, C. (2017). Driving Deforestation: The Impact of Expanding Palm Oil Demand through Biofuel Policy. London: Rainforest Foundation Norway and Cerulogy.

Marshall, A.J. (2009). Are montane forests demographic sinks for Bornean white-bearded gibbons Hylobates albibarbis. Biotropica 41(2):257-267.

Marshall, A. J., M. Leighton (2006). How does food availability limit the population density of whitebearded gibbons? Feeding ecology in apes and other primates, 48, 313.

Marshall A.J., C.H. Cannon, M. Leighton (2009a). Competition and Niche Overlap Between Gibbons (Hylobates albibarbis) and Other Frugivorous Vertebrates in Gunung Palung National Park, West Kalimantan, Indonesia. In: Whittaker D., Lappan S. (eds) The Gibbons. Developments in Primatology: Progress and Prospects. Springer, New York, NY

Marshall, A.J., C.M. Boyko, K.L. Feilen, R.H. Boyko, M. Leighton (2009b). Defining fallback foods and assessing their importance in primate ecology and evolution. Physical Anthropology. 140(4):603614. 
Marshall, A.J., L. Beaudrot, H.U. Wittmer (2014). Responses of primates and other frugivorous vertebrates to plant resource variability over space and time at Gunung Palung National Park. International Journal of Primatology 34: 1178-1201.

Marshall, A.J., Nardiyono, L.M. Engstrom, B. Pamungkas, J. Palapa, E. Meijaard, S.A. Stanley (2006). The blowgun is mightier than the chainsaw in determining population density of Bornean orangutans (Pongo pygmaeus morio) in the forests of East Kalimantan. Biological Conservation 129(4):566578.

Mathai, J., D. Jathanna, J.W. Duckworth (2013). How useful are transect surveys for studying carnivores in the tropical rainforests of Borneo? The Raffles Bulletin of Zoology 28: 9-20.

Mathai, J., J. Hon, N. Juat, A. Peter, M. Gumal (2010). Small carnivores in a logging concession in the Upper Baram, Sarawak, Borneo. Small Carnivore Conservation 42: 1-9.

Mathai, J., J.W. Duckworth, E. Meijaard, G. Fredriksson, J. Hon, et al. (2016). Carnivore conservation planning on Borneo: identifying key carnivore landscapes, research priorities and conservation interventions. Raffles Bulletin of Zoology: 186-217.

Matsubayashi, H., E. Bosi, S. Kohshima (2003). Activity and habitat use of lesser mouse-deer (Tragulus javanicus). Journal of Mammalogy 84(1):234-242.

McAlpine, C.A., A. Johnson, A. Salazar, J. Syktus, K. Wilson, E. Meijaard, L. Seabrook, P. Dargusch, H. Nordin, D. Sheil (2018). Forest loss and Borneo's climate. Environmental Research Letters 13(4).

Meek, P.D., G. Ballard, A. Clairidge, R. Kays, K. Moesby, T. O’Brien, A. O'Connell, J. Sanderson, D.E. Swann, M. Tobler, S. Townsend (2014). Recommended guiding principles for reporting on camera trapping research. Biodiversity and Conservation 23:2321-2343.

Meijaard, E., D. Sheil (2007). Is Wildlife research useful for wildlife conservation in the tropics? A review of Borneo with global implications. Biodiversity and Conservation 16: 3053-3065.

Meijaard, E., D. Sheil (2008). The persistence and conservation of Borneo's mammals in lowland rain forests managed for timber: observations, overviews and opportunities. Ecological Research, 23(21). 
Miettinen, J., C. Shi, S.C. Liew (2016). Land cover distribution in the peatlands of Peninsular Malaysia, Sumatra and Borneo in 2015 with changes since 1990. Global Ecology and Conservation 6:67-78.

Moegenburg, S.M., D.J. Levey (2003). Do frugivores respond to fruit harvest? An experimental study of short-term responses. Ecology 84(10):2600-2512.

Mohamed, A., H. Samejima, A. Wilting (2009). Records of five Bornean cat species from Deramakot Forest Reserve in Sabah, Malaysia. CATnews 51: 12-15.

Mohamed, A., R. Sollmann, S.T. Wong, J. Niedballa, J.F. Abrams, J. Kissling, A. Wilting (2019). Counting Sunda clouded leopards with confidence: incorporating individual heterogeneity in density estimates. Oryx: 1-10.

Mohd-Azlan, J., E. Lading (2006). Camera trapping and conservation in Lambir Hills National Park, Sarawak. Raffles Bulletin of Zoology 54:469-475.

Morais, A.R., M.N. Siqueira, P.Lemes, N.M. Maciel, P. De Marco, D. Brito (2013). Unravelling the conservation status of Data Deficient species. Biological Conservation 166:98-102,

Niedballa, J., R. Sollmann, A. Courtiol, A. Wilting (2016). camtrapR: an R package for efficient camera trap data management. Methods in Ecology and Evolution 7(12):1457-1462.

Noss, R.F., H.B. Quigley, M.G. Hornocker, T. Merrill, P.C. Pacquet (1996). Conservation biology and carnivore conservation in the Rocky Mountains. Conservation Biology 10(4):949-963.

Nowak, R. M., E.P. Walker (1999). Walker's Mammals of the World (Vol. 1). JHU press.

Nowak, K. (2012). Mangrove and Peat Swamp Forests: Refuge habitats for primate species and felids. Folia Primatol 83:361-376.

Nowak, K., A. Le Roux, S.A. Richards, C.P.J. Schijen, R.A. Hill (2014). Human observers impact habituated samago monkeys' perceived landscape of fear. Behavioral Ecology 25(5):1199-1204.

Ocampo-Penuela, N., J. Garcia-Ulloa, I. Kornecki, C.D. Philipson, J. Ghazoul (2020). Impacts of four decades of forest loss on vertebrate functional habitat on Borneo. Frontiers in Forests and Global Change 3(53). 
O'Connor, K.M., L.R. Nathan, M.R. Liberati, M.W. Tingley, J.C. Vokoun, T.A.G. Rittenhouse (2017).

Camera trap arrays improve detection probability of wildlife: investigating study design considerations using an empirical dataset. PLOS ONE 12(14): e0175684.

Oliver, W. L. (Ed.). (1993). Pigs, peccaries, and hippos: status survey and conservation action plan (Vol. 19). IUCN.

Oriol-Cotterill, A., M. Valeix, L.G. Frank, C. Riginos, and D.W. Macdonald (2015). Landscape of coexistence for terrestrial carnivores: the ecological consequences of being downgraded from ultimate to penultimate predator by humans. Oikos 124:1263-1273.

Ostfeld, R.S., F. Keesing (2000). Pulsed resources and community dynamics of consumers in terrestrial ecosystems. Trends in Ecology \& Evolution. 15(6):232-237.

Pantel,S., S.Y. Chin (2009). Pangolin capture and trade in Malaysia. Proceedings of the Workshop on Trade and Conservation of Pangolins Native to South and Southeast Asia, 30 June-2 July 2008, Singapore Zoo, Singapore.

Paoli, G.D., D.R. Peart, M. Leighton (2001). An ecological and economic assessment of the non-timber forest product Gaharu Wood in Gunung Palung National Park, West Kalimantan, Indonesia. Conservation Biology 15(6): 1721-1732.

Pfeffer, P., J. Caldecott (1986). The bearded pig (Sus barbatus) in East Kalimantan and Sarawak. Journal of the Malaysian Branch of the Royal Asiatic Society. 59(2): 81-100.

Phillips, Q. (2016). Phillips' field guide to the mammals of Borneo and their ecology: Sabah, Sarawak, Brunei, and Kalimantan. Vol. 105. Princeton University Press.

Pimm, S.L., C.N. Jenkins, R. Abell, T.M. Brooks, J.L. Gittleman, L.N. Joppa, P.H. Raven, C.M. Roberts, J.O. Sexton (2014). The biodiversity of species and their rates of extinction, distribution, and protection. Science 344(6187).

Pollock, K.H., J.D. Nichols, T.R. Simons, G.L.Farnsworth, L.L.Bailey, J.R. Sauer (2002).Large scale wildlife monitoring studies: statistical methods for design and analysis. Environmetrics, 13: 105-119. 
Proctor, S., C.J. McClean, J.K. Hill (2011). Protected areas of Borneo fail to protect forest landscapes with high habitat connectivity. Biodiversity and Conservation 20(2693).

Rabinowitz, A., P. Andau, P.P. Chai (1987). The clouded leopard in Malaysian Borneo. Oryx.21(2):107111.

Razgour, O., C. Korine, D. Saltz (2011). Does interspecific competition drive patterns of habitat use in desert bat communities? Oecologia 167:493-502.

R Core Team (2013). R: A language and environment for statistical computing. $R$ foundation for statistical computing, Vienna, Austria. URL http://www.R-project.org .

Redford, K. H. (1992). The empty forest. BioScience, 42(6): 412-422.

Resosudarmo, B. P. (Ed.). (2005). The politics and economics of Indonesia's natural resources. Institute of Southeast Asian Studies.

Rich, L.N., D.A.W. Miller, H.S. Robinson, J.W. McNutt, M.J. Kelly (2016). Using camera trapping and hierarchical occupancy modelling to evaluate the spatial ecology of an African mammal community. Journal of Applied Ecology 53(4):1225-1235.

Riginos, C. (2014). Climate and landscape of fear in an African savanna. Journal of Animal Ecology 84(1):124-133.

Rodriguez, J.P (2003). Challenges and opportunities for surveying and monitoring tropical biodiversity -a response to Danielsen et al. Oryx 37(4):411.

Rodriguez, J.P., L. Brotons, J. Bustamante, J. Seoane (2007). The Application of predictive modelling of species distribution to biodiversity conservation. Diversity and Distributions 13(3):243-251.

Rolland, J., M. Basille, E. Marboutin, J.M. Gaillard (2011). Comparing profile methods and site-occupancy modelling for the study of occurrence of an elusive species. European Journal of Wildlife Research. 57:1115-1118.

Ross, J., A.J. Hearn, P.J. Johnson, D.W. Macdonald (2013). Activity patterns and temporal avoidance by prey in response to Sunda clouded leopard predation risk. Journal of Zoology 290(2):96-106. 
Rovero, F., E. Martin, M. Rosa, J.A. Ahumada, D. Spitale (2014). Estimating species richness and modelling habitat preferences of tropical forest mammals from camera trap data. PLOS ONE 9(7): e103300.

Rovero, F., J. Ahumada (2017). The Tropical Ecology, Assessment and Monitoring (TEAM) network: an early warning system for tropical rain forests. Science of the Total Environment 574(1):914-923.

Royle, J.A., J.D. Nichols, M. Kery (2005). Modelling occurrence and abundance of species when detection is imperfect. Oikos 110(2):353-359.

Schmeller, D.S., R. Julliard, P.J. Bellingham, M. Bohm, N. Brummitt, A. Chiarucci, D. Couvet, S. Elmendorf, D. M. Forsyth, J.G. Moreno, R.D. Gregory, W.E. Magnusson, L.J. Martin, M.A. McGeoch, J.P. Mihoub, H.M. Pereira, V. Proenca, C.A.M. van Swaay, J. Belnap (2015). Towards a global terrestrial species monitoring program. Journal for Nature Conservation 25: 51-57.

Schoener, T. W. (1974). Resource partitioning in ecological communities. Science, 185(4145):27-39.

Shelford, R. W. C. (1917). A naturalist in Borneo. EP Dutton.

Sih, A. (1980). Optimal behavior: can foragers balance two conflicting demands? Science, 210(4473):1041-1043.

Sinclair, A.R.E., S. Mduma, J.S. Brashares (2003). Patterns of predation in a diverse predator-prey system. Nature 425:288-290.

Sinclair, S. J., M. D. White, and G. R. Newell (2010). How useful are species distribution models for managing biodiversity under future climates? Ecology and Society 15(1): 8.

Smith-Ramirez, C., J.J. Armesto (1994). Flowering and fruiting patterns in the temperate rainforest of Chiloe, Chile-ecologies and climatic constraints. Ecology 82:353-365.

Sollmann, R., M. Linkie, I.A. Haidir, D.W. Macdonald (2014). Bringing clarity to the clouded leopard Neofelis diardi: first density estimates from Sumatra. Oryx 48(4):536-539.

Steenweg, R., M. Hebblewhite, R. Kays, J. Ahumada, J.T. Fisher, C. Burton, S.E. Townsend, C. Carbone, J.M. Rowcliffe, J. Whittington, J. Brodie, J.A. Royle, A. Switalski, A.P. Clevenger, N. Heim, L.N. Rich 
(2017). Scaling-up camera traps: monitoring the planet's biodiversity with networks of remote sensors. Front Ecol Environ 15(1):26-34.

Steinmetz, R., N. Seuaturien, W. Chutipong (2013). Tigers, leopards, and dholes in a half-empty forest: assessing species interactions in a guild of threatened carnivores. Biological Conservation, 163:6878.

Struebig, M.J., L. Christy, D. Pio, E. Meijaard (2008). Bats of Borneo: diversity, distributions and representation in protected areas. Biodiversity and Conservation 19:449-469.

Tan, C.K.W., D.G. Rocha, G. Reuben Clements, E. Brenes-Mora, L. Hedges, K. Kawanishi, S. Wan Mohamad, D. Mark Rayan, G. Bolongon, J. Moore, J. Wadey, A. Campos-Arceiz, D.W. Macdonald (2017). Habitat use and predicted range for the mainland clouded leopard Neofelis nebulosa in peninsular Malaysia. Biological Conservation 206 (2017):65-74.

Tobler, M.W., A.Z. Hartley, S.E. Carrillo-Percastegui, G.V.N. Powell (2015). Spatiotemporal hierarchical modelling of species richness and occupancy using camera trap data. Journal of Applied Ecology 52(2): 413-421.

Toft, C.A., D.L.Trauger, H.W. Murdy (1982)Tests for Species Interactions: Breeding Phenology and Habitat Use in Subarctic Ducks The American Naturalist 120(5): 586-613.

Trenberth, K.E., T.J. Hoar (1997). El Nino and Climate change. Geophysical Research Letters 24(23):30573060.

Tydecks, L., J.M. Jeschke, M. Wolf, G. Singer, K. Tockner (2018). Spatial and topical imbalances in biodiversity research. PLOS ONE 13(7): e0199327.

Valeix, M., S. Chamaillé-Jammes, H. Fritz (2007). Interference competition and temporal niche shifts: elephants and herbivore communities at waterholes. Oecologia 153:739-748.

Vamosi, J.C., S.M. Vamosi (2008). Extinction risk escalates in the tropics. PLoS ONE 3(12): e3886.

Wallace, A.R. (1856). III.-On the habits of Orang-Utan of Borneo. Annals and Magazine of Natural History 18 (103):26-32. 
Wearn, O.R., J.M. Rowcliffe, C. Carbone, H. Bernard, R.M. Ewers (2013). Assessing the status of wild felids in a highly disturbed commercial forest reserve in Borneo and the implications for camera trap survey design. PLOS ONE 8(11): e77598.

Webb, C.O., D.R. Peart (2001). High seed dispersal rates in faunally intact tropical rain forest: theoretical and conservation implications. Ecology Letters 4(5): 491-499.

Wei, T., and V. Simko (2017). R package "corrplot": visualization of a correlation matrix (version 0.84). available from https://github.com/taiyun/corrplot

Werner, E. E., J.F. Gilliam, D.J. Hall, G.G. Mittelbach (1983). An experimental test of the effects of predation risk on habitat use in fish. Ecology, 64(6):1540-1548.

Wich, S.A., C.P. Van Schaik (2000). The impact of El Nino on mast fruiting in Sumatra and elsewhere in Malesia. Journal of Tropical Ecology 16:563-577.

Wickham, H (2016). Ggplot2: elegant graphics for data analysis. Springer-Verlag, New York.

Wilcove, D.S., L.P. Koh (2010). Addressing the threats to biodiversity from oil-palm agriculture. Biodiversity and Conservation 19:999-1007.

Williams, B. K., J.D. Nichols, M.J. Conroy (2002). Analysis and management of animal populations. Academic Press.

Williamson, G.B., K. Ickes (2002). Mast fruiting and ENSO cycles-does the cue betray a cause? Oikos 97(3):459-461.

Wilson, E.O. (1985). The Biological Diversity Crisis. BioScience, 35(11):700-706.

Wilting, A., F. Fischer, S.A. Bakar, K.E. Linsenmair (2006). Clouded leopards, the secretive top-carnivore of South-East Asian rainforests: their distribution, status and conservation needs in Sabah, Malyasia. BMC Ecology 6: 16.

Wilting, A., P. Christiansen, A.C. Kitchener, Y.J.M. Kemp, L. Ambu, J. Fickel (2011). Geographical variation in and evolutionary history of the Sunda clouded leopard (Neofelis diardi) (Mammalia: Carnivora: 
Felidae) with the description of a new subspecies from Borneo. Molecular Phylogenetics and Evolution 58(2):317-328.

Wilting, A., A. Mohamed, L.N. Ambu, P. Lagan, S. Mannan, H. Hofer, R. Sollmann (2012). Density of the vulnerable Sunda clouded leopard Neofelis diardi in two commercial forest reserves in Sabah, Malaysian Borneo. Oryx 46(3):423-426.

Wisz, M.S., J. Pottier, W.D. Kissling, L. Pellissier, J. Lenoir, C. F. Damgaard, C.F. Dormann, M.C. Forchhammer, J.A. Grytnes, et al. (2013). The role of biotic interactions in shaping distributions and realised assemblages of species: implication for species distribution modelling. Biological Reviews 88(1):15-30.

Wong, S.T., C. Servheen, L. Ambu, A. Norhayati (2005). Impacts of fruit production cycles on Malayan sun bears and bearded pigs in lowland tropical forest of Sabah, Malaysian Borneo. Journal of Tropical Ecology 21: 627-639.

Wong, S.T., C. Servheen (2010). From the temperate zone to the tropic--sun bear research and conservation from Montana to Borneo. Intermountain Journal of Sciences 16(4):134-134.

Woodroffe, R., J.R. Ginsberg (1998). Edge effects and the extinction of populations inside protected areas. Science 280(5372):2126-2128.

Yang, L.H., J.L. Bastow, K.O. Spence, A.N. Wright (2008). What we can learn from resource pulses. Ecology 89(3):621-634.

Yeh, S.W., J.S. Kug, B. Dewitte, M.H. Kwon, B.P. Kirtman, F.F. Jin (2009). El Nino in a changing climate. Nature 461:511-514. 


\section{SUPPLEMENTARY MATERIAL}

Table S.1: Set of candidate models for modelling habitat use of lesser mousedeer (Tragulus kanchil), greater mousedeer (T. napu), Bornean yellow muntjac (Muntiacus atherodes), red muntjac ( $M$. muntjak), and bearded pigs (Sus barbatus). Detection was kept as a general model defined as $p$ (effort + off-trail).

\begin{tabular}{|c|c|}
\hline Model & No. parameters $(K)$ \\
\hline$\Psi()$. & 4 \\
\hline$\Psi$ (humans) & 5 \\
\hline$\Psi$ (fruit) & 5 \\
\hline$\Psi($ elev $)$ & 5 \\
\hline$\Psi\left(e l e v^{2}\right)$ & 6 \\
\hline$\Psi$ (habitat) & 9 \\
\hline$\Psi$ (time) & 5 \\
\hline$\Psi$ (humans + fruit) & 6 \\
\hline$\Psi($ humans + elev $)$ & 6 \\
\hline$\Psi\left(\right.$ humans + elev $\left.^{2}\right)$ & 7 \\
\hline$\Psi$ (humans + habitat) & 10 \\
\hline$\Psi($ humans + time $)$ & 6 \\
\hline$\Psi$ (fruit + elev) & 6 \\
\hline$\Psi\left(\right.$ fruit $\left.+e l e v^{2}\right)$ & 7 \\
\hline$\Psi$ (fruit + habitat) & 10 \\
\hline$\Psi$ (fruit + time) & 6 \\
\hline$\Psi($ elev + time $)$ & 6 \\
\hline$\Psi\left(e l e v^{2}+\right.$ time $)$ & 7 \\
\hline$\Psi($ habitat + time $)$ & 10 \\
\hline
\end{tabular}


Table S.2: Set of candidate models for detection probabilities of lesser mousedeer (Tragulus kanchil), greater mousedeer (T. napu), Bornean yellow muntjac (Muntiacus atherodes), red muntjac ( $M$. muntjak), and bearded pigs (Sus barbatus). Habitat use was kept as a general model defined as $\Psi($ elevation + fruit + time + humans).

\begin{tabular}{l|c}
\multicolumn{1}{c|}{ Model } & No. parameters $(\boldsymbol{K})$ \\
\hline$p()$. & 6 \\
$p$ (effort) & 7 \\
$p$ (off-trail) & 7 \\
$p$ (effort + off-trail) & 8
\end{tabular}

Table S.3: The independent detections of ungulate species across forest types in CPRS. To reduce the likelihood of recording the same individual twice, multiple sightings at a location within a day are pooled.

\begin{tabular}{|c|c|c|c|c|c|}
\hline Forest type & $\begin{array}{c}\text { Lesser } \\
\text { mousedeer }\end{array}$ & $\begin{array}{c}\text { Greater } \\
\text { mousedeer }\end{array}$ & $\begin{array}{c}\text { Bornean } \\
\text { yellow } \\
\text { muntjac }\end{array}$ & Red muntjac & Bearded pig \\
\hline Peat swamp & 487 & 9 & 20 & 8 & 193 \\
\hline Freshwater swamp & 308 & 67 & 16 & 22 & 322 \\
\hline Alluvial bench & 155 & 97 & 52 & 35 & 469 \\
\hline Lowland sandstone & 13 & 53 & 130 & 65 & 412 \\
\hline Lowland granite & 0 & 0 & 175 & 75 & 140 \\
\hline $\begin{array}{r}\text { Upland } \\
\text { granite/montane }\end{array}$ & 0 & 1 & 105 & 139 & 239 \\
\hline total & 963 & 227 & 498 & 344 & 1775 \\
\hline
\end{tabular}

Table S.4: The detections of ungulates at on and off trail locations in CPRS standardized for number of cameras ( $n=134$ on trial, $n=58$ off trail).

\begin{tabular}{r|ccccc} 
Camera placement & $\begin{array}{c}\text { Lesser } \\
\text { mousedeer }\end{array}$ & $\begin{array}{c}\text { Greater } \\
\text { mousedeer }\end{array}$ & $\begin{array}{c}\text { Bornean } \\
\text { yellow } \\
\text { muntjac }\end{array}$ & Red muntjac & Bearded pig \\
\hline ON trail & 4.75 & 1.59 & 3.42 & 2.05 & 10.57 \\
OFF trail & 5.64 & 0.24 & 0.69 & 1.19 & 6.24
\end{tabular}


Table S.5: The average fruit availability and variability for each forest type between July 2015-October 2019 at CPRS. Fruit availability was calculated as the density of stems bearing ripe fruit per hectare, averaged across all sampling periods and associated standard deviation.

\begin{tabular}{l|cc} 
Forest type & Average fruit availability & Standard deviation \\
\hline Upland granite/montane & 6.68 & 2.50 \\
Freshwater swamp & 6.62 & 2.51 \\
Peat swamp & 6.15 & 2.71 \\
Alluvial bench & 5.95 & 3.90 \\
Lowland granite & 5.41 & 2.55 \\
Lowland sandstone & 4.88 & 3.12
\end{tabular}

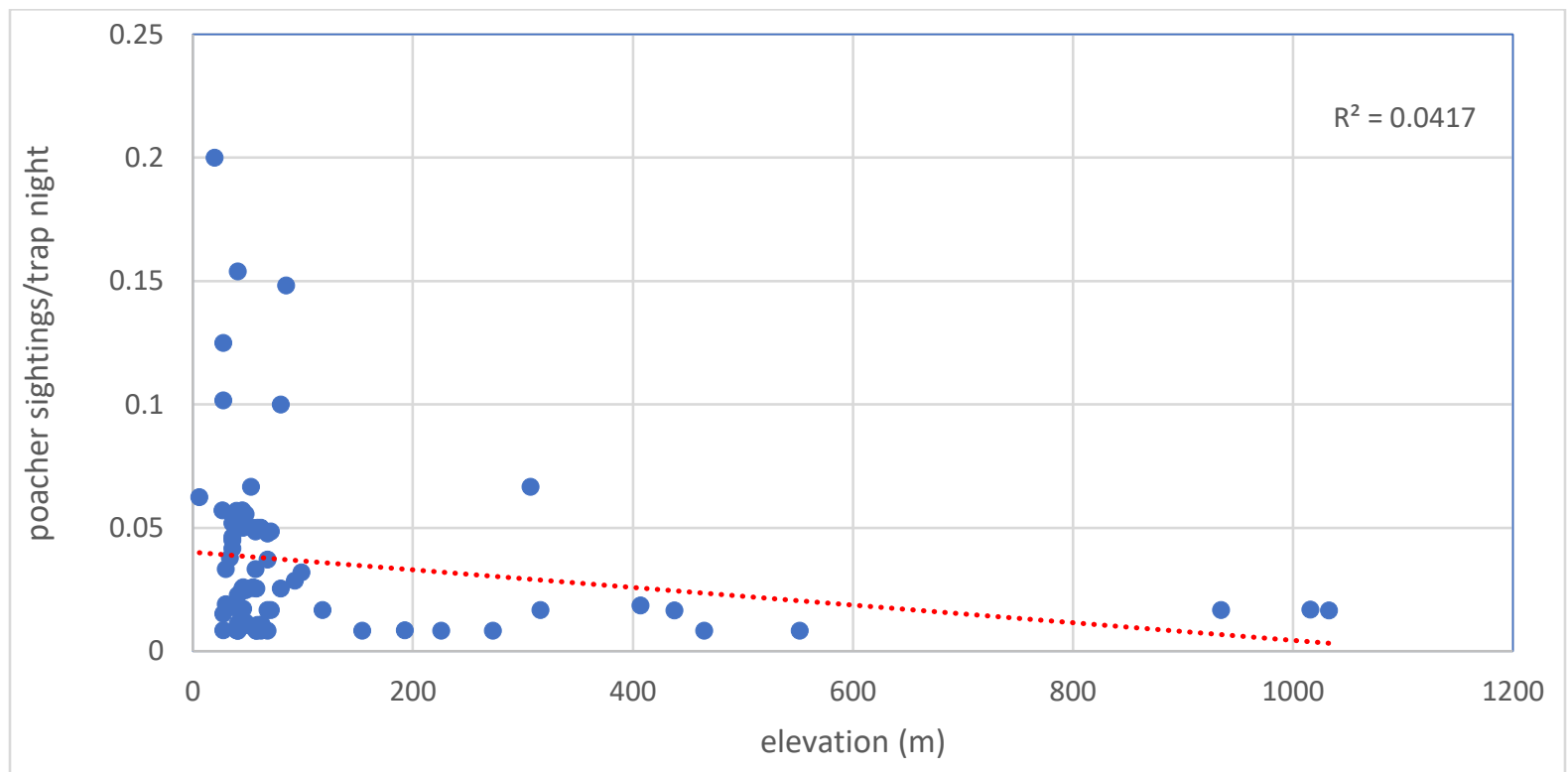

Figure S.1: Index of detections of poachers at camera sites in CPRS along an elevational gradient. Poaching index is calculated as the number of sightings at a location in a sampling period over the number of active trap nights for that camera during the same period. 